\title{
Six-, Five-, and Four-Coordinate Ruthenium(II) Hydride Complexes Supported by $N$-Heterocyclic Carbene Ligands: Synthesis, Characterization, Fundamental Reactivity, and Catalytic Hydrogenation of Olefins, Aldehydes, and Ketones
}

\author{
John P. Lee, ${ }^{\dagger}$ Zhuofeng Ke, ${ }^{\ddagger}{ }^{\S}$ Magaly A. Ramírez ${ }^{\dagger}$ T. Brent Gunnoe, ${ }^{*, l}$ \\ Thomas R. Cundari, ${ }^{*}{ }^{\ddagger}$ Paul D. Boyle, ${ }^{\dagger}$ and Jeffrey L. Petersen ${ }^{\perp}$ \\ Department of Chemistry, University of Virginia, Charlottesville, Virginia 22904, Department of \\ Chemistry, North Carolina State University, Raleigh, North Carolina 27695-8204, Center for Advanced \\ Scientific Computing and Modeling (CASCaM), Department of Chemistry, University of North Texas, \\ Box 305070, Denton, Texas 76203-5070, C. Eugene Bennett Department of Chemistry, West Virginia \\ University, Morgantown, West Virginia 26506-6045, and School of Chemistry \& Chemical Engineering, \\ Sun Yat-sen University, Guangzhou 510275, P.R. China
}

Received November 21, 2008

The Ru(II) hydride complex (IMes) ${ }_{2} \mathrm{Ru}(\mathrm{Cl})(\mathrm{H})(\mathrm{CO})(\mathbf{1})$ IMes = 1,3-bis-(2,4,6-trimethylphenyl)imidazol-2-ylidene $\}$ was synthesized from $\left[\mathrm{Ru}(\mathrm{CO})_{2} \mathrm{Cl}_{2}\right]_{n}$ and free IMes. Complex 1 rapidly reacts with $\mathrm{CO}$ to produce the cis-dicarbonyl $\mathrm{Ru}(\mathrm{II})$ complex (IMes) ${ }_{2} \mathrm{Ru}(\mathrm{Cl})(\mathrm{H})(\mathrm{CO})_{2}(\mathbf{2})$. The reaction of $\mathbf{1}$ with $\mathrm{NaBAr}_{4}$ $\left\{\mathrm{Ar}^{\prime}=3,5-\left(\mathrm{CF}_{3}\right) \mathrm{C}_{6} \mathrm{H}_{3}\right\}$ produces the four-coordinate $\mathrm{Ru}(\mathrm{II})$ cationic complex [(IMes) $\left.{ }_{2} \mathrm{Ru}(\mathrm{H})(\mathrm{CO})\right]\left[\mathrm{BAr}_{4}^{\prime}\right]$ (4), which can be trapped by two equivalents of tert-butylisonitrile to produce [(IMes) ${ }_{2} \mathrm{Ru}(\mathrm{H})$ $\left.(\mathrm{CO})\left(\mathrm{CN}^{\prime} \mathrm{Bu}\right)_{2}\right]\left[\mathrm{BAr}_{4}^{\prime}\right](5)$. Experimental and computational studies suggest that complex 4 is a diamagnetic system that adopts a sawhorse structure. The hydride ligand of complex $\mathbf{2}$ is readily displaced as dihydrogen upon reaction with $\mathrm{HCl}$ to produce (IMes) $)_{2} \mathrm{Ru}(\mathrm{Cl})_{2}(\mathrm{CO})_{2}(\mathbf{3})$. Both complex $\mathbf{1}$ and $\mathbf{4}$ were found to react with $\mathrm{D}_{2}(30 \mathrm{psi})$ at room temperature to produce the isotopomers $(\mathrm{IMes})_{2} \mathrm{Ru}(\mathrm{Cl})(\mathrm{D})(\mathrm{CO})\left(\mathbf{1}-\mathbf{d}_{\mathbf{1}}\right)$ and [(IMes) $\left.)_{2} \mathrm{Ru}(\mathrm{D})(\mathrm{CO})\right]\left[\mathrm{BAr}_{4}^{\prime}\right]\left(\mathbf{4}-\mathbf{d}_{\mathbf{1}}\right)$, respectively, with the rate of formation of 4-d $\mathbf{d}_{\mathbf{1}}$ at least 28 times faster than the conversion of $\mathbf{1} / D_{2}$ to $\mathbf{1}-\mathbf{d}_{\mathbf{1}}$. In the presence of excess $D_{2}$ complex $\mathbf{4}$ reversibly incorporates deuterium into the ortho methyl groups of the IMes ligands, whereas complex $\mathbf{1}$ does not show evidence of H/D exchange with the IMes ligands. Both $\mathbf{1}$ and $\mathbf{4}$ were found to catalyze the hydrogenation of olefins, ketones, and aldehydes.

\section{Introduction}

Since the initial discovery of a transition metal dihydrogen complex in 1983 by Kubas et al., ${ }^{1-4}$ there has been significant interest in the coordination chemistry of dihydrogen. ${ }^{5,6}$ It has been shown that coordination of dihydrogen can precede $\mathrm{H}-\mathrm{H}$ bond cleavage to form two hydride ligands (i.e., oxidative addition, Scheme 1), which is a key step in many catalytic hydrogenation reactions. ${ }^{7-9}$ For example, Wilkinson's catalyst

* To whom correspondence should be addressed. E-mail: tbg7h@ virginia.edu.

North Carolina State University.

$\doteqdot$ University of North Texas.

$\S$ Sun Yat-sen University.

"University of Virginia.

$\perp$ West Virginia University.

(1) Kubas, G. J.; Ryan, R. R.; Swanson, B. I.; Vergamini, P. J.; Wasserman, H. J. J. Am. Chem. Soc. 1984, 106, 451-452.

(2) Kubas, G. J. Acc. Chem. Res. 1988, 21, 120-128.

(3) Kubas, G. J. Metal Dihydrogen and $\sigma$-Bond Complexes; Kluwer Academic/Plenum Publishers: New York, 2001; pp 259-296.

(4) Kubas, G. J. Chem. Rev. 2007, 107, 4152-4205.

(5) Heinekey, D. M., Jr. Chem. Rev. 1993, 93, 913-926.

(6) Jessop, P. G.; Morris, R. H. Coord. Chem. Rev. 1992, 121, 155284.

(7) de Vries, J. G.; Elsevier, C. J. Handbook of Homogenous Hydrogenation; Wiley-VCH: New York, 2007; Vol. 1.

(8) Chaloner, P. A.; Esteruelas, M. A.; Joo, F.; Oro, L. A. Homogenous Hydrogenation; Kluwer: Boston, 1994.

(9) Brunner, H. Applied Homogenous Catalysis with Organometallic Compounds; VCH: New York, 1996; Vol. 1.
$\left(\mathrm{PPh}_{3}\right)_{3} \mathrm{RhCl}$ and related systems commonly adopt what has been referred to as the dihydride mechanism for catalytic hydrogenation, where coordination and subsequent oxidative addition of $\mathrm{H}_{2}$ occur along the catalytic pathway. ${ }^{7,10}$ Interest in transition metal-mediated coordination and activation of dihydrogen also emanates from the close relevance to the coordination/activation of other nonpolar $\mathrm{X}-\mathrm{H}$ bonds (e.g., $\mathrm{X}=\mathrm{C}$ or $\mathrm{Si}){ }^{11-17}$ Significant effort has been directed toward the isolation of metal complexes with $\sigma$-coordinated $\mathrm{H}-\mathrm{H}, \mathrm{C}-\mathrm{H}, \mathrm{Si}-\mathrm{H}$, and related bonds as well as understanding the factors that control the equilibrium between the $\sigma$-adduct and the oxidative addition product. $^{18-32}$

(10) Collman, J. P.; Hegedus, L. S.; Norton, J. R.; Finke, R. G. Principles and Applications of Organotransition Metal Chemistry; University Science: Mill Valley, 1987.

(11) Ritleng, V.; Sirlin, C.; Pfeffer, M. Chem. Rev. 2002, 102, 17311769.

(12) Dyker, G. Angew. Chem., Int. Ed. 1999, 38, 1698-1712.

(13) Goldberg, K. I.; Goldman, A. S. Activation and Functionalization of C-H Bonds.; American Chemical Society: Washington, DC, 2004; Vol. 885 .

(14) Kakiuchi, F.; Murai, S. Acc. Chem. Res. 2002, 35, 826-834.

(15) Shilov, A. E.; Shul'pin, G. B. Activation and Catalytic Reactions of Saturated Hydrocarbons in the Presence of Metal Complexes; Kluwer Academic Publishers: Dordrecht, 2000; Vol. 21.

(16) Labinger, J. A.; Bercaw, J. E. Nature 2002, 417, 507-514.

(17) Goj, L. A.; Gunnoe, T. B. Curr. Org. Chem. 2005, 9, 671-685.

(18) Corey, J. Y.; Braddock-Wilking, J. Chem. Rev. 1999, 99, 175292.

(19) Crabtree, R. H. J. Chem. Soc., Dalton Trans. 2001, 2437-2450. 
Scheme 1. Coordination of Dihydrogen and Subsequent Oxidative Addition

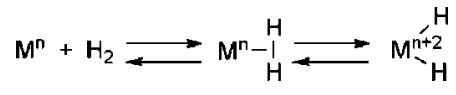

The $\mathrm{d}^{6}$ metals $\mathrm{Ru}$ (II) and Os(II) have been commonly used to form $\sigma$-complexes with $\mathrm{H}_{2}$, and in many cases such species also serve as effective hydrogenation catalysts. ${ }^{33-35}$ Ruthenium monohydride systems often serve as precursors to hydrogenation catalysts and/or dihydrogen complexes. ${ }^{34,36-38}$ Most germane to the work presented herein are the monohydride $\mathrm{Ru}(\mathrm{II})$ complexes supported by $\mathrm{N}$-heterocyclic carbenes (NHC) and/ or phosphines. For example, the five-coordinate Ru(II) complex $\left(\mathrm{PCy}_{3}\right)_{2} \mathrm{Ru}(\mathrm{Cl})(\mathrm{H})(\mathrm{CO})$, where the $\mathrm{Ru}$ possesses square pyramidal geometry with the hydride ligand in the apical position, has been reported to catalytically hydrogenate olefins at room temperature under $1 \mathrm{~atm}$ of $\mathrm{H}_{2}$ with high turnover frequencies. ${ }^{37}$ NHC ligands have been employed by many research groups as stable and strongly electron-donating alternatives to phosphine ligands. ${ }^{39-42}$ Nolan et al. have replaced a single phosphine ligand of $\left(\mathrm{PCy}_{3}\right)_{2} \mathrm{Ru}(\mathrm{Cl})(\mathrm{H})(\mathrm{CO})$ with an NHC to produce (IMes) $\left(\mathrm{PCy}_{3}\right) \mathrm{Ru}(\mathrm{Cl})(\mathrm{H})(\mathrm{CO})$ \{IMes = 1,3-bis-(2,4,6-trimethylphenyl)imidazol-2-ylidene $\}.{ }^{38}$ The mixed NHC/phosphine complex is less active as a hydrogenation catalyst (at room temperature) than the bis-phosphine complex $\left(\mathrm{PCy}_{3}\right)_{2}-$ $\mathrm{Ru}(\mathrm{Cl})(\mathrm{H})(\mathrm{CO})$ but exhibits similar activity at elevated temperatures. The decreased activity for the mixed NHC/phosphine complex at ambient temperature is proposed to be due to a combination of stronger coordination of IMes (versus $\mathrm{PCy}_{3}$ ) and enhanced steric congestion at the metal center. The addition of $\mathrm{HBF}_{4}$ to $(\mathrm{IMes})\left(\mathrm{PCy}_{3}\right) \mathrm{Ru}(\mathrm{Cl})(\mathrm{H})(\mathrm{CO})$ is proposed to trap the putative four-coordinate, 14-electron intermediate (IMes)Ru-

(20) Crabtree, R. H. Chem. Rev. 1985, 85, 245-269.

(21) Geftakis, S.; Ball, G. E. J. Am. Chem. Soc. 1998, 120, 9953-9954

(22) Geftakis, S.; Ball, G. E. J. Am. Chem. Soc. 1999, 121, 6336-6336.

(23) Lawes, D. J.; Geftakis, S.; Ball, G. E. J. Am. Chem. Soc. 2005, $127,4134-4135$.

(24) Lawes, D. J.; Darwish, T. A.; Clark, T.; Harper, J. B.; Ball, G. E. Angew. Chem., Int. Ed. 2006, 45, 4486-4490.

(25) Bart, S. C.; Lobkovsky, E. B.; Chirik, P. J. J. Am. Chem. Soc. 2004, 126, 13794-13807.

(26) Waterman, R.; Hayes, P. G.; Tilley, T. D. Acc. Chem. Res. 2007, 40, 712-719.

(27) Kubas, G. J. Proc. Nat. Acad. Sci. U.S.A. 2007, 104, 6901-6907.

(28) Weiller, B. H.; Wasserman, E. P.; Bergman, R. G.; Moore, C. B.; Pimentel, G. C. J. Am. Chem. Soc. 1989, 111, 8288-8290.

(29) Bengali, A. A.; Schultz, R. H.; Moore, C. B.; Bergman, R. G. J. Am. Chem. Soc. 1994, 116, 9585-9589.

(30) Chen, G. S.; Labinger, J. A.; Bercaw, J. E. Proc. Nat. Acad. Sci. U.S.A. 2007, 104, 6915-6920.

(31) Ball, G. E.; Brookes, C. M.; Cowan, A. J.; Darwish, T. A.; George, M. W.; Kawanami, H. K.; Portius, P.; Rourke, J. P. Proc. Nat. Acad. Sci. U.S.A. 2007, 104, 6927-6932.

(32) Clot, E.; Eisenstein, O.; Jones, W. D. Proc. Nat. Acad. Sci. U.S.A. 2007, 104, 6939-6944.

(33) Sabo-Etienne, S.; Chaudret, B. Coord. Chem. Rev. 1998, 178180, 381-407.

(34) Chan, W. C.; Lau, C. P.; Chen, Y. Z.; Fang, Y. Q.; Ng, S. M.; Jia, G. Organometallics 1997, 16, 34-44.

(35) Moreno, B.; Sabo-Etienne, S.; Chaudret, B.; Rodríguez, A.; Jalon, F.; Trofimenko, S. J. Am. Chem. Soc. 1995, 117, 7441-7451.

(36) Yi, C. S.; Lee, D. W.; He, Z.; Rheingold, A. L.; Lam, K. C.; Concolino, T. E. Organometallics 2000, 19, 2909-2915.

(37) Yi, C. S.; Lee, D. W. Organometallics 1999, 18, 5152-5156.

(38) Lee, H. M.; Smith, D. C.; He, Z.; Stevens, E. D.; Yi, C. S.; Nolan, S. P. Organometallics 2001, 20, 794-797.

(39) Scott, N. M.; Nolan, S. P. Eur. J. Inorg. Chem. 2005, 1815-1828.

(40) Herrmann, W. A. Angew. Chem., Int. Ed. 2002, 41, 1290-1309.

(41) Herrmann, W. A.; Schutz, J.; Frey, G. D.; Herdtweck, E. Organometallics 2006, 25, 2437-2448.

(42) Cavallo, L.; Correa, A.; Costabile, C.; Jacobsen, H. J. Organomet. Chem. 2005, 690, 5407-5413.
$(\mathrm{Cl})(\mathrm{H})(\mathrm{CO})$ (via the production of $\left[\mathrm{HPCy}_{3}\right]\left[\mathrm{BF}_{4}\right]$ ), which was found to be a more active catalyst than the 16-electron precursor $(\mathrm{IMes})(\mathrm{PCy}) \mathrm{Ru}(\mathrm{Cl})(\mathrm{H})(\mathrm{CO}){ }^{38}$ Also, a series of trans- $(\mathrm{NH}-$ C) $\mathrm{Ru}^{\mathrm{II}}$ mono and dihydride complexes have been prepared, ${ }^{43}$ and though these complexes were not studied for hydrogenation, they show interesting reactivity toward intra- and intermolecular $\mathrm{X}-\mathrm{H}(\mathrm{X}=\mathrm{C}, \mathrm{N} \text {, or } \mathrm{O})^{44-47}$ and $\mathrm{C}-\mathrm{X}(\mathrm{X}=\mathrm{C} \text { or } \mathrm{N})^{47,48}$ bond activation.

Studies have shown that NHC's may possess similar electronic properties to trisalkylphosphines. ${ }^{39-42,49,50}$ However, with "fan-shaped" geometries the steric properties of NHCs are distinct from phosphines. In some cases, NHC ligands have been found to simultaneously enhance catalyst stability and activity (compared to their phosphine analogs) including applications in olefin metathesis, ${ }^{51-56}$ hydrogenation, ${ }^{38,57-59}$ and hydrosilylation reactions. ${ }^{60}$ Herein, we describe the synthesis, characterization, and initial reactivity studies of five- and fourcoordinate $\mathrm{Ru}(\mathrm{II})$ hydride complexes supported by two IMes ligands.

\section{Results and Discussion}

Synthesis, Characterization and Reactivity of (IMes) $)_{2}$ $\mathbf{R u}(\mathbf{C l})(\mathbf{H})(\mathbf{C O})$ (1). Heating the previously reported $[\mathrm{Ru}-$ $\left.(\mathrm{CO})_{2} \mathrm{Cl}_{2}\right]_{\mathrm{n}}$ with excess IMes in toluene followed by the addition of methanol forms the five-coordinate $\mathrm{Ru}(\mathrm{II})$ complex $(\mathrm{IMes})_{2} \mathrm{Ru}(\mathrm{Cl})(\mathrm{H})(\mathrm{CO})(\mathbf{1})$ in $32 \%$ isolated yield (eq 1). During the course of our studies, the synthesis of $(\mathrm{IMes})_{2} \mathrm{Ru}(\mathrm{Cl})(\mathrm{H})(\mathrm{CO})$ (1) from $\mathrm{Ru}\left(\mathrm{AsPh}_{3}\right)_{3}(\mathrm{CO}) \mathrm{H}_{2}$ or $\mathrm{Ru}(\mathrm{IMes})_{2}(\mathrm{CO})(\mathrm{OH}) \mathrm{H}$ was reported by Whittlesey et al. ${ }^{61}$ Our spectroscopic data for complex $\mathbf{1}$ are consistent with the previously reported data. For example, the ${ }^{1} \mathrm{H}$ NMR spectrum of $\mathbf{1}$ shows a singlet assigned as the $\mathrm{Ru}-H$ at $-25.4 \mathrm{ppm}\left(\mathrm{C}_{6} \mathrm{D}_{6}\right)$ while the IR spectrum (thin

(43) Jazzar, R. F. R.; Bhatia, P. H.; Mahon, M. F.; Whittlesey, M. K. Organometallics 2003, 22, 670-683.

(44) Chatwin, S. L.; Davidson, M. G.; Doherty, C.; Donald, S. M.; Jazzar, R. F. R.; Macgregor, S. A.; McIntyre, G. J.; Mahon, M. F.; Whittlesey, M. K. Organometallics 2006, 25, 99-110.

(45) Burling, S.; Paine, B. M.; Nama, D.; Brown, V. S.; Mahon, M. F.; Prior, T. J.; Pregosin, P. S.; Whittlesey, M. K.; Williams, J. M. J. J. Am. Chem. Soc. 2007, 129, 1987-1995.

(46) Burling, S.; Mahon, M. F.; Paine, B. M.; Whittlesey, M. K.; Williams, J. M. J. Organometallics 2004, 23, 4537-4539.

(47) Jazzar, R. F. R.; Macgregor, S. A.; Mahon, M. F.; Richards, S. R.; Whittlesey, M. K. J. Am. Chem. Soc. 2002, 124, 4944-4945.

(48) Burling, S.; Mahon, M. F.; Powell, R. E.; Whittlesey, M. K.; Williams, J. M. J. J. Am. Chem. Soc. 2006, 128, 13702-13703.

(49) Jafarpour, L.; Stevens, E. D.; Nolan, S. P. J. Organomet. Chem. 2000, 606, 49-54.

(50) Diez-Gonzalez, S.; Nolan, S. P. Coord. Chem. Rev. 2007, 251, 874883.

(51) Sanford, M. S.; Love, J. A.; Grubbs, R. H. J. Am. Chem. Soc. 2001, $123,6543-6554$

(52) Scholl, M.; Ding, S.; Lee, C. W.; Grubbs, R. H. Org. Lett. 1999, $1,953-956$.

(53) Jafarpour, L.; Nolan, S. P. J. Organomet. Chem. 2001, 617-618, $17-27$.

(54) Huang, J.; Stevens, E. D.; Nolan, S. P.; Petersen, J. L. J. Am. Chem. Soc. 1999, 121, 2674-2678.

(55) Trnka, T. M.; Grubbs, R. H. Acc. Chem. Res. 2001, 34, 18-29.

(56) Nolan, S. P. N-Heterocyclic Carbenes in Synthesis; Wiley-VCH: Weinheim, 2006.

(57) Lee, H. M.; Jiang, T.; Stevens, E. D.; Nolan, S. P. Organometallics 2001, 20, 1255-1258.

(58) Hillier, A. C.; Lee, H.; Stevens, E. D.; Nolan, S. P. Organometallics 2001, 20, 4246-4252.

(59) Vazquez-Serrano, L. D.; Owens, B. T.; Buriak, J. M. Chem. Commun. 2002, 2518-2519.

(60) Marko, I. E.; Sterin, S.; Buisine, O.; Mignani, G.; Branlard, P.; Tinant, B.; Declercq, J. Science 2002, 298, 204-206.

(61) Chantler, V. L.; Chatwin, S. L.; Jazzar, R. F. R.; Mahon, M. F.; Saker, O.; Whittlesey, M. K. J. Chem. Soc., Dalton Trans. 2008, 26032614 


\section{Scheme 2. Proposed Fluxional Bond Rotations of 1 in Solution ${ }^{a}$}

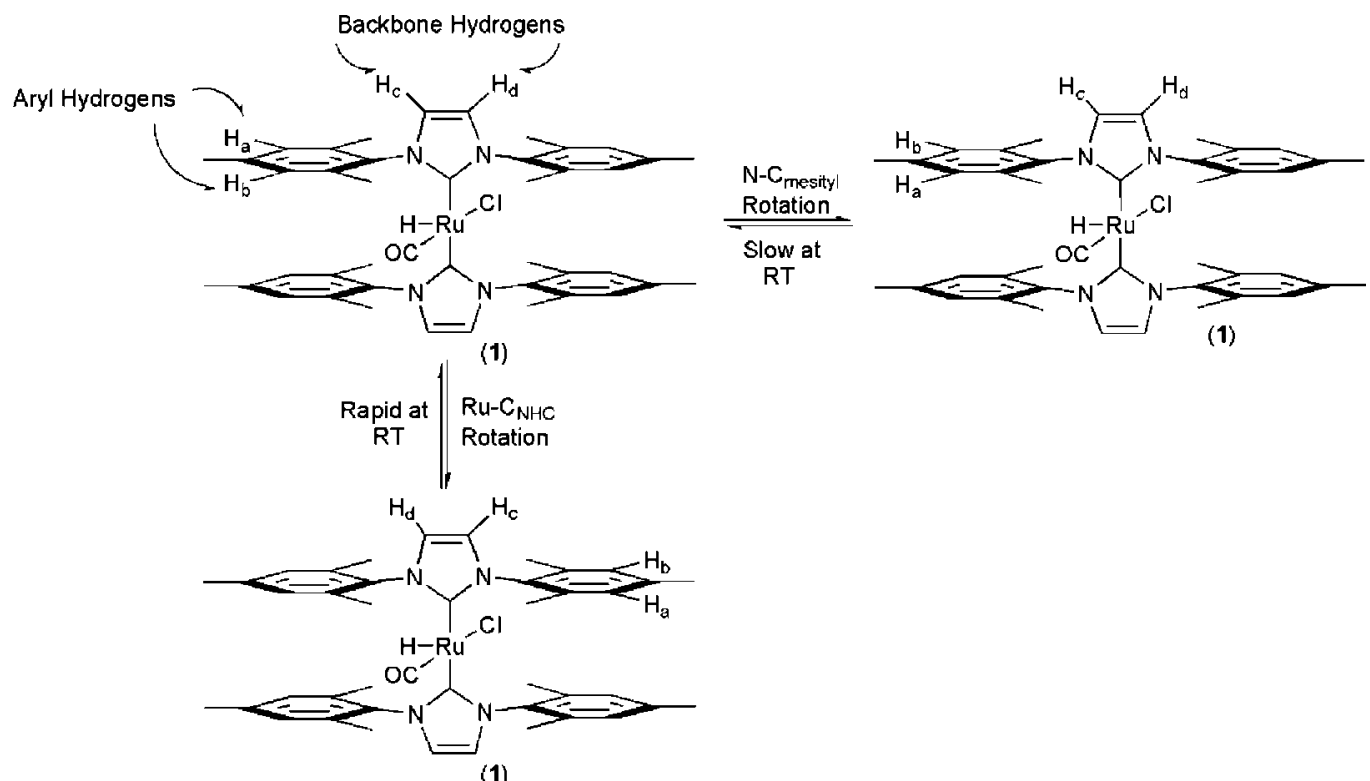

(1)

${ }^{a}$ IMes backbone and aryl hydrogens have been labeled. RT = room temperature.

film on $\mathrm{KBr}$ ) of 1 reveals $v_{\mathrm{CO}}$ at $1886 \mathrm{~cm}^{-1}$. In addition, we used variable temperature ${ }^{1} \mathrm{H}$ NMR spectroscopy to further study the structure and bonding of complex $\mathbf{1}$ (see below).

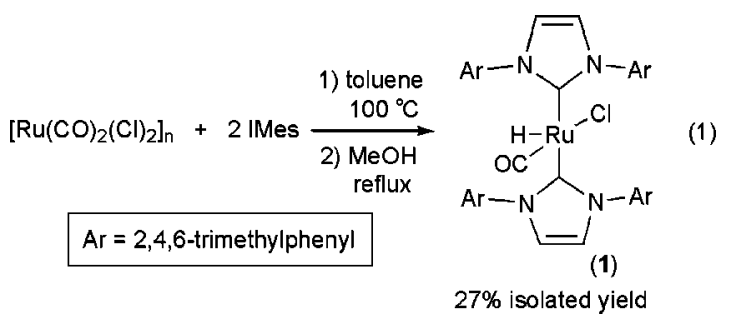

The source of the hydride ligand in $\mathbf{1}$ is unclear. Use of $\mathrm{CD}_{3} \mathrm{OD}$ in place of $\mathrm{CH}_{3} \mathrm{OH}$ or toluene- $d_{8}$ in place of perprotiotoluene does not result in deuterium incorporation into the final product $\left({ }^{1} \mathrm{H}\right.$ NMR spectroscopy reveals no change for syntheses using these deuterated reagents). Heating $\left[\mathrm{Ru}(\mathrm{CO})_{2} \mathrm{Cl}_{2}\right]_{\mathrm{n}}$ with two equivalents of free IMes in toluene- $d_{8}$ (prior to methanol addition) results in a mixture of products (by NMR and IR spectroscopy) including a single $\mathrm{Ru}-\mathrm{H}$ resonance at $-4.5 \mathrm{ppm}$ without evidence of complex 1. Reflux of this mixture (after heating in toluene- $d_{8}$ ) in either $\mathrm{CH}_{3} \mathrm{OH}$ or $\mathrm{CD}_{3} \mathrm{OD}$ produces complex 1 without evidence of deuterium incorporation into the hydride position.

At room temperature, the ${ }^{1} \mathrm{H}$ NMR spectrum of $\mathbf{1}$ is consistent with $C_{\mathrm{s}}$ molecular symmetry (with a mirror plane that contains $\mathrm{Ru}, \mathrm{H}, \mathrm{Cl}$, and $\mathrm{CO}$, if the square pyramidal geometry is assumed, see above) and rapid rotation about the $\mathrm{Ru}-\mathrm{C}_{\mathrm{NHC}}$ bonds, and hindered $\mathrm{N}_{\text {carbene }}-\mathrm{C}_{\text {mesityl }}$ rotation (Scheme 2). For example, the methyl groups of the mesityl rings resonate as three equivalent broad singlets, one singlet is observed for the olefin backbone hydrogen atoms and two singlets appear due to inequivalent aryl hydrogens of the IMes ligands (see Scheme 2). Heating a toluene- $d_{8}$ solution of 1 to $95^{\circ} \mathrm{C}$ does not result in any changes in the ${ }^{1} \mathrm{H}$ NMR spectrum. However, at $-20{ }^{\circ} \mathrm{C}$, two of the methyl groups begin to broaden and decoalesce, and at $-40{ }^{\circ} \mathrm{C}$ resonances due to aryl hydrogen atoms begin to decoalesce. At $-60{ }^{\circ} \mathrm{C}$, the resonance due to the olefinic IMes hydrogen atoms decoalesces into two broad singlets that integrate for $2 \mathrm{H}$ each.

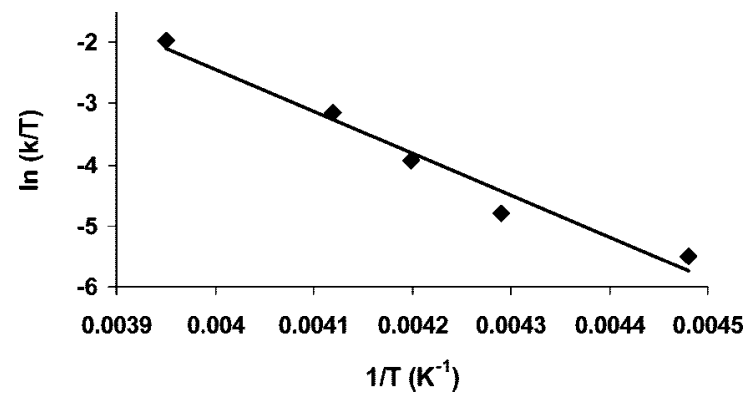

Figure 1. Eyring plot from variable temperature ${ }^{1} \mathrm{H}$ NMR spectroscopy of $1\left(R^{2}=0.97\right)$. The plot relates rate constants for $\mathrm{Ru}-\mathrm{C}_{\mathrm{NHC}}$ bond rotation as a function of temperature.

Also at $-60{ }^{\circ} \mathrm{C}$, the aryl hydrogens resonate as four singlets that integrate for $2 \mathrm{H}$ each, and the methyl groups are observed as five singlets (likely six symmetry unique groups with two overlapping resonances). The NMR spectra at low temperatures are consistent with hindered $\mathrm{C}-\mathrm{N}_{\text {mesityl }}$ and hindered $\mathrm{Ru}-\mathrm{C}_{\mathrm{NHC}}$ bond rotation (Scheme 2). At room temperature, rotation about the $\mathrm{Ru}-\mathrm{C}_{\mathrm{NHC}}$ bonds is rapid relative to the NMR time scale. Using $\mathrm{CD}_{2} \mathrm{Cl}_{2}$ as the solvent, kinetic data for $\mathrm{Ru}-\mathrm{C}_{\mathrm{NHC}}$ bond rotation have been derived at various temperatures. In $\mathrm{CD}_{2} \mathrm{Cl}_{2}$, the slow exchange regime for $\mathrm{Ru}-\mathrm{C}_{\mathrm{NHC}}$ bond rotation was reached at $-65{ }^{\circ} \mathrm{C}$ (based on decoalescence of an IMes-Me broad singlet into two singlets), and these data were used to calculate activation parameters for rotation about the $\mathrm{Ru}-\mathrm{C}_{\mathrm{NHC}}$ bond (Figure 1). The process is enthalpically dominated $\left\{\Delta H^{\ddagger}\right.$ $=13.7(1) \mathrm{kcal} / \mathrm{mol}\}$ with relatively negligible entropy contributions $\left\{\Delta S^{\ddagger}=2.7(6) \mathrm{eu}\right\}$, which is consistent with an intramolecular fluxional process.

Complex $\mathbf{1}$ is formulated as a 16-electron complex with an available coordination site. However, the presence of two sterically bulky IMes ligands might be expected to inhibit coordination of a sixth ligand. To explore whether or not ligand association is accessible, we reacted 1 with neutral 2-electron donating substrates. Heating complex 1 up to $100{ }^{\circ} \mathrm{C}$ in the presence of acetonitrile or in $\mathrm{C}_{6} \mathrm{D}_{6}$ with an excess $\mathrm{PMe}_{3}$ results in no observed reaction by ${ }^{1} \mathrm{H}$ NMR spectroscopy (Scheme 3 ). 
Scheme 3. Complex 1 Does Not React with Acetonitrile or Trimethylphosphine

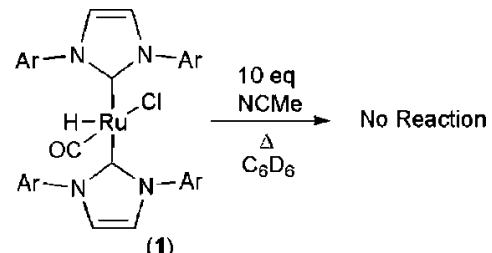

(1)

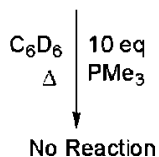

In contrast to $\mathrm{NCMe}$ and $\mathrm{PMe}_{3}$, the reaction of 1 with $\mathrm{CO}$ (1 atm) at room temperature rapidly produces the cis-dicarbonyl $\mathrm{Ru}(\mathrm{II})$ complex (IMes) ${ }_{2} \mathrm{Ru}(\mathrm{Cl})(\mathrm{H})(\mathrm{CO})_{2}$ (2) (eq 2). The synthesis, characterization, and crystal structure of (IMes) ${ }_{2}-$ $\mathrm{Ru}(\mathrm{Cl})(\mathrm{H})(\mathrm{CO})_{2}(2)$ have been previously reported $;{ }^{61}$ however, the $\mathrm{Ru}-\mathrm{H}$ IR stretch of $\mathbf{2}$ was not disclosed. Consistent with the reported data for 2 , the ${ }^{1} \mathrm{H}$ NMR spectrum reveals the resonance due to the hydride ligand at $-4.20 \mathrm{ppm}\left(\mathrm{C}_{6} \mathrm{D}_{6}\right)$. The IR spectrum (thin film on $\mathrm{KBr}$ ) shows a low intensity absorption at $1941 \mathrm{~cm}^{-1}$ assigned as the $\nu_{\mathrm{Ru}-\mathrm{H}}$ stretch as well as symmetric and asymmetric $v_{\mathrm{CO}}$ stretches at 2035 and $1905 \mathrm{~cm}^{-1}$, respectively. The assignment of the absorption at $1941 \mathrm{~cm}^{-1}$ (IR) as $v_{\mathrm{Ru}-\mathrm{H}}$ is supported by the synthesis of the isotopomer (IMes) ${ }_{2} \mathrm{Ru}(\mathrm{Cl})(\mathrm{D})(\mathrm{CO})_{2}\left(\mathbf{2}-\mathbf{d}_{\mathbf{1}}\right)$ from $\mathbf{2}$ and $\mathrm{D}_{2}(30 \mathrm{psi})$ (eq 3). In the IR spectrum of $\mathbf{2}-\mathbf{d}_{\mathbf{1}}$, the band at $1941 \mathrm{~cm}^{-1}$ is absent. The calculated $\nu_{\mathrm{Ru}-\mathrm{D}}$ of $\mathbf{2}-\mathbf{d}_{\mathbf{1}}$ (based on difference in reduced mass) is approximately $1384 \mathrm{~cm}^{-1}$; however, the IR spectrum of 2 between $1485 \mathrm{~cm}^{-1}$ and $1380 \mathrm{~cm}^{-1}$ contains multiple absorptions, and we were unable to identify the $\mathrm{Ru}-\mathrm{D}$ stretch in the IR spectrum of $\mathbf{2}-\mathbf{d}_{\mathbf{1}}$. The mechanism for the conversion of $\mathbf{2}$ and $\mathrm{D}_{2}$ to $\mathbf{2}-\mathbf{d}_{\mathbf{1}}$ has not been probed, although it is reasonable to assume that it involves an initial ligand dissociation.

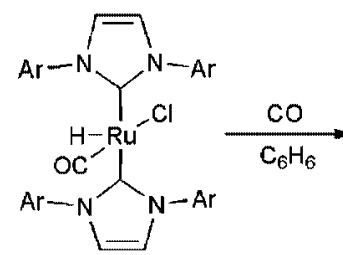

(1)

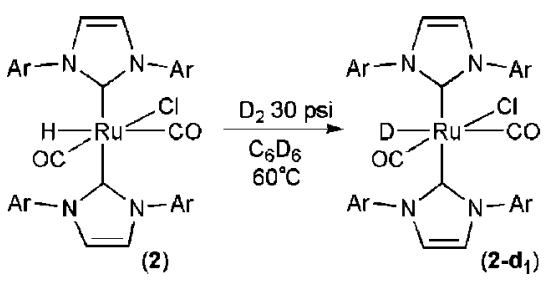

A single crystal of $\mathbf{2}$ suitable for an X-ray diffraction study was grown, and the resulting structure is shown in Figure 2 with crystallographic data and collection parameters given in Table 1. The data for $\mathbf{2}$ from our study are similar to those previously reported. ${ }^{61}$ The structure contains a $\mathrm{CO} / \mathrm{Cl}$ site disorder with the positions of the disordered atoms obtained from a difference Fourier map (see Supporting Information). The hydride position of $\mathbf{2}$ was recovered from a difference map with a $\mathrm{Ru}-\mathrm{H}$ bond distance of 1.54(2) $\AA$, which is in agreement with other reported $\mathrm{Ru}^{\mathrm{II}}-\mathrm{H}$ bond distances from $\mathrm{X}$-ray diffraction studies including (IMes) $\left(\mathrm{PCy}_{3}\right) \mathrm{Ru}(\mathrm{Cl})(\mathrm{H})(\mathrm{CO})\{\mathrm{Ru}-\mathrm{H}$
1.57(2) $\AA\},{ }^{38} \mathrm{CpRu}(\mathrm{dppe}) \mathrm{H}\{\mathrm{Ru}-\mathrm{H} 1.60(2) \AA\}$, and CpRu(dpbz) $\mathrm{H}\{\mathrm{Ru}-\mathrm{H} 1.56(5) \AA\} .{ }^{62}$ The heterocyclic rings of the trans IMes ligands of $\mathbf{2}$ approach coplanarity with the imidazole rings only slightly twisted twist angle $\left(\theta_{\mathrm{t}}\right)=0.5[\mathrm{~N} 3-\mathrm{C} 24-\mathrm{C} 3-\mathrm{N} 1$ $+\mathrm{N} 4-\mathrm{C} 24-\mathrm{C} 3-\mathrm{N} 2]\}^{43}$ by $17.2^{\circ}$ relative to one another. Twisting of IMes ligands has been observed in other transIMes $_{2} \mathrm{Ru}$ complexes. ${ }^{43}$ The $\mathrm{C} 24-\mathrm{Ru}-\mathrm{C} 3$ bond angle deviates from linearity to $168.69(5)^{\circ}$ with a slight bending of the two carbene ligands away from the $\mathrm{CO}$ ligand (C1) toward the hydride ligand (H1). This may be a result of the slight steric bulk of $\mathrm{CO}$ compared with the hydride ligand; however, electronic effects cannot be eliminated as a root cause of the $\mathrm{C} 24-\mathrm{Ru}-\mathrm{C} 3$ bending. For example, Eisenstein et al. have discussed electronic factors that contribute to $\mathrm{P}-\mathrm{Os}-\mathrm{P}$ angular distortions $\left(167.5^{\circ}\right.$ and $\left.141.4^{\circ}\right)$ in six-coordinate Os(II) systems $\left(\mathrm{PR}_{3}\right)_{2} \mathrm{Os}(\mathrm{Cl})(\mathrm{CO})(\mathrm{X})$ (carbene) $(X=\mathrm{H}$ or $\mathrm{Cl}) .{ }^{63}$ The Os system resembles complex 2 with two strong $\sigma$-donors $\left(\mathrm{PR}_{3}\right.$ for the $\mathrm{Os}$ complex and IMes for 2 ), two strong $\pi$-acids (carbene and $\mathrm{CO}$ for the Os systems and $2 \mathrm{CO}$ ligands for complex 2) and $\mathrm{Cl} / \mathrm{H}$ ligands. Thus, bending of the IMes ligands away from the $\pi$-acid CO may enhance Ru-to-CO d $\pi$-back-bonding. ${ }^{63}$

At room temperature, 2 and excess $\mathrm{HCl}$ produce the 6-coordinate $\mathrm{Ru}(\mathrm{II})$ complex (IMes) $)_{2} \mathrm{Ru}(\mathrm{Cl})_{2}(\mathrm{CO})_{2}(\mathbf{3})$, which is isolated as a white solid in $82 \%$ yield (eq 4 ). The ${ }^{1} \mathrm{H}$ NMR spectrum of $\mathbf{3}$ shows no resonance upfield of $0 \mathrm{ppm}$, which is consistent with the absence of a hydride ligand. The IMes ligands of 3 approach coplanarity as determined by ${ }^{1} \mathrm{H}$ NMR spectroscopy. For example, two resonances are observed in a 2:1 ratio due to the ortho and para methyl groups. Variable temperature NMR experiments have not been performed to differentiate between a static structure or transient access to a symmetric geometry. The IR spectrum (thin film on $\mathrm{KBr}$ ) shows the symmetric and asymmetric CO absorption at 2025 and 1955 $\mathrm{cm}^{-1}$. Complex 3 is likely produced via protonation of the hydride ligand followed by $\mathrm{H}_{2} / \mathrm{Cl}^{-}$ligand exchange. Monitoring the reaction by ${ }^{1} \mathrm{H}$ NMR spectroscopy did not allow the observation of $\left[(\mathrm{IMes})_{2} \mathrm{Ru}(\mathrm{Cl})\left(\eta^{2}-\mathrm{H}_{2}\right)(\mathrm{CO})_{2}\right][\mathrm{Cl}]$ (no reaction intermediates were observed at room temperature); however, free $\mathrm{H}_{2}$ was observed at $4.42 \mathrm{ppm}\left({ }^{1} \mathrm{H} \mathrm{NMR}\right)$. Since the hydride ligand of complex $\mathbf{2}$ was readily replaced with a chloride ligand via reaction with $\mathrm{HCl}$, we attempted the same reaction with complex 1. However, neither reaction with $\mathrm{HCl}$ nor other sources of chlorine (e.g., $\mathrm{N}$-chlorosuccinimide or $\mathrm{CCl}_{4}$ ) resulted in the clean formation of (IMes) $)_{2} \mathrm{Ru}(\mathrm{Cl})_{2}(\mathrm{CO})$ from (IMes) ${ }_{2} \mathrm{Ru}(\mathrm{Cl})(\mathrm{H})(\mathrm{CO})(\mathbf{1})$ (see Supporting Information).

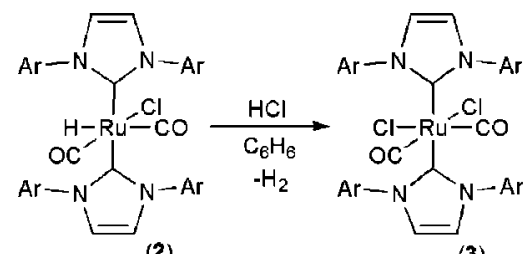

Synthesis and Characterization of $\left[(\mathrm{IMes})_{2} \mathrm{Ru}(\mathrm{H})(\mathrm{CO})\right]-$ [BAr ${ }_{4}{ }_{4}$ ] (4). The reaction of 1 with $\mathrm{NaBAr}_{4}^{\prime}\left\{\mathrm{Ar}^{\prime}=3,5-\right.$ $\left.\left(\mathrm{CF}_{3}\right) \mathrm{C}_{6} \mathrm{H}_{3}\right\}$ at room temperature produces a new species assigned as four-coordinate [(IMes) $\left.)_{2} \mathrm{Ru}(\mathrm{H})(\mathrm{CO})\right]\left[\mathrm{BAr}_{4}{ }_{4}\right](\mathbf{4})(\mathrm{eq}$ 5 ), which is isolated in $70 \%$ yield as a brick-red powder. The ${ }^{1} \mathrm{H}$ NMR spectrum of $\mathbf{4}$ shows the $\mathrm{Ru}-\mathrm{H}$ as a broad resonance at $-26.4 \mathrm{ppm}\left(\mathrm{C}_{6} \mathrm{D}_{6}\right)$, which integrates to $1 \mathrm{H}$, and the IR

(62) Guan, H.; Masanori, I.; Magee, M. P.; Norton, J. R.; Janak, K. E. Organometallics 2003, 22, 4084-4089. 498.
(63) Gérard, H.; Clot, E.; Eisenstein, O. New J. Chem. 1999, 23, 495- 


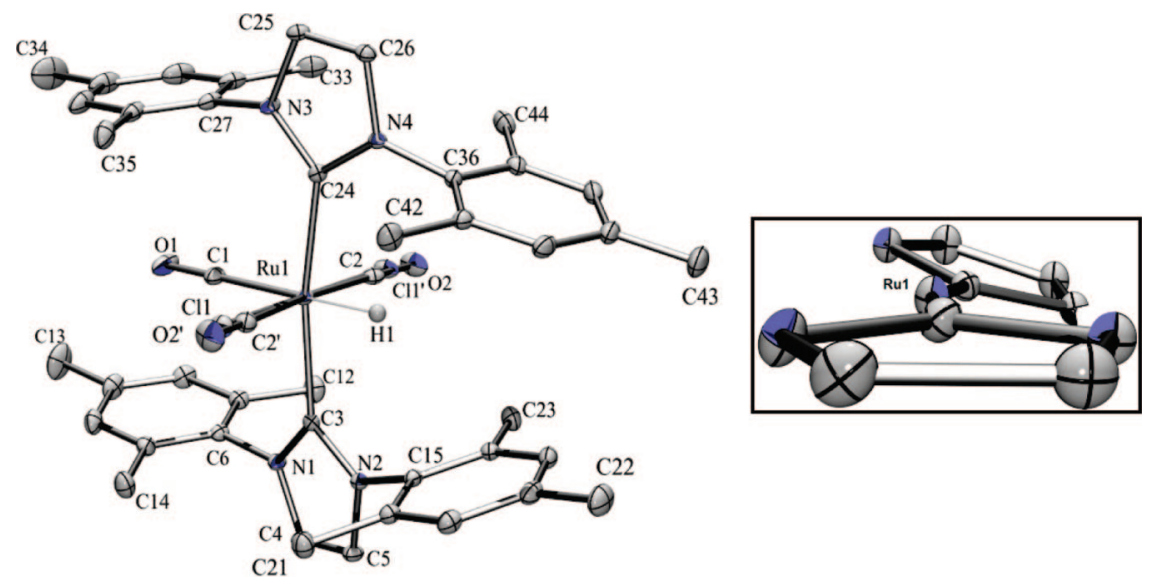

Figure 2. ORTEP of $(\mathrm{IMes})_{2} \mathrm{Ru}(\mathrm{Cl})(\mathrm{H})(\mathrm{CO})_{2}(\mathbf{2})(30 \%$ probability with most hydrogen atoms omitted). Selected bond lengths $(\AA)$ : Ru-C3, 2.115(1); $\mathrm{Ru}-\mathrm{C} 24,2.110(1) ; \mathrm{Ru}-\mathrm{Cl}, 1.986(2) ; \mathrm{Ru}-\mathrm{H} 1,1.54(2) ; \mathrm{C} 1-\mathrm{O} 1,1.136(2)$. Selected bond angles (deg): $\mathrm{C} 3-\mathrm{Ru}-\mathrm{C} 24,168.69(5)$; $\mathrm{C} 1-\mathrm{Ru}-\mathrm{H} 1,179.3(7) ; \mathrm{C} 24-\mathrm{Ru}-\mathrm{C} 1,96.13(5) ; \mathrm{C} 3-\mathrm{Ru}-\mathrm{H} 1,85.4(7) ; \mathrm{C} 24-\mathrm{Ru}-\mathrm{H} 1,83.2(7)$. (Inset) Complex 2 viewed down the $\mathrm{C} 3-\mathrm{Ru}-\mathrm{C} 24$ bond (only the imidazolyl rings and $\mathrm{Ru}$ are shown) to highlight the degree to which the imidazolyl rings are twisted.

Table 1. Selected Crystallographic Data and Collection Parameters for $(\mathrm{IMes})_{2} \mathrm{Ru}(\mathrm{Cl})(\mathrm{H})(\mathrm{CO})_{2}(2)$ and $\left[(\mathrm{IMes})_{2} \mathrm{Ru}(\mathrm{H})\left(\mathrm{CN}^{t} \mathrm{Bu}\right)_{2}(\mathrm{CO})\right]\left[\mathrm{BAr}_{4}^{\prime}\right](5)$

\begin{tabular}{lll}
\hline & \multicolumn{1}{c}{$\mathbf{2}$} & \multicolumn{1}{c}{$\mathbf{5}$} \\
\hline empirical formula & $\mathrm{C}_{44} \mathrm{H}_{49} \mathrm{ClN}_{4} \mathrm{O}_{2} \mathrm{Ru}$ & $\mathrm{C}_{85} \mathrm{H}_{79} \mathrm{BF}_{24} \mathrm{~N}_{6} \mathrm{ORu}$ \\
fW & 802.39 & 1768.42 \\
crystal system & monoclinic & monoclinic \\
space group & $P 2{ }_{1} / c$ & $\mathrm{P} 2{ }_{1} / \mathrm{n}$ \\
$a(\AA)$ & $21.109(8)$ & $16.535(1)$ \\
$b(\AA)$ & $10.832(4)$ & $24.432(2)$ \\
$c(\AA)$ & $18.474(2)$ & $21.548(1)$ \\
$\beta($ deg $)$ & $108.41(2)$ & $97.57(1)$ \\
$V(\AA 3)$ & $4008.1(3)$ & $8629.2(9)$ \\
$Z$ & 4 & 4 \\
crystal size $(\mathrm{mm})$ & $0.22 \times 0.16 \times 0.16$ & $0.12 \times 0.14 \times 0.40$ \\
$R 1, w R 2\{l>2 \sigma(1)\}$ & $0.375,0.0772$ & $0.0548,0.143$ \\
GOF & 1.038 & 1.011
\end{tabular}

spectrum shows a $v_{\mathrm{CO}}$ stretch at $1933 \mathrm{~cm}^{-1}\left(\mathrm{C}_{6} \mathrm{H}_{6}\right)$. Thus, conversion of 1 to 4 results in a $47 \mathrm{~cm}^{-1}$ increase in the $\mathrm{CO}$ absorption energy, which is consistent with the decrease in electron density and metal $\mathrm{d} \pi$-back-bonding to $\mathrm{CO}$ that is expected upon removal of chloride to generate a cationic complex. Similar to $\mathbf{1}$, the $\mathrm{Ru}-\mathrm{H}$ stretching frequency was not identified in the IR spectrum of 4 . In agreement with our assignment of $\mathbf{4}$ as the product of chloride abstraction, the reaction of $\mathbf{4}$ with $\left[\mathrm{Bu}_{4} \mathrm{~N}\right][\mathrm{Cl}]$ quantitatively produces $\mathbf{1}$ (by ${ }^{1} \mathrm{H}$ NMR spectroscopy, $\mathrm{C}_{6} \mathrm{D}_{6}$ ) at room temperature (eq 5).

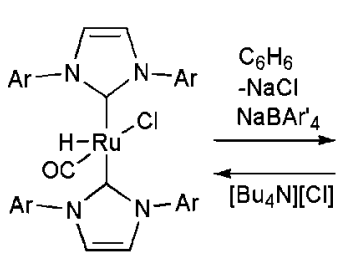

(1)

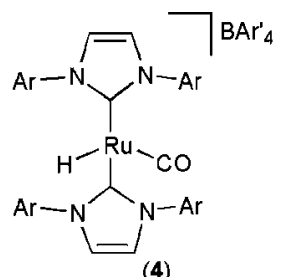

(4)
On the basis of characterization data (see below), complex 4 appears to be a four-coordinate $\mathrm{Ru}(\mathrm{II})$ complex. Although scant, recent examples of formally four-coordinate 14-electron $\mathrm{Ru}(\mathrm{II})$ systems have been reported, and as anticipated, such systems are highly reactive. ${ }^{64-68}$ With limited exceptions, octahedral

(64) Ingleson, M. J.; Yang, X.; Pink, M.; Caulton, K. G. J. Am. Chem. Soc. 2005, 127, 10846-10847.

(65) Walstrom, A. N.; Watson, L. A.; Pink, M.; Caulton, K. G. Organometallics 2004, 23, 4814-4816. geometries in which $\mathrm{C}-\mathrm{H}$ agostic interactions complete the "sixcoordinate" nature are adopted for these systems. ${ }^{69-72}$ For example, the complex $\left[\left\{\mathrm{P}\left({ }^{t} \mathrm{Bu}_{2} \mathrm{Me}\right)\right\}_{2} \mathrm{Ru}(\mathrm{Ph})(\mathrm{CO})\right]\left[\mathrm{BAr}_{4}{ }_{4}\right]$ has been reported with an IR spectrum that is consistent with $\mathrm{C}-\mathrm{H}$ agostic interactions $\left(v_{\mathrm{CH}}=2722\right.$ and $\left.2672 \mathrm{~cm}^{-1}\right){ }^{70}$ The $\mathrm{Ru}(\mathrm{II})$ complex $\left[\left\{\mathrm{P}\left({ }^{t} \mathrm{Bu}_{2} \mathrm{Me}\right)\right\}_{2} \mathrm{Ru}(\mathrm{H})(\mathrm{CO})\right]\left[\mathrm{BAr}_{4}^{\prime}\right]$, which is closely related to complex $\mathbf{4}$ with two strongly donating ligands (alkylphosphines) and hydride/CO ligands, has been reported to possess two $\mathrm{C}-\mathrm{H}$ agostic interactions as determined by $\mathrm{X}$-ray crystallography. ${ }^{71}$ Studies by Nolan et al. of low coordinate Rh and $\mathrm{Ir}$ systems with $\mathrm{N}$-heterocyclic carbene ligands are also relevant here. ${ }^{73}$ Two interesting $\mathrm{Ru}(\mathrm{II})$ systems that are fourcoordinate without evidence of stabilizing agostic interactions are $\left(\mathrm{PNP}{ }^{\mathrm{tBu}}\right) \mathrm{Ru}(\mathrm{Cl})\left\{\mathrm{PNP}^{\mathrm{tBu}}=\left[\left({ }^{\mathrm{t}} \mathrm{Bu}\right)_{2} \mathrm{PCH}_{2} \mathrm{SiMe}_{2}\right)_{2} \mathrm{~N}\right\}$ and $\kappa^{2}-$ $P, O-\left({ }^{\mathrm{t}} \mathrm{Bu}_{2} \mathrm{PCH}_{2} \mathrm{SiMe}_{2} \mathrm{O}\right)_{2} \mathrm{Ru}$ reported by Caulton et al. ${ }^{74-76}$ The triplet ground-state of these $\mathrm{d}^{6}$ complexes has been attributed to the square planar geometry and $\pi$-donating $\mathrm{N}$ - or O-based ligands. ${ }^{74} \mathrm{By}$ IR and ${ }^{1} \mathrm{H}$ NMR spectroscopy (see below), we see no evidence of $\mathrm{C}-\mathrm{H}$ agostic bonding for 4 . For example, there are no absorption bands between 2750 and $2000 \mathrm{~cm}^{-1}$ in the IR spectrum (see Supporting Information). In addition, variable temperature ${ }^{1} \mathrm{H}$ NMR spectroscopy in toluene- $d_{8}$ under an argon atmosphere reveals no evidence of fluxionality down to $-40{ }^{\circ} \mathrm{C}$. Below $-40{ }^{\circ} \mathrm{C}$, solubility issues complicate the NMR analysis. Furthermore, IR spectra of $\mathbf{4}$ in toluene, methylene chloride and hexafluorobenzene reveal no significant

(66) Watson, L. A.; Pink, M.; Caulton, K. G. J. Mol. Catal. A: Chem. 2004, 224, 51-59.

(67) Ingleson, M. J.; Pink, M.; Huffman, J. C.; Fan, H.; Caulton, K. G. Organometallics 2006, 25, 1112-1119.

(68) Walstrom, A.; Pink, M.; Yang, X.; Tomaszewski, J.; Baik, M.; Caulton, K. G. J. Am. Chem. Soc. 2005, 127, 5330-5331.

(69) Huang, D.; Huffman, J. C.; Bollinger, J. C.; Eisenstein, O.; Caulton, K. G. J. Am. Chem. Soc. 1997, 119, 7398-7399.

(70) Huang, D.; Streib, W. E.; Bollinger, J. C.; Caulton, K. G.; Winter, R. F.; Scheiring, T. J. Am. Chem. Soc. 1999, 121, 8087-8097.

(71) Huang, D.; Bollinger, J. C.; Streib, W. E.; Folting, K.; Young, J., V.; Eisenstein, O.; Caulton, K. G. Organometallics 2000, 19, 2281-2290.

(72) Baratta, W.; Herdtweck, E.; Rigo, P. Angew. Chem., Int. Ed. 1999, 39, 1629-1631.

(73) Scott, N. M.; Dorta, R.; Stevens, E. D.; Correa, A.; Cavallo, L.; Nolan, S. P. J. Am. Chem. Soc. 2005, 127, 3516-3526.

(74) Watson, L. A.; Ozerov, O. V.; Pink, M.; Caulton, K. G. J. Am. Chem. Soc. 2003, 125, 8426-8427.

(75) Walstrom, A. N.; Pink, M.; Caulton, K. G. Inorg. Chem. 2006, 45, 5617-5620.

(76) Yang, X.; Walstrom, A.; Nikolay, T.; Maren, P.; Caulton, K. G. Inorg. Chem. 2007, 46, 4612-4616. 


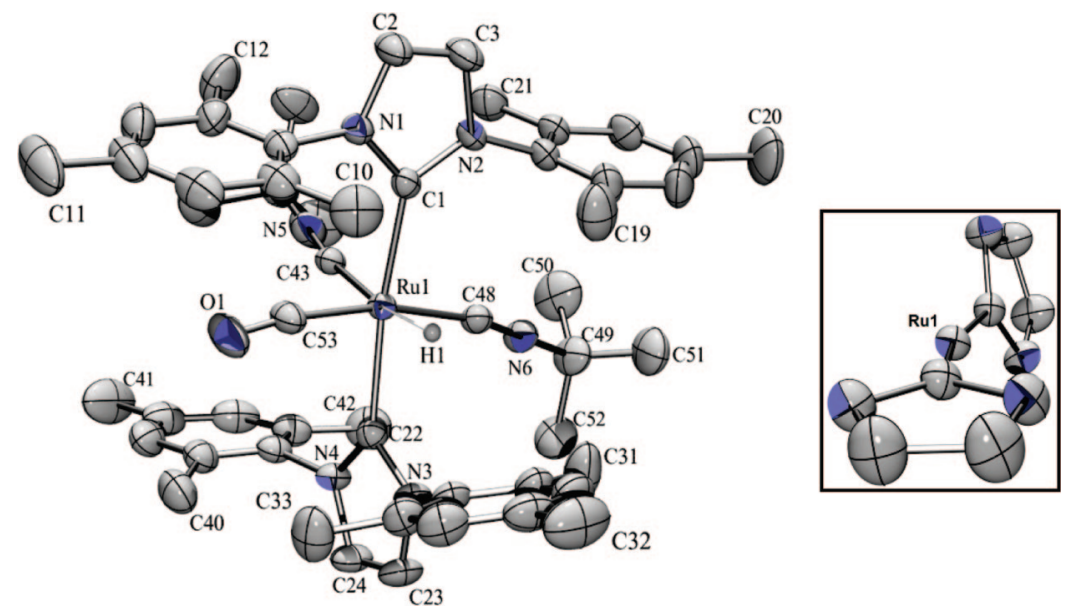

Figure 3. ORTEP of $\left[(\mathrm{IMes})_{2} \mathrm{Ru}(\mathrm{H})\left(\mathrm{CN}^{t} \mathrm{Bu}\right)_{2}(\mathrm{CO})\right]^{+}(\mathbf{5})\left(30 \%\right.$ probability; BAr ${ }_{4}$ anion and most hydrogen atoms omitted). Selected bond lengths $(\AA): \mathrm{Ru}-\mathrm{C} 1,2.11(2) ; \mathrm{Ru}-\mathrm{C} 22,2.12(2) ; \mathrm{Ru}-\mathrm{C} 53,1.87(2) ; \mathrm{Ru}-\mathrm{C} 48,2.05(2) ; \mathrm{Ru}-\mathrm{H} 1,1.68 ; \mathrm{C} 53-\mathrm{O} 1,1.15(3)$; C48-N6, 1.15(2); C43-N5, 1.16(3). Selected bond angles (deg): C1-Ru-C22, 167.5(7); C1-Ru-H1, 82.1; C43-Ru-C48, 86.8(8); C53-Ru-H1, 88.2; C43-Ru-H1, 172.2; C53-Ru-C48, 168.2(8); Ru1-C53-O1, 171(2); Ru1-C48-N6, 168(2); Ru1-C43-N5, 171(2). (Inset) Complex 5 viewed down the $\mathrm{C} 22-\mathrm{Ru}-\mathrm{C} 1$ axis (only the imidazoly1 rings and $\mathrm{Ru}$ are shown) to highlight the degree to which the imidazoly 1 rings are twisted.

change within the deviation of the instrument in the $\mathrm{CO}$ stretching frequency, which suggests that solvent does not coordinate to complex 4 .

Cooling a solution of $\mathbf{4}$ in toluene- $d_{8}$ in the NMR probe results in the appearance of resonances due to a new complex with a simultaneous decrease in the intensity of the resonances due to complex 4. At $-60{ }^{\circ} \mathrm{C}$, an approximate $2: 1$ molar ratio of the resonances due to complex $\mathbf{4}$ and the new complex is observed (based on integration of resonances due to IMes olefinic groups). Upon warming back to room temperature, the original ${ }^{1} \mathrm{H}$ NMR spectrum is acquired. These data suggest a temperature dependent and reversible equilibrium, and we propose that an equilibrium between complex 4 and the $\mathrm{N}_{2}$ adduct [(IMes) $)_{2}$ $\left.\mathrm{Ru}(\mathrm{H})(\mathrm{CO})\left(\mathrm{N}_{2}\right)\right]\left[\mathrm{BAr}_{4}^{\prime}\right]$ (4-N $\mathbf{N}_{2}$ ) is likely (eq 6). To further confirm coordination of dinitrogen by $\mathbf{4}$ at low temperatures, a toluene- $d_{8}$ solution of $\mathbf{4}$ was transferred to a J-Young NMR tube and was thoroughly degassed via multiple freeze - pump-thaw cycles and back-filled with argon (1 atm). Cooling this solution in the NMR probe from 20 to $-40{ }^{\circ} \mathrm{C}$ results in no observable changes. Hence, in the absence of dinitrogen, at low temperatures the second complex assigned as the nitrogen adduct $\mathbf{4 - \mathbf { N } _ { 2 }}$ is not observed. In addition, pressurizing a J-Young NMR tube containing a solution of $\mathbf{4}$ with 80 psi of dinitrogen results in the observation of a mixture of $\mathbf{4}$ and $\mathbf{4 - N _ { 2 }}$ at room temperature (by ${ }^{1} \mathrm{H}$ NMR spectroscopy). Furthermore, subsequent degassing of this reaction tube with argon (via multiple freeze-pump-thaw cycles) results in the disappearance of $\mathbf{4 - \mathbf { N } _ { 2 }}$ and quantitative conversion back to complex 4. Unfortunately, attempts to acquire low temperature IR spectra (in order to observe the coordinated dinitrogen ligand) were thwarted by decomposition of 4 (see the Supporting Information for details). Several attempts were made to grow crystals of $\mathbf{4}$ suitable for an X-ray diffraction study. In all attempts, complex 4 apparently crystallizes as [(IMes) $2_{2}^{-}$ $\left.\mathrm{Ru}(\mathrm{H})(\mathrm{CO})\left(\mathrm{N}_{2}\right)\right]\left[\mathrm{BAr}_{4}^{\prime}\right]\left(\mathbf{4}-\mathbf{N}_{\mathbf{2}}\right)$; however, the X-ray structure analysis is complicated by disorder. Details of a representative data set are provided in the Supporting Information. Finally, recrystallization of complex $\mathbf{4}$ under an argon atmosphere with a variety of solvent combinations did not produce X-ray quality crystals.

Additional evidence for the identity of complex $\mathbf{4}$ comes from reaction with tert-butylisonitrile. At room temperature $\mathbf{4}$ and

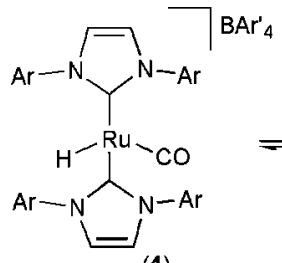

(4)

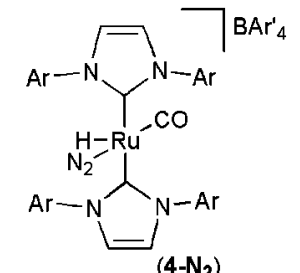

$\left(4-N_{2}\right)$ excess $\mathrm{CN}^{t} \mathrm{Bu}$ rapidly produce the cis-isonitrile $\mathrm{Ru}(\mathrm{II})$ complex $\left[(\mathrm{IMes})_{2} \mathrm{Ru}(\mathrm{H})\left(\mathrm{CN}^{t} \mathrm{Bu}\right)_{2}(\mathrm{CO})\right]\left[\mathrm{BAr}_{4}{ }_{4}\right]$ (5) (eq 7). The ${ }^{1} \mathrm{H}$ NMR spectrum of 5 shows the $\mathrm{Ru}-\mathrm{H}$ resonance at $-7.99 \mathrm{ppm}\left(\mathrm{C}_{6} \mathrm{D}_{6}\right)$, and the IR spectrum (thin film on $\mathrm{KBr}$ ) shows an absorption at $1975 \mathrm{~cm}^{-1}$ assigned as $v_{\mathrm{CO}}$ as well as symmetric and asymmetric $v_{\mathrm{CN}}$ stretches at 2150 and $2120 \mathrm{~cm}^{-1}$, respectively. A small shoulder is observed for the $\mathrm{CO}$ absorption at $1975 \mathrm{~cm}^{-1}$, which is likely due to an overlap of a low intensity $\mathrm{Ru}-\mathrm{H}$ stretch with the $\mathrm{CO}$ absorption.

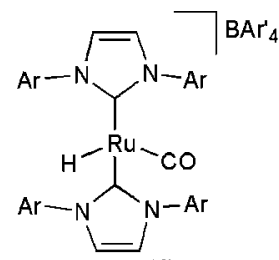

(4)

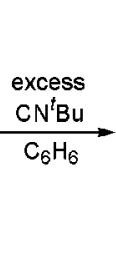

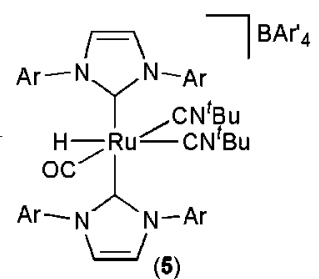

(7)
A single crystal of $\mathbf{5}$ suitable for an X-ray diffraction study was grown, and the resulting structure is shown in Figure 3 with crystallographic data collection and parameters given in Table 1 . The hydride ligand of $\mathbf{5}$ was located with a $\mathrm{Ru}-\mathrm{H}$ bond distance of $1.68 \AA$. In contrast to 2 , the trans IMes ligands of $\mathbf{5}$ are approximately perpendicular to each other with a twist angle $\theta_{\mathrm{t}}\{0.5[\mathrm{~N} 1-\mathrm{C} 1-\mathrm{C} 22-\mathrm{N} 4+\mathrm{N} 2-\mathrm{C} 1-\mathrm{C} 22-\mathrm{N} 3]\}^{43}$ of $74.4^{\circ}$. Both of the isonitrile ligands were found to be slightly bent into an open area between the mesityl rings of an IMes ligand. These open "pockets" are a result of twisting of the IMes ligands. For example, the Ru1-C48-N6 bond angle is $168(2)^{\circ}$ with the isonitrile bent away from a mesityl group of the $\mathrm{C} 1-\mathrm{NHC}$ into an opening between the mesityl rings of the C22-NHC ligand. Likewise, the Ru1-C43-N5 bond angle is $172(2)^{\circ}$ with the isonitrile bent away from the mesityl ring of 


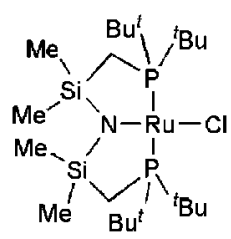

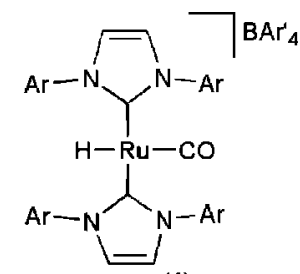

(4)

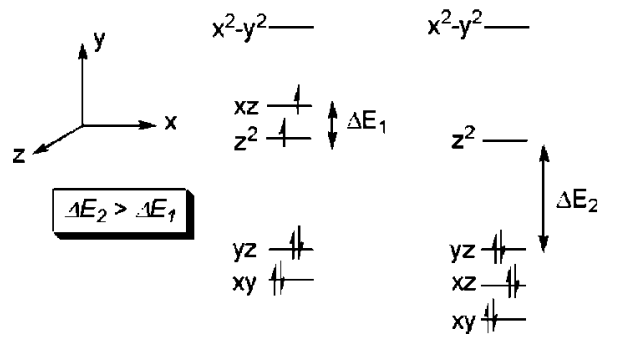

Figure 4. Qualitative d-orbital splitting diagram for [(IMes $)_{2}$ $\mathrm{Ru}(\mathrm{H})(\mathrm{CO})]\left[\mathrm{BAr}_{4}^{\prime}\right](4)$ and $\left(\mathrm{PNP}^{\mathrm{tBu}}\right) \mathrm{Ru}(\mathrm{Cl})$.

the C22-NHC ligand into an open pocket. The bending of the isonitrile ligands are within the range observed for other isonitrile ligands, which readily distort as a consequence of packing interactions. ${ }^{77,78} \mathrm{Yu}$ et al. have recently discussed the softness of the bending modes of the tert-butyl isonitrile ligand. ${ }^{79}$ Hence, it is plausible to surmise that these ligands will readily distort as a consequence of packing interactions.

Although we have not been able to obtain a crystal of 4 suitable for X-ray diffraction, spectroscopic data, reactivity, and computational chemistry studies (see below) are consistent with the formulation of $\mathbf{4}$ as a monomeric four-coordinate $\mathrm{Ru}(\mathrm{II})$ complex in solution at room temperature. Furthermore, NMR spectra of $\mathbf{4}$ are consistent with a diamagnetic system, and utilization of the Evans NMR method to detect paramagnetic systems resulted in no difference in chemical shift of internal and external standards. It is interesting that $\mathbf{4}$ is apparently diamagnetic while related four-coordinate $\mathrm{Ru}(\mathrm{II})$ systems reported by Caulton et al. (see above) are paramagnetic triplet species. The triplet ground states for the two complexes reported by Caulton et al. have been attributed in part to the $\pi$-donating ability of the amido and alkoxo moieties. ${ }^{74,75}$ Figure 4 depicts a qualitative molecular orbital diagram for the (PNP) $\mathrm{Ru}(\mathrm{Cl})$ systems reported by Caulton et al. that provides a rationalization for their high spin electron configuration. The increased energy of $\mathrm{d}_{x z}$, which takes on antibonding character due to $\pi$-interaction with the amido moiety, results in a small energy gap between orbitals that possess $\mathrm{d}_{z}^{2}$ and $\mathrm{d}_{x z}$ character. In contrast, complex 4 does not possess a $\pi$-donor ligand but has a strongly $\pi$-acidic $\mathrm{CO}$ ligand. Hence, the Ru-CO back-bonding interaction is anticipated to lower the energy of $\mathrm{d}_{x z}$ and $\mathrm{d}_{x y}$ relative to the PNP-Ru system and thus increase the HOMO-LUMO gap of 4 relative to the Caulton system, which might account for the low spin ground state. To explore the structure of $\mathbf{4}$, we employed DFT calculations.

Computational Studies for $\left[(\mathrm{IMes})_{2} \mathrm{Ru}(\mathrm{H})(\mathrm{CO})\right]^{+}$(4). Fourcoordinate transition metal complexes generally adopt three ideal geometries: tetrahedron, square planar and sawhorse. ${ }^{80} \mathrm{~A}$

(77) Leach, P. A.; Geib, S. J.; Cooper, N. J. Organometallics 1992, 11, 4367-4370.

(78) Leach, P. A.; Geib, S. J.; Corella II, J. A.; Warnock, G. F.; Cooper, N. J. J. Am. Chem. Soc. 1994, 116, 8566-8574.

(79) Yu, Y.; Sadique, A. R.; Smith, J. M.; Dugan, T. R.; Cowley, R. E.; Brennessel, W. W.; Flaschenriem, C. J.; Bill, E.; Cundari, T. R.; Holland, P. L. J. Am. Chem. Soc. 2008, 130, 6624-6638.

(80) Cirera, J.; Ruiz, E.; Alvarez, S. Inorg. Chem. 2008, 47, 2871-2889.

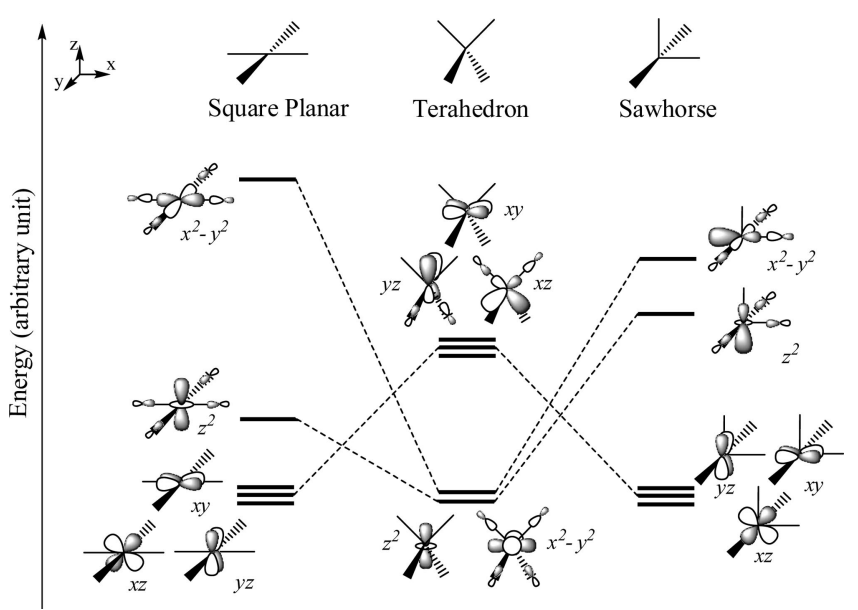

Figure 5. d-block orbitals for four-coordinate transition metal complexes in the tetrahedron, square planar, and sawhorse coordination geometries.

qualitative correlation diagram linking the d-block orbitals for these three geometries is shown in Figure 5. [(IMes) $2_{2}^{-}$ $\mathrm{Ru}(\mathrm{H})(\mathrm{CO})]^{+}$(4) has a $\mathrm{Ru}(\mathrm{II})$ metal center with a $\mathrm{d}^{6}$ configuration. This $\mathrm{d}^{6}$ complex is less likely to adopt a tetrahedral geometry, due to the large energy splitting between the nonbonding pair $\left(\mathrm{d}_{z^{2}}, \mathrm{~d}_{x^{2}-y^{2}}\right)$ and the antibonding triad $\left(\mathrm{d}_{x y}, \mathrm{~d}_{y z}\right.$, and $\mathrm{d}_{x z}$; Figure 5). Additionally, steric repulsion is anticipated to promote a trans orientation of the two bulky IMes ligands. In fact, no examples of a tetrahedral structure for related fourcoordinate 14-electron Ru(II) systems have been reported. These $\mathrm{Ru}$ (II) systems adopt either a sawhorse structure, ${ }^{69-72}$ in which the open sites of the metal center form $\mathrm{C}-\mathrm{H} \cdots \mathrm{Ru}$ agostic interactions to complete the "six-coordinate" nature, or a square planar structure without formation of $\mathrm{C}-\mathrm{H}$ agostic interactions. ${ }^{74,75}$ Our spectral analysis shows no evidence of $\mathrm{C}-\mathrm{H}$ agostic interactions in complex $\mathbf{4}$. It is also very interesting that $\mathbf{4}$ is characterized to be diamagnetic, which contrasts the reported square planar PNP-Ru-X systems that are suggested to be paramagnetic triplet species. ${ }^{74,75}$ Density functional theory (DFT) calculations were thus carried out to interpret the geometry and electronic structure of the four-coordinate complex 4.

When adopting a square planar structure without $\mathrm{C}-\mathrm{H}$ agostic interactions, a $\mathrm{d}^{6}$ complex has the possibility to be a singlet or triplet depending on the magnitude of d-orbital splitting (Figure 5 ). A $\pi$-donor ligand may raise the energy of one or more of the nonbonding d-orbitals closer to that of the $\mathrm{d}_{z}^{2}$ orbital, leading to a triplet state. However, a $\pi$-acidic ligand, such as $\mathrm{CO}$, might stabilize the nonbonding d-orbitals and increase the d-splitting energy, resulting in a singlet state (Figure 4). To evaluate the spin multiplicity of $\mathbf{4}$ in an assumed square planar geometry and the $\pi$-donor and $\pi$-acceptor effects of the ligand on the ground-state spin multiplicity, DFT calculations were employed for $\left[(\mathrm{IMes})_{2} \mathrm{Ru}(\mathrm{H})(\mathrm{CO})\right]^{+}(4)$ and a hypothetical (IMes) ${ }_{2} \mathrm{Ru}-$ $(\mathrm{H})\left(\mathrm{NH}_{2}\right)(6)$ complex in both singlet and triplet spin states. The optimized structures are shown in Figure 6. The optimization of singlet 4 from a square planar starting geometry leads to two minima. One $\left(\mathbf{4}_{\text {SP-S-1 }}\right)$ is square planar, while the other minimum $\left(\mathbf{4}_{\text {SP-S-2 }}\right)$ has two trans-oriented $\mathrm{C}-\mathrm{H}$ agostic interactions to complete a "six-coordinate" octahedral geometry, as shown in Figure 6 . In $\mathbf{4}_{\text {SP-S-2 }}$, the $\mathrm{Ru} \cdots \mathrm{CH}_{3}$ distances are calculated to be $\sim 2.7 \AA$, which is quite similar to those of the complex $\left[\left\{\mathrm{P}\left({ }^{t} \mathrm{Bu}_{2} \mathrm{Me}\right)\right\}_{2} \mathrm{Ru}(\mathrm{Ph})(\mathrm{CO})\right]\left[\mathrm{BAr}_{4}^{\prime}\right]$ (with two short $\mathrm{Ru}-\mathrm{CH}_{3}$ distances: 2.87 and $\left.2.88 \AA\right){ }^{70}$ The $\mathrm{Ru} \cdot \cdots \mathrm{H}$ distances for the agostic interaction in $\mathbf{4}_{\mathrm{SP}-\mathrm{S}-2}$ are calculated to be short at 

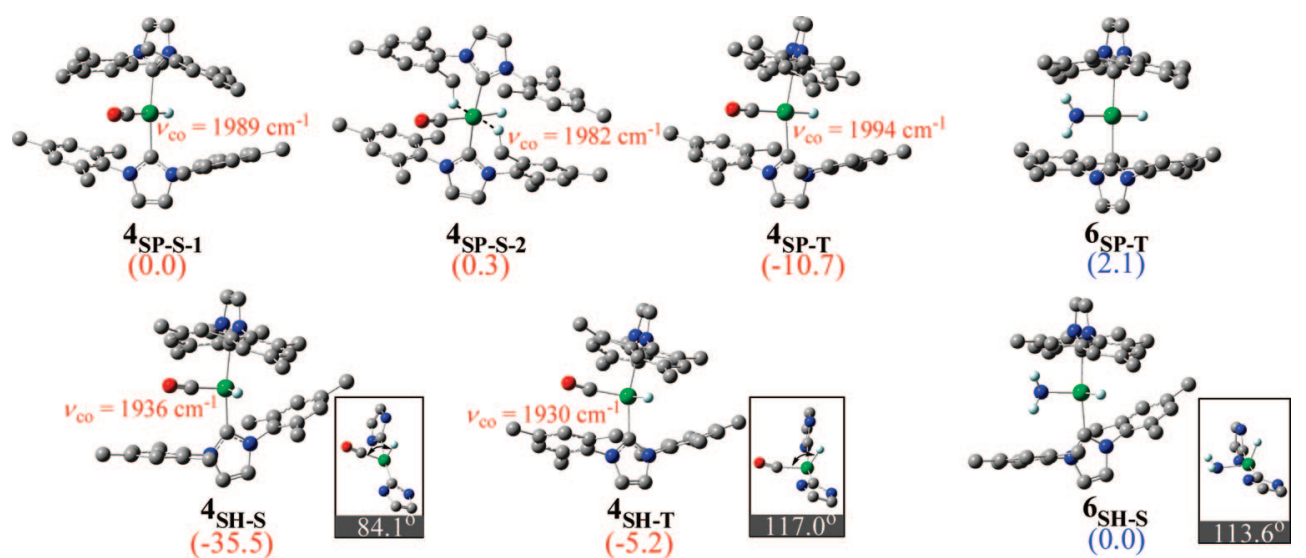

Figure 6. Optimized structures for singlet/triplet [(IMes) $\left.)_{2} \mathrm{Ru}(\mathrm{H})(\mathrm{CO})\right]^{+}$complex (4) and hypothetical $(\mathrm{IMes}){ }_{2} \mathrm{Ru}(\mathrm{H})\left(\mathrm{NH}{ }_{2}\right)(\mathbf{6}) . \mathrm{Subscript} \mathrm{SP}$ and SH denote square planar and sawhorse structures, respectively; subscript S and T indicate singlet and triplet states, respectively. Most hydrogen atoms on the IMes ligands are omitted for clarity. Calculated free energies are shown in parentheses at $289.15 \mathrm{~K}$ and 1 atm (unit: $\mathrm{kcal} / \mathrm{mol})$.

$1.89 \AA$. Nevertheless, as compared with $\mathbf{4}_{\text {SP-S-1 }}, \mathbf{4}_{\text {SP-S-2 } 2}$ is 0.3 $\mathrm{kcal} / \mathrm{mol}$ higher in free energy even though it has agostic interactions. Excluding entropic effects, $\mathbf{4}_{\text {SP-S-2 }}$ is calculated to be $5.4 \mathrm{kcal} / \mathrm{mol}$ lower in enthalpy than $\mathbf{4}_{\mathrm{SP}-\mathrm{S}-1}$, which indicates that the lack of observation of $\mathrm{C}-\mathrm{H}$ agostic interactions for $\mathbf{4}$ may be a result of a substantial entropic penalty for restraining the orientation of the IMes ligands. More importantly, DFT calculations indicate a more stable triplet square planar structure $\mathbf{4}_{\text {SP-T }}$, which is $10.7 \mathrm{kcal} / \mathrm{mol}$ lower in free energy than the singlet $\mathbf{4}_{\text {SP-S-1 }}$. As shown in Figure 5, for an ideal square planar complex ( $\sigma$-only ligands), the $\mathrm{d}_{z}^{2}$ is expected to be close in energy to the nonbonding $\mathrm{d}_{x y}, \mathrm{~d}_{y z}$ and $\mathrm{d}_{x z}$ orbitals. Although the $\mathrm{d}_{x y}$ and $\mathrm{d}_{x z}$ can be stabilized by the $\pi$-acceptor ligand $\mathrm{CO}$, the $\mathrm{d}_{y z}$ orbital remains unperturbed, leading to a nearly unchanged $\Delta E$ between $\mathrm{d}_{y z}$ and $\mathrm{d}_{z}{ }^{2}\left(\mathrm{~d}_{y z}\right.$ may also be stabilized by IMes ligands, however, the rotation of IMes ligands can also result in steric repulsion between $\mathrm{CO}$ and IMes). The calculated $\mathrm{d}$-splitting of $\mathbf{4}_{\text {SP-T }}$ is only $0.41 \mathrm{eV}$. Thus, assuming a square planar geometry, [(IMes) $\left.{ }_{2} \mathrm{Ru}(\mathrm{H})(\mathrm{CO})\right]^{+}$is more likely to be a triplet $\mathrm{d}^{6}$ complex (i.e., paramagnetic). The DFT calculations suggest that the $\pi$-acceptor effect of CO cannot lead to a singlet 4 in a square planar structure, which is contrary to the experimental observation that the cation $\left[(\mathrm{IMes})_{2} \mathrm{Ru}(\mathrm{H})(\mathrm{CO})\right]^{+}$ is diamagnetic. Replacing $\mathrm{CO}$ with the $\pi$-donor ligand $\mathrm{NH}_{2}$, we cannot locate a square planar stationary point for the singlet $(\mathrm{IMes})_{2} \mathrm{Ru}(\mathrm{H})\left(\mathrm{NH}_{2}\right)(\mathbf{6})$. Singlet $\mathbf{6}$ changed from a square planar starting geometry to a sawhorse geometry upon full DFT geometry optimization. For the square planar geometry, the perturbation due to $\pi$-donor effects of $\mathrm{NH}_{2}$ raises the $\mathrm{d}_{x z}$ slightly higher than $\mathrm{d}_{z}^{2}$ in energy, resulting in a small d-splitting, similar to the case in Caulton's system. ${ }^{74}$ As shown in Figure 7, the $\mathrm{d}$-splitting energy for $\mathbf{6}_{\text {SP-T }}$ is calculated to be only $0.15 \mathrm{eV}$. Thus, in a square planar geometry, the IMes-Ru(II) system tends to be paramagnetic with both $\pi$-acceptor or $\pi$-donor ligands. This initial set of simulations suggests a possible resolution to the apparent theory-experiment mismatch vis-àvis complex 4, i.e., a sawhorse geometry.

A sawhorse structure can be viewed as the cis-divacant fragment of an octahedral complex. The energy of $\mathrm{d}_{z}{ }^{2}$ is thus expected to be much higher than that of the nonbonding $\mathrm{d}_{x y}, \mathrm{~d}_{y z}$ and $\mathrm{d}_{x z}$ orbitals, as shown in Figure 5. Therefore, the $\mathrm{d}^{6}$ complex may tend to be diamagnetic with doubly occupied nonbonding $\mathrm{d}_{x y}, \mathrm{~d}_{y z}$ and $\mathrm{d}_{x z}$ orbitals. The optimized sawhorse structures for both singlet and triplet $\mathbf{4}$ are shown in Figure 6. The singlet $\mathbf{4}_{\mathrm{SH}-\mathrm{S}}$ is much more stable than the square planar singlet $\mathbf{4}_{\mathrm{SP-S}-\mathbf{1}}$,

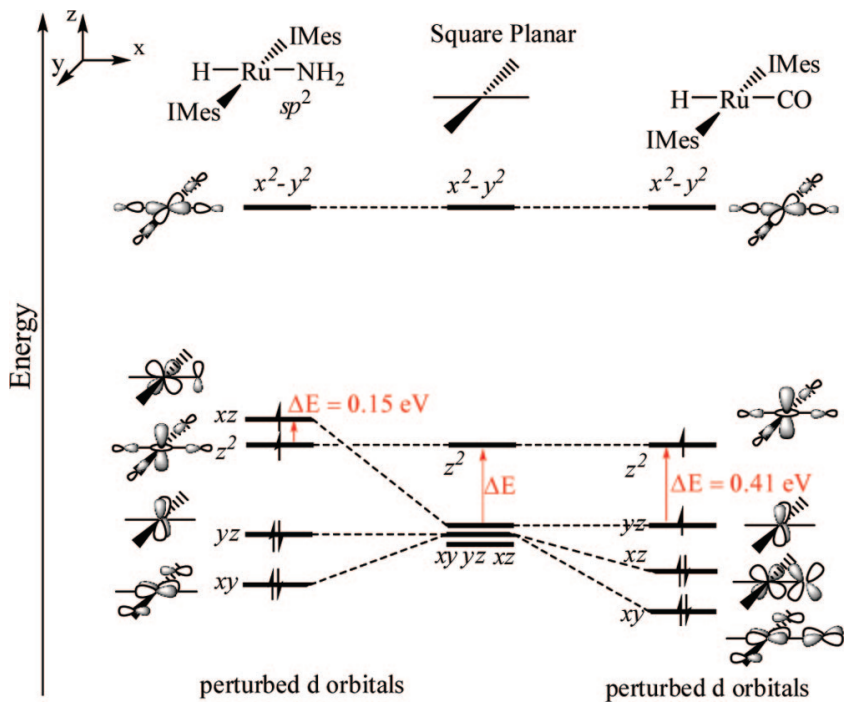

Figure 7. Perturbed d-block of $\left[(\mathrm{IMes})_{2} \mathrm{Ru}(\mathrm{H})(\mathrm{CO})\right]^{+}$(4) and hypothetical (IMes) ${ }_{2} \mathrm{Ru}(\mathrm{H})\left(\mathrm{NH}_{2}\right)(\mathbf{6})$ in a square planar geometry. The d-splittings are obtained from single point RODFT calculations with the unrestricted DFT optimized structures.

being lower in free energy by $35.5 \mathrm{kcal} / \mathrm{mol}$. This singlet sawhorse $\mathbf{4}_{\mathbf{S H}-\mathrm{S}}$ is also more stable than the square planar triplet $\mathbf{4}_{\text {SP-T }}$, lower in free energy by $24.8 \mathrm{kcal} / \mathrm{mol}$. However, the triplet sawhorse $\mathbf{4}_{\text {SH-T }}$ is calculated to be $30.3 \mathrm{kcal} / \mathrm{mol}$ higher in free energy than $\mathbf{4}_{\mathrm{SH}-\mathrm{S} .}{ }^{81}$ Therefore, the singlet $\mathbf{4}_{\mathrm{SH}-\mathrm{S}}$ in sawhorse geometry is calculated to be the most thermodynamically stable structure for cation $\left[(\mathrm{IMes})_{2} \mathrm{Ru}(\mathrm{H})(\mathrm{CO})\right]^{+}$. As depicted in Figure 8, because of the stabilization of the d-orbitals by $\pi$-acceptor ligands, IMes and CO, the HOMO/LUMO gap of $\mathbf{4}_{\mathrm{SH}-\mathrm{S}}$ is calculated to be $3.92 \mathrm{eV}$, significantly higher than that of the $\mathbf{4}_{\mathrm{SP}-\mathrm{S}}(2.05 \mathrm{eV})$. The $\mathrm{H}-\mathrm{Ru}-\mathrm{CO}$ angle of $\mathbf{4}_{\mathrm{SH}-\mathrm{S}}$ is calculated to be $84.1^{\circ}$, while that of triplet $\mathbf{4}_{\mathrm{SH}-\mathrm{T}}$ is $117.0^{\circ}$. The triplet $\mathbf{4}_{\text {SH-T }}$ is thus more akin to an equatorial-vacant trigonal bipyramid. Typically, $\mathrm{d}^{6}$ diamagnetic complexes have strong $\mathrm{C}-\mathrm{H}$ agostic interactions due to the vacant sites on the metal centers when adopting a sawhorse geometry. ${ }^{69-72}$ However, for the cationic complex $\left[(\mathrm{IMes})_{2} \mathrm{Ru}(\mathrm{H})(\mathrm{CO})\right]^{+}$, DFT calculations

(81) The optimized $4_{\mathrm{SH}-\mathrm{T}}$ has one small imaginary frequency, $2.85 \mathrm{i} \mathrm{cm}^{-1}$. Because the free energy difference between $\mathbf{4}_{\mathrm{SH}-\mathrm{T}}$ and $\mathbf{4}_{\mathrm{SH}-\mathrm{S}}$ is large, this small imaginary frequency will not affect our discussion. No further attempts were made due to the formidable workload of reoptimization. 


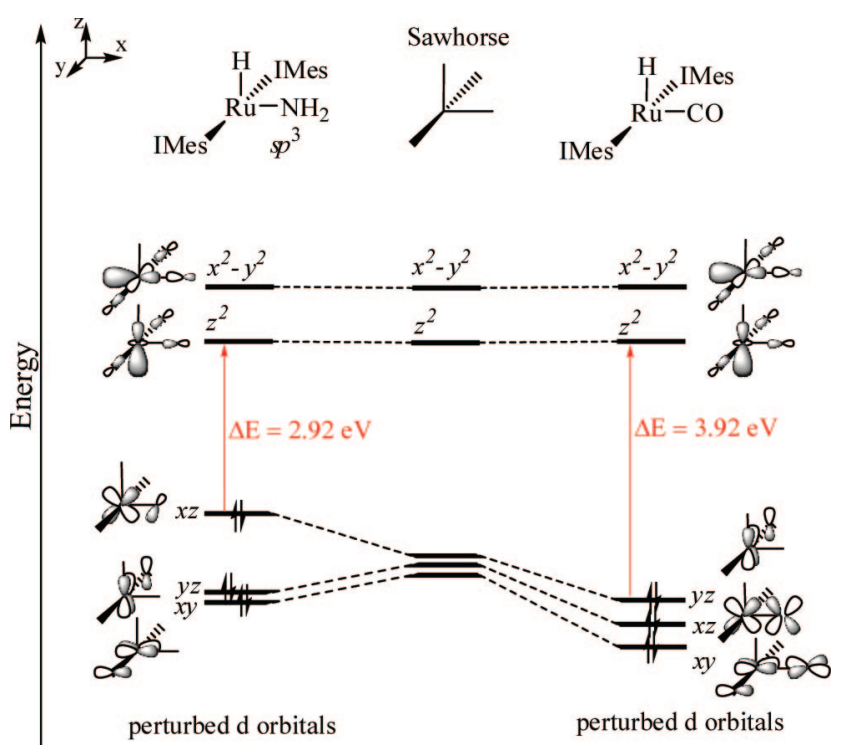

Figure 8. Perturbed d-block of the cation $\left[(\mathrm{IMes})_{2} \mathrm{Ru}(\mathrm{H})(\mathrm{CO})\right]^{+}$ (4) and hypothetical (IMes) $)_{2} \mathrm{Ru}(\mathrm{H})\left(\mathrm{NH}_{2}\right)(6)$ in a sawhorse geometry.

did not locate a stationary point with $\mathrm{C}-\mathrm{H}$ agostic interactions, perhaps due to the bulky IMes ligands. As discussed above, even with the more Lewis acidic nonbonding vacant $\mathrm{d}_{z^{2}}$ in the singlet state, $\mathbf{4}_{\text {SP-S-2 }}$ is less stable than the $\mathbf{4}_{\text {SP-S-1 }}$ by $0.3 \mathrm{kcal} /$ mol. Thus, the combined experimental and computational studies indicate that the four-coordinate cation $\left[(\mathrm{IMes})_{2} \mathrm{Ru}(\mathrm{H})(\mathrm{CO})\right]^{+}$ is a diamagnetic complex, with a sawhorse structure, and without $\mathrm{C}-\mathrm{H}$ agostic interactions.

Additional support for the congruity between experiment and theory for complex $\mathbf{4}$ is the calculated $v_{\mathrm{CO}}$ for the singlet sawhorse structure, which is $1936 \mathrm{~cm}^{-1}$ after scaling for anharmonicity (compared with the experimental value of 1933 $\mathrm{cm}^{-1}$ ). The calculated $\mathrm{CO}$ absorption energies for the square planar geometry (with and without agostic interactions) are between 1982 and $1994 \mathrm{~cm}^{-1}$. Furthermore, the room temperature ${ }^{1} \mathrm{H}$ NMR spectrum of $\mathbf{4}$ is consistent with the sawhorse geometry in which there is rapid rotation (relative to the NMR time scale) around the $\mathrm{Ru}-\mathrm{C}_{\mathrm{NHC}}$ bonds to render the four mesityl rings time average equivalent as well as all four $=\mathrm{CH}$ moieties of the NHC ligands. The three methyl groups on each mesityl ring remain inequivalent, presumably due to hindered $\mathrm{N}-\mathrm{C}$ bond rotation.

Previous reports of four-coordinate $\mathrm{Ru}(\mathrm{II})$ complexes fall into two categories: (1) square planar and paramagnetic stabilized by a $\pi$-donor ligand and (2) diamagnetic sawhorse structure with two $\mathrm{C}-\mathrm{H}$ agostic interactions to complete an octahedral coordination sphere. These prior results suggest that the presence of a strongly $\pi$-donating ligand can drive the preferred geometry from octahedral (or sawhorse if the $\mathrm{C}-\mathrm{H}$ agostic interactions are discounted) to square planar, which results in a triplet ground state. In their report on (PNP)RuCl, Caulton et al. made the acute observation, "The present structure shows that agostic interactions are not inevitable in a 14-electron species, but that a triplet state, with half-filling of two orbitals, is another way to make the best outcome of an otherwise electron-deficient (14electron) situation." ${ }^{, 73}$ The combined experimental and computational studies of $\left[(\mathrm{IMes})_{2} \mathrm{Ru}(\mathrm{H})(\mathrm{CO})\right]^{+}$(4) suggest that a diamagnetic 14-electron species is also accessible in the absence of agostic interactions, a result that was previously suggested by Caulton et al. based on computational studies on the structure of the model complex $\left[\mathrm{Ru}(\mathrm{Ph})(\mathrm{CO})\left(\mathrm{PH}_{3}\right)_{2}\right]^{+}{ }^{82}$ Thus, it is possible that the presence/absence of $\pi$-active (donor or acceptor) ligands dictates the ground-state geometry and that the presence/absence of agostic interactions plays a minor role. But, the calculations also suggest that (IMes) ${ }_{2} \mathrm{Ru}(\mathrm{H})\left(\mathrm{NH}_{2}\right)$ will adopt a diamagnetic sawhorse ground state, which indicates that the square planar paramagnetic $\mathrm{Ru}(\mathrm{II})$ complexes may result from a constrained ligand geometry rather than the presence of a $\pi$-donor ligand. However, experimental results to corroborate the calculations are not yet available for (IMes) ${ }_{2} \mathrm{Ru}(\mathrm{H})\left(\mathrm{NH}_{2}\right)$.

Computational Studies for $\left[(\mathrm{IMes})_{2} \mathrm{Ru}(\mathrm{H})(\mathrm{CO})\left(\mathrm{N}_{2}\right)\right]-$ $\left[\mathrm{BAr}_{4}{ }_{4}\right.$ ] (4-N $\left.\mathbf{N}_{2}\right)$. DFT calculations were also performed to evaluate the formation of the dinitrogen complex $\mathbf{4 - \mathbf { N } _ { 2 }}$. The coordination of $\mathrm{N}_{2}$ to $\mathbf{4}$ leads to two isomers of $\mathbf{4}-\mathbf{N}_{\mathbf{2}}$. As shown in Scheme 4, one isomer positions $\mathrm{N}_{2}$ trans to the hydride ligand (4- $\mathbf{N}_{2}-1$ ), while the second isomer has $\mathrm{N}_{2}$ trans to the carbonyl (4- $\left.\mathbf{N}_{2}-2\right)$. 4- $\mathbf{N}_{2}-2$ is calculated to be more stable than $4-\mathbf{N}_{2}-\mathbf{1}$ by

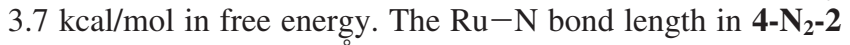
is calculated to be $2.089 \AA$, which is markedly shorter than that in 4- $\mathbf{N}_{2}-\mathbf{1}(2.185 \AA)$. The calculated thermodynamic data indicate a temperature dependent and reversible equilibrium between 4 , 4-N $\mathbf{N}_{2}-\mathbf{1}$ and $\mathbf{4 - N _ { 2 } - 2}$. At $273.15 \mathrm{~K}$, the coordination of $\mathrm{N}_{2}$ to 4 to form $\mathbf{4 - N _ { 2 } - 2}$ is calculated to be exergonic by $2.8 \mathrm{kcal} / \mathrm{mol}$;

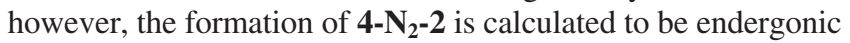
by $0.2 \mathrm{kcal} / \mathrm{mol}$ at $298.15 \mathrm{~K}$. These calculations are consistent with experimental observations in which the formation of $\mathbf{4 - \mathbf { N } _ { \mathbf { 2 } }}$ is only observed at low temperature (at atmospheric pressure of $\mathrm{N}_{2}$ ). Additionally, the more stable $4-\mathbf{N}_{2}-2$ isomer is calculated to be close in energy to the isomer $\mathbf{4 - N _ { 2 } - 1}$. Therefore, it is not surprising that X-ray data for $\mathbf{4}-\mathbf{N}_{\mathbf{2}}$ are complicated by disorder.

H/D Exchange of Hydride with $\mathrm{D}_{2}$ : (IMes) $)_{2} \mathrm{Ru}(\mathrm{Cl})-$ $(\mathrm{H})(\mathrm{CO})$ (1) Versus [(IMes) $\left.)_{2} \mathrm{Ru}(\mathrm{H})(\mathrm{CO})\right]\left[\mathrm{BAr}_{4}{ }_{4}\right]$ (4). Following the reaction of (IMes) $)_{2} \mathrm{Ru}(\mathrm{Cl})(\mathrm{H})(\mathrm{CO})(\mathbf{1})$ with $\mathrm{D}_{2}(30 \mathrm{psi})$ at room temperature by ${ }^{1} \mathrm{H}$ NMR spectroscopy reveals the production of $(\mathrm{IMes})_{2} \mathrm{Ru}(\mathrm{Cl})(\mathrm{D})(\mathrm{CO})\left(\mathbf{1}-\mathbf{d}_{\mathbf{1}}\right)$ and free $\mathrm{HD}(1$ : $1: 1$ triplet, ${ }^{1} J_{\mathrm{HD}}=43 \mathrm{~Hz}, 4.42 \mathrm{ppm}$ ) (Scheme 5), which compares well to free $\mathrm{HD}\left({ }^{1} J_{\mathrm{HD}}=43 \mathrm{~Hz}\right) \cdot{ }^{3,83}$ At later reaction times, the production of free $\mathrm{H}_{2}$ (singlet, $4.42 \mathrm{ppm}$ ) is also observed, which likely results from the reaction of HD with $\mathbf{1}$ to produce 1-d $\mathbf{d}_{\mathbf{1}}$ and $\mathrm{H}_{2}$. Consistent with the incorporation of deuterium into the hydride position of $\mathbf{1}$ to produce $\mathbf{1 - d _ { 1 }}$, the reaction of 1 with $D_{2}$ results in the disappearance of the resonance at $-25.4 \mathrm{ppm}$ in the ${ }^{1} \mathrm{H}$ NMR spectrum. Furthermore, the H/D exchange of the Ru-hydride has been confirmed with a ${ }^{2} \mathrm{H}$ NMR spectrum of $\mathbf{1}-\mathbf{d}_{\mathbf{1}}$, which shows a singlet at approximately $-25 \mathrm{ppm}$ (Figure 9). Consistent with the ${ }^{1} \mathrm{H}$ NMR spectrum from the reaction of 1 with $\mathrm{D}_{2}$, the ${ }^{2} \mathrm{H}$ NMR of $\mathbf{1 - d _ { 1 }}$ does not display deuterium incorporation at other ligand positions.

Reaction of the formally 14-electron cation [(IMes) $)_{2}$ $\mathrm{Ru}(\mathrm{H})(\mathrm{CO})]\left[\mathrm{BAr}_{4}^{\prime}\right]$ (4) with $\mathrm{D}_{2}(30 \mathrm{psi})$ at room temperature produces the isotopomer [(IMes) $\left.)_{2} \mathrm{Ru}(\mathrm{D})(\mathrm{CO})\right]\left[\mathrm{BAr}_{4}{ }_{4}\right]\left(\mathbf{4}-\mathbf{d}_{\mathbf{1}}\right)$ by ${ }^{1} \mathrm{H}$ NMR spectroscopy (Scheme 5). Neither free $\mathrm{HD}$ nor $\mathrm{H}_{2}$ is observed in the ${ }^{1} \mathrm{H}$ NMR at room temperature (see below), but consistent with the H/D exchange the resonance at $-26.4 \mathrm{ppm}$ disappears. In contrast to 1 , in addition to $H / D$ exchange at the hydride ligand, the reaction of $\mathbf{4}$ with $\mathrm{D}_{2}$ incorporates deuterium into the ortho methyl groups of the IMes ligands as observed by ${ }^{1} \mathrm{H}$ and ${ }^{2} \mathrm{H}$ NMR spectroscopy. This result suggests that an

(82) Huang, D.; Streib, W. E.; Eisenstein, O.; Caulton, K. G. Angew. Chem., Int. Ed. 1997, 36, 2004-2006.

(83) Maltby, P. A.; Schlaf, M.; Steinbeck, M.; Lough, A. J.; Morris, R. H.; Klooster, W. T.; Koetzle, T. F.; Srinivas, R. C. J. Am. Chem. Soc. 1996, 118, 5396-5407. 
Scheme 4. Coordination of $\mathrm{N}_{2}$ to Singlet Sawhorse $\left[(\mathrm{IMes})_{2} \mathrm{Ru}(\mathrm{H})(\mathrm{CO})\right]^{+}(4)^{a}$

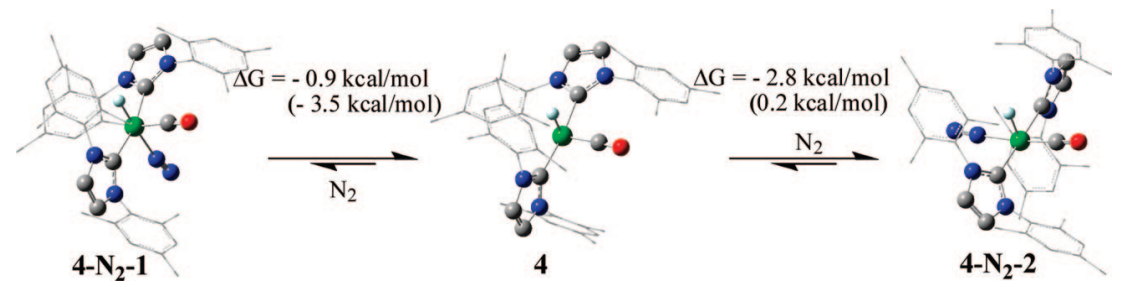

${ }^{a}$ Hydrogen atoms are omitted and the aryl groups of IMes ligands are shown in wire frame for clarity. Free energies are obtained using unscaled vibrational frequencies in the gas phase at $1 \mathrm{~atm}$ and $213.15 \mathrm{~K}$; data in parentheses are obtained at $298.15 \mathrm{~K}$.

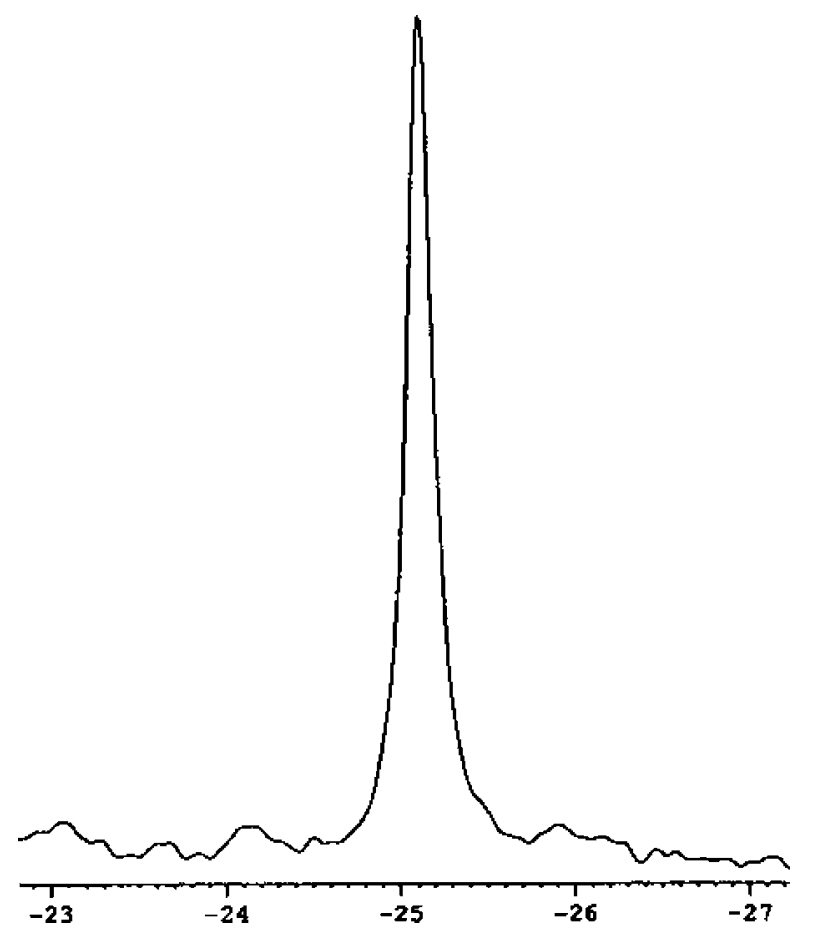

Figure 9. ${ }^{2} \mathrm{H} \mathrm{NMR}$ of $(\mathrm{IMes})_{2} \mathrm{Ru}(\mathrm{Cl})(\mathrm{D})(\mathrm{CO})\left(\mathbf{1}-\mathbf{d}_{\mathbf{1}}\right)$ showing $\mathrm{Ru}-\mathrm{D}$ resonance at approximately $-25 \mathrm{ppm}$.

Scheme 5. Hydride/Deuteride Ligand Exchange for Complexes 1 and 4 upon Reaction with $D_{2}$

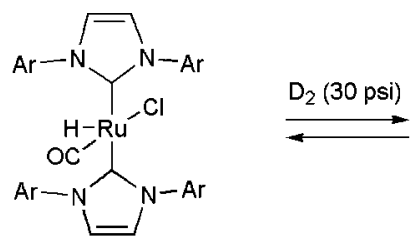

(1)
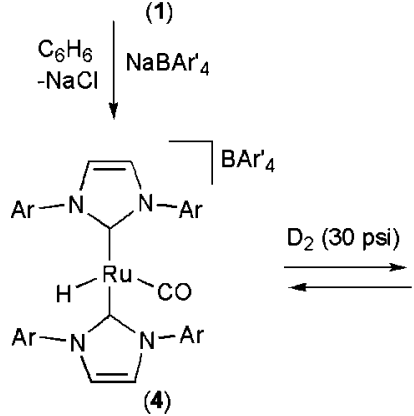

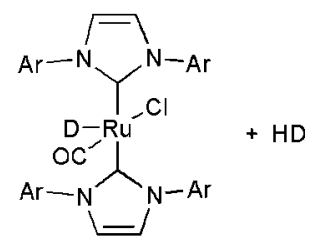

$\left(1-d_{1}\right)$

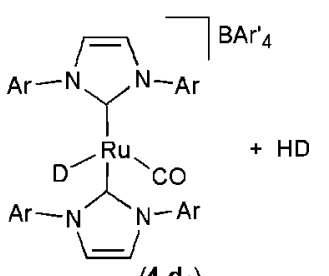

$\left(4-d_{1}\right)$ agostic-like species is energetically accessible, even though the calculations suggest that it may not be a stable minimum. After $3 \mathrm{~h}$ at room temperature at $30 \mathrm{psi} \mathrm{D}_{2}, 20 \% \mathrm{H} / \mathrm{D}$ exchange (by integration of ${ }^{1} \mathrm{H}$ NMR spectra) is observed at the IMes methyl groups. Prolonged reaction with $\mathrm{D}_{2}$ results in the production of multiple uncharacterized (IMes)Ru products, and a decrease in intensity of resonances due to complex 4.

Careful monitoring of the reaction of $\mathbf{4}$ with $\mathrm{D}_{2}$ (30 psi) reveals production of the isotopomer $\mathbf{4}-\mathbf{d}_{\mathbf{1}},\left[(\mathrm{IMes})_{2} \mathrm{Ru}(\mathrm{D})(\mathrm{CO})\right]^{+}$ after $5 \mathrm{~min}$ with negligible deuterium incorporation into the ortho methyl groups. The system was then frozen and degassed to remove all $\mathrm{D}_{2}$ and placed under $\mathrm{N}_{2}(1 \mathrm{~atm})$. After $15 \mathrm{~min}$ at room temperature, the hydride resonance $(-26.4 \mathrm{ppm})$ returns by ${ }^{1} \mathrm{H}$ NMR spectroscopy (Scheme 6). These results suggest that $H / D$ exchange into the ortho methyl groups of the IMes ligands upon reaction of $\mathbf{4}$ and $\mathrm{D}_{2}$ likely occurs by initial H/D exchange at the $\mathrm{Ru}-\mathrm{H}$ position followed by $\mathrm{H} / \mathrm{D}$ exchange between the methyl groups and Ru-D (Scheme 6), which may occur via metalation of a methyl group of the mesityl ring. Deuterium should be incorporated into the ortho methyl groups of the IMes ligands; however, the anticipated multiplet by ${ }^{1} \mathrm{H}$ NMR spectroscopy of a $\mathrm{CH}_{2} \mathrm{D}$ group is not observed. This is likely due to the H/D exchange occurring with all eight ortho methyl groups of the IMes ligands (two resonances by ${ }^{1} \mathrm{H}$ NMR spectroscopy), which result in only $2.5 \% \mathrm{D}$ at each methyl ligand (20\% total deuterium incorporation evenly spread over 8 methyl groups). The rate of H/D exchange into the ortho methyl groups of the IMes ligands of $\mathbf{4}$ was determined at 40 ${ }^{\circ} \mathrm{C}\left(30 \mathrm{psi} \mathrm{D}_{2}\right)$ to be approximately $1.4 \times 10^{-4} \mathrm{~s}^{-1}$ (Supporting Information). A short induction period (approximately $10 \mathrm{~min}$ ) was observed prior to significant change at the ortho position of the IMes ligands, which is likely due to H/D exchange at the $\mathrm{Ru}-\mathrm{H}$ position prior to incorporation into the methyl groups. We were unable to measure the rate accurately over three halflives due to a competitive decomposition pathway at prolonged reaction times. This decomposition precluded attempts to measure the rate of $\mathrm{H} / \mathrm{D}$ exchange back to perprotio[(IMes) $\left.)_{2} \mathrm{Ru}(\mathrm{H})(\mathrm{CO})\right]\left[\mathrm{BAr}_{4}^{\prime}\right](4)$ when the solution was degassed and pressurized with $\mathrm{H}_{2}(30 \mathrm{psi})$. Intramolecular $\mathrm{C}-\mathrm{H}, \mathrm{C}-\mathrm{N}$ and $\mathrm{C}-\mathrm{C}$ bond activations of $\mathrm{Ru}^{\mathrm{II}}$ bound IMes (and other NHCs) ligands have been reported: $\mathrm{C}-\mathrm{C}$ and $\mathrm{C}-\mathrm{N}$ bond activations were found to be stoichiometric and lead to new cyclometalated IMes ligands $(\mathrm{C}-\mathrm{C} \text { activation })^{47}$ or new $N$-coordinated $\mathrm{NHC}$ ligands $\left(\mathrm{C}-\mathrm{N}\right.$ activation) ${ }^{48}$ The intramolecular $\mathrm{C}-\mathrm{H}$ bond activation of IMes produces an IMes cyclometalated $\mathrm{Ru}^{\mathrm{II}}$ complex ${ }^{47}$ and other NHCs that show intramolecular $\mathrm{C}-\mathrm{H}$ activation have been successfully incorporated into catalytic $\mathrm{C}-\mathrm{C}$ bond formation reactions. ${ }^{45,46}$

Variable-temperature ${ }^{1} \mathrm{H}$ NMR was used to further explore the lack of observation of free $\mathrm{H}_{2} / \mathrm{HD}$ upon reaction of $\mathbf{4}$ with $\mathrm{D}_{2}$ at room temperature (see above). A toluene- $d_{8}$ solution of $\mathbf{4}$ in a J-Young NMR tube was pressurized with $\mathrm{D}_{2}$ (30 psi), and placed in the NMR probe. At room temperature the spectrum showed resonances consistent with complex 4-d $\mathbf{d}_{\mathbf{1}}$. Cooling the probe from 20 to $-60^{\circ} \mathrm{C}$ did not result in any observable change in the spectrum (i.e., no observation of free $\mathrm{H}_{2}$ or $\mathrm{HD}$ ). The probe was then warmed from 20 to $80^{\circ} \mathrm{C}$, which did not show 
Scheme 6. Reversible H/D Scrambling into the Ortho IMes Methyl Groups of 4

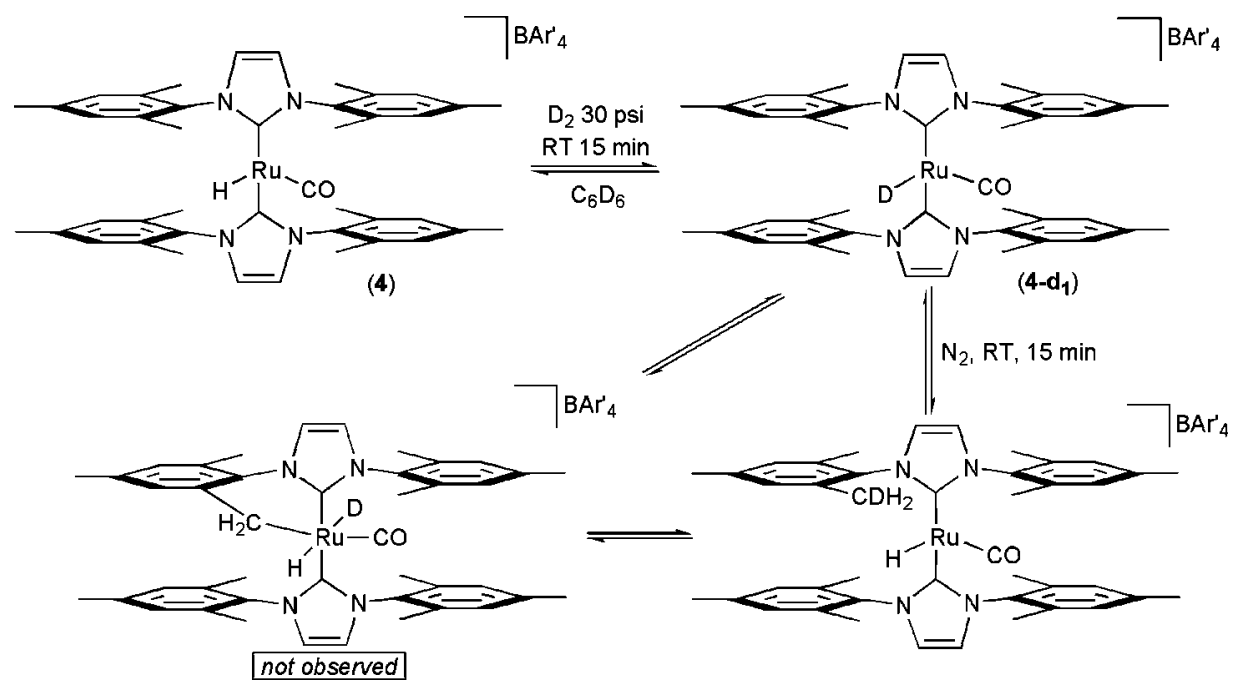

any observable change in the spectrum; however, the extent of $\mathrm{H} / \mathrm{D}$ exchange at the IMes ortho methyl positions was found to increase (as expected) as the temperature was increased.

In a separate experiment, a J-Young NMR tube containing a toluene- $d_{8}$ solution of 4 was pressurized with $\mathrm{D}_{2}$ (30 psi) for $20 \mathrm{~min}$. After the reaction time, complete H/D exchange at the $\mathrm{Ru}-\mathrm{H}$ position was observed by ${ }^{1} \mathrm{H}$ NMR spectroscopy, and the solution was degassed by freeze-pump-thaw cycles and backfilled with $\mathrm{H}_{2}$ (30 psi). At room temperature the spectrum showed resonances consistent with complex $\mathbf{4}-\mathbf{d}_{\mathbf{1}}$, and a broad resonance at $0.62 \mathrm{ppm}$. Cooling the probe from 20 to $-60{ }^{\circ} \mathrm{C}$ resulted in the observation of the resonance at $0.62 \mathrm{ppm}$ broadening into the baseline. The probe was then warmed from 20 to $80^{\circ} \mathrm{C}$ resulted in the observation of the resonance at 0.62 $\mathrm{ppm}$ increasing in intensity. These data suggest that the resonance at $0.62 \mathrm{ppm}$ is a time average of free $\mathrm{H}_{2}$ and the $\mathrm{Ru}-\mathrm{H}$ resonances undergoing rapid exchange on the ${ }^{1} \mathrm{H}$ NMR time scale. Indeed, pressurizing a J-Young NMR tube with $\mathrm{H}_{2}$ (30 psi) containing a toluene- $d_{8}$ solution of $\mathbf{4}$ resulted in the same observations as $\mathbf{4}-\mathbf{d}_{\mathbf{1}}$ under $\mathrm{H}_{2}$ pressure. Thus, we suggest a time average resonance at $0.62 \mathrm{ppm}$ for free $\mathrm{H}_{2}$ and the $\mathrm{Ru}-\mathrm{H}$ where we were unable to reach the decoalescence point at low temperatures and at room and elevated temperatures the rate of exchange is fast, which is consistent with the lack of observation of free HD for reaction of $\mathbf{4}$ with $\mathrm{D}_{2}$.

We were interested in determining the extent to which removal of chloride from 1 impacts the rate of hydride/deuteride ligand exchange. The reaction of $\mathbf{1}$ with $\mathrm{D}_{2}(30 \mathrm{psi})$ at room temperature was followed by ${ }^{1} \mathrm{H}$ NMR spectroscopy over the course of three hours, at which time conversion to $\mathbf{1 - d _ { \mathbf { 1 } }}$ is complete. A plot of $\ln [\mathbf{1}]$ versus time gives a linear fit, and the average $k_{\mathrm{obs}}$ from multiple reactions is $1.70(2) \times 10^{-4} \mathrm{~s}^{-1}$. The reaction of 4 with $D_{2}(30 \mathrm{psi})$ at room temperature results in complete conversion to $\mathbf{4}-\mathbf{d}_{\mathbf{1}}$ in less than 5 min as determined by ${ }^{1} \mathrm{H}$ NMR spectroscopy. Thus, at room temperature the halflife for the conversion of $\mathbf{4} / \mathrm{D}_{2}$ to $\mathbf{4 - \mathbf { d } _ { \mathbf { 1 } }}$ is less than $150 \mathrm{~s}$ compared to approximately $70 \mathrm{~min}$ for the conversion of $1 / \mathrm{D}_{2}$

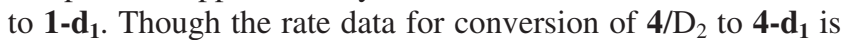
not quantitative, the reaction is at least 28 times faster than production of $\mathbf{1 - d _ { 1 }}$ from $\mathbf{1} / \mathrm{D}_{2}$.

For H/D exchange with complex 1, we also probed the impact of $\mathrm{D}_{2}$ pressure on the reaction rate. Increasing the $\mathrm{D}_{2}$ pressure was found to not have an impact on the rate of H/D exchange at the hydride position for complex 1. This suggests that the rate-determining step may involve IMes ligand dissociation. A mechanism for the H/D exchange between $\mathbf{4} / \mathrm{D}_{2}$ to $\mathbf{4 - d _ { 1 }}$ is shown in Scheme 7, and a similar mechanism can be proposed for conversion of $\mathbf{1} / \mathrm{D}_{2}$ to $\mathbf{1 - d _ { 1 }}$ with the addition of IMes ligand dissociation prior to $\mathrm{D}_{2}$ coordination and D-D cleavage. Attempts to measure the rate of $H / D$ exchange of 1 with $D_{2}$ (30 psi) and added free IMes were thwarted due to decomposition of the reaction solution to uncharacterized species. However, though only qualitative, the large enhancement of rate of H/D exchange upon removal of a $\mathrm{Cl}^{-}$anion is consistent with a dissociative pathway.

Catalytic Hydrogenation. Since the hydride complexes $\mathbf{1}$ and 4 were found to activate $D_{2}$, we attempted catalytic hydrogenation reactions. Both $\mathbf{1}$ and $\mathbf{4}$ are active for the addition of $\mathrm{H}-\mathrm{H}$ bonds across $\mathrm{C}=\mathrm{C}$ and $\mathrm{C}=\mathrm{O}$ bonds. As depicted in Table 2, the olefin substrate scope ranges from terminal to internal olefins including mono- and disubstituted olefins. Hydrogenation was also extended to $\mathrm{C}=\mathrm{O}$ bonds of acetone and benzaldehyde (Table 3). All hydrogenation reactions were monitored by ${ }^{1} \mathrm{H}$ NMR spectroscopy, and only complex $\mathbf{1}$ or $\mathbf{4}$ was observed during the course of the reaction, which suggests that the monohydride systems are the catalyst resting states.

Using complex $\mathbf{4}$ as catalyst, the rates of hydrogenation for hexenes follow the trend: trans-3-hexene $>$ trans-2-hexene $>1$ hexene (entries 2-4, Table 2). In fact, monitoring the hydrogenation of 1-hexene by ${ }^{1} \mathrm{H}$ NMR spectroscopy reveals initial and complete isomerization to trans-2-hexene prior to hydrogenation (Scheme 8). Due to overlapping resonances, it cannot be stated with certainty whether trans-2-hexene is further isomerized to trans-3-hexene prior to hydrogenation, although this seems likely given the rapid rate of isomerization compared with rate of hydrogenation. The present results are in agreement with other monohydride $\mathrm{Ru}$ systems that isomerize olefins. ${ }^{37}$ Attempts at the hydrogenation of benzene with $\mathbf{4}$ resulted in no reaction $\left(60^{\circ} \mathrm{C}, 30 \mathrm{psi} \mathrm{H}_{2}\right)$ or decomposition of $4\left(120^{\circ} \mathrm{C}, 60\right.$ psi $\mathrm{H}_{2}$ ). The hydrogenation of the disubstituted olefin 1,4cyclohexadiene occurs at approximately the same rate as the monosubstituted olefin cyclohexene (entries 6 and 7, Table 2). During the course of 1,4-cyclohexadiene hydrogenation, cyclohexene is observed as a short-lived intermediate. The hydrogenation of styrene using $\mathrm{D}_{2}$ in place of $\mathrm{H}_{2}$ results in the incorporation of deuterium into the ethyl group of ethylbenzene (eq 8). The ${ }^{1} \mathrm{H}$ NMR spectrum of the reaction product of styrene with $\mathrm{D}_{2}$ shows broad multiplets at 2.43 and $1.06 \mathrm{ppm}$ for the methylene and methyl groups of ethylbenzene, respectively. 
Scheme 7. Possible Pathways for the Reaction of 4 with $D_{2}$ to Produce 4-d

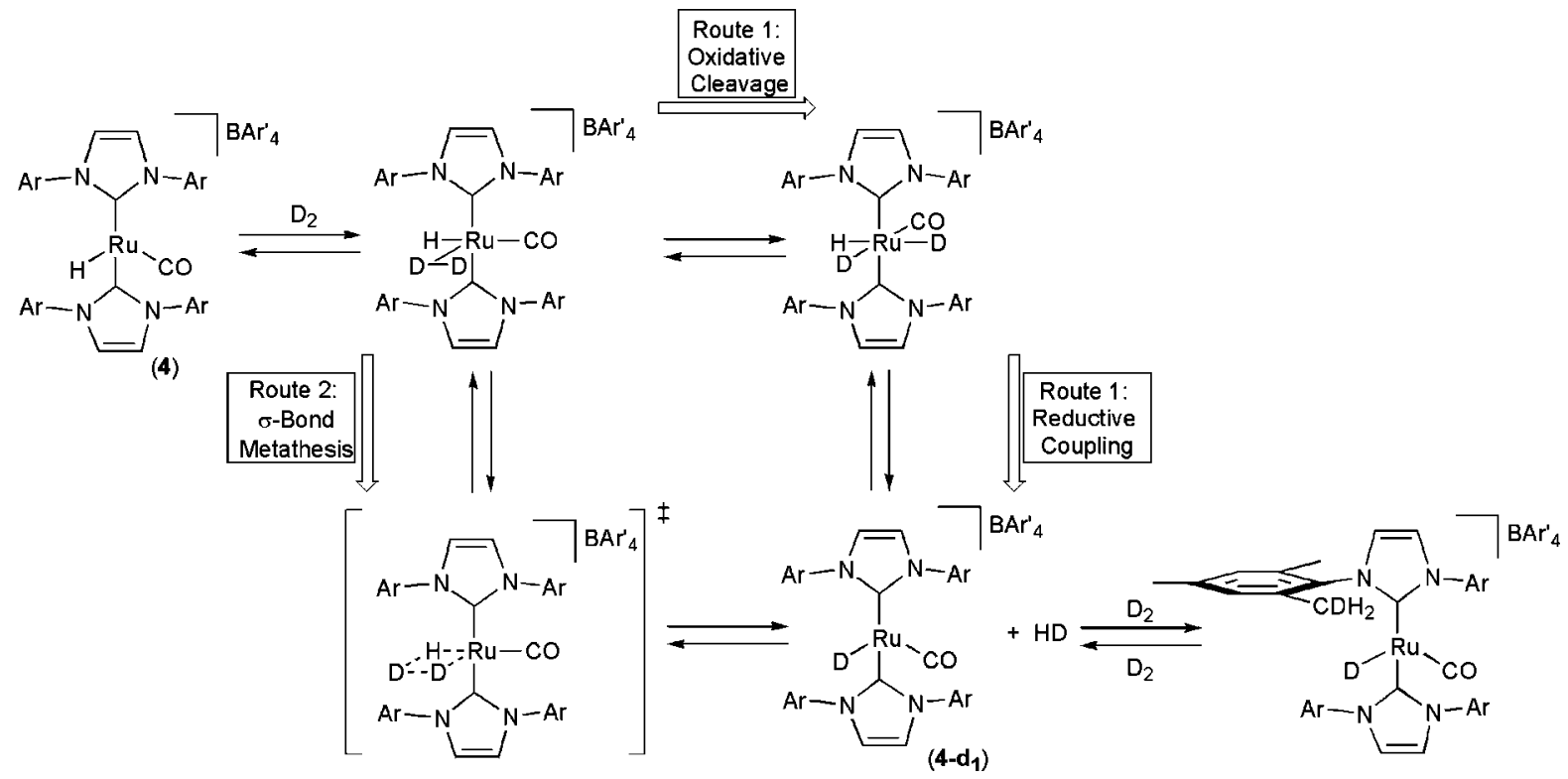

Table 2. Ru-Catalyzed Hydrogenation of Olefins (Unless Noted Otherwise, Reactions Performed in $\mathrm{C}_{6} \mathrm{D}_{6}$, at $60{ }^{\circ} \mathrm{C}, 30 \mathrm{psi} \mathrm{H}_{2}$ and $5 \mathrm{~mol} \%$ of Catalyst Relative to Olefin Concentration)

\begin{tabular}{|c|c|c|c|c|c|c|}
\hline entry & substrate & $\begin{array}{l}\text { catalyst } \\
\text { (5 mol \%) }\end{array}$ & Time (hrs) & $\%$ conversion ${ }^{a}$ & TOF $^{b}$ & product \\
\hline 1 & & 1 & 27 & 100 & 2.1 & \\
\hline 2 & & 4 & 6 & 100 & 9.3 & \\
\hline 3 & & 4 & 4 & 100 & 13.9 & \\
\hline 4 & & 4 & 2 & 100 & 27.8 & \\
\hline 5 & & 4 & 13 & $100^{c}$ & 4.3 & \\
\hline 6 & & 4 & 18 & 100 & 3.1 & \\
\hline 7 & & 4 & 19 & $100^{\mathrm{d}}$ & 2.9 & \\
\hline $8^{e}$ & & 4 & 18 & 0 & - & none \\
\hline
\end{tabular}

${ }^{a}$ Percent conversations were determined by ${ }^{1} \mathrm{H}$ NMR spectroscopy. ${ }^{b} \mathrm{TON} / \mathrm{sec}\left(10^{-4}\right)$. ${ }^{c}$ No observation of aromatic hydrogenation. ${ }^{d}$ Percent conversation to cyclohexane. ${ }^{e}$ Sixty psi $\mathrm{H}_{2} 100{ }^{\circ} \mathrm{C}$.

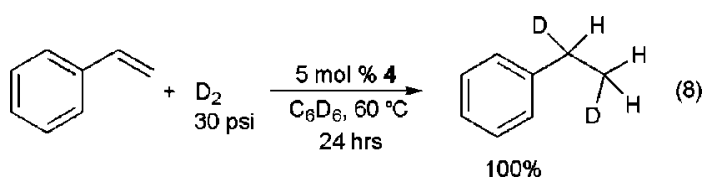

The cationic and coordinatively unsaturated complex $\mathbf{4}$ is a more active catalyst for hydrogenation than complex 1. For example, under the same conditions, the hydrogenation of 1-hexene is complete in only $6 \mathrm{~h}$ using 4 and after $27 \mathrm{~h}$ with complex 1 as catalyst (entries 1 and 2, Table 2). Both 1 and 4 are significantly less active for the hydrogenation of 1-hexene compared to the previously reported $\left(\mathrm{PCy}_{3}\right)_{2} \mathrm{Ru}(\mathrm{Cl})(\mathrm{H})(\mathrm{CO})^{37}$ and $(\mathrm{IMes})(\mathrm{PCy}) \mathrm{Ru}(\mathrm{Cl})(\mathrm{H})(\mathrm{CO})^{38}$ systems. The catalytic hydrogenation of 1-hexene using $\left(\mathrm{PCy}_{3}\right)_{2} \mathrm{Ru}(\mathrm{Cl})(\mathrm{H})(\mathrm{CO})$ has a TOF of $12000 \mathrm{~h}^{-1}$ at room temperature and 1 atm $\mathrm{H}_{2}$, and for
(IMes) $\left(\mathrm{PCy}_{3}\right) \mathrm{Ru}(\mathrm{Cl})(\mathrm{H})(\mathrm{CO})$ the $\mathrm{TOF}$ is $3000 \mathrm{~h}^{-1}$ at room temperature and $4 \mathrm{~atm} \mathrm{H}_{2} \cdot{ }^{37,38}$ Complex $\mathbf{1}$ and $\mathbf{4}$ were found to hydrogenate 1-hexene with a TOF of 0.8 and $3.3 \mathrm{~h}^{-1}$, respectively $\left(60{ }^{\circ} \mathrm{C}\right.$ and $\left.2 \mathrm{~atm} \mathrm{H}_{2}\right)$. At room temperature, $5 \mathrm{~mol} \% 4$ was found to hydrogenate/isomerize 1-hexene completely (by $\left.{ }^{1} \mathrm{H} \mathrm{NMR}\right)$ to a mixture of trans-2-hexene (10\%) and hexane $(90 \%)$, at which time significant catalyst decomposition had occurred. The substantially decreased activity of the bis-IMes complex 4 compared to the mixed IMes/phosphine, and to an even greater extent the bis-phosphine complex, is most likely a combination of steric factors and the strong binding nature of IMes ligands, which prohibits ligand dissociation and may thus inhibit olefin coordination. Over the course of catalytic hydrogenation reactions using $\mathbf{4}$, there is no evidence of olefin coordination to the 4-coordinate 14-electron $\mathrm{Ru}$ (II) cation, which further supports the steric argument. 
Table 3. Ru-Catalyzed Hydrogenation of Carbonyl Groups (All Reactions Performed in $\mathrm{C}_{6} \mathrm{D}_{6}$, at $60{ }^{\circ} \mathrm{C}, 30$ psi $\mathrm{H}_{2}$ and 5 mol \% of Catalyst Relative to Carbonyl Concentration)

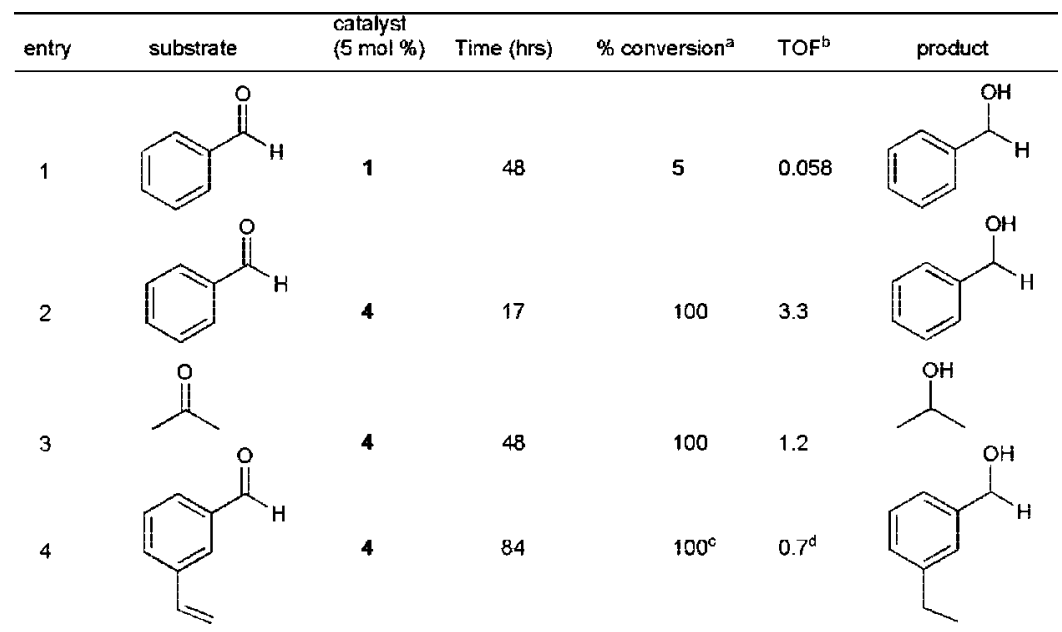

${ }^{a}$ Percent conversations were determined by ${ }^{1} \mathrm{H}$ NMR spectroscopy. ${ }^{b} \mathrm{TON} / \mathrm{sec}\left(10^{-4}\right) .{ }^{c}$ Percent conversation to 3 -ethyl-benzylacohol. ${ }^{d}$ TOF for 2 equiv of $\mathrm{H}_{2}$.

As noted above, 4 isomerizes 1-hexene to trans-2-hexene prior to hydrogenation. Thus, we studied the reaction of $\mathbf{4}$ with trans-2-hexene in the absence of $\mathrm{H}_{2}$ (eq 9). After $20 \mathrm{~h}, 27 \%$ conversion of trans-2-hexene to trans-3-hexene is observed with $5 \mathrm{~mol} \% 4$ at $60{ }^{\circ} \mathrm{C}$, longer times resulted in no further changes by ${ }^{1} \mathrm{H}$ NMR spectroscopy. Recently, Grotjahn et al. have reported the remarkable isomerization of dotriacont-31-en-ol to dotriacontan-2-one catalyzed by a cationic $\mathrm{Ru}(\mathrm{II})$ complex, which moves the $\mathrm{C}=\mathrm{C}$ double bond $30 \mathrm{C}-\mathrm{C}$ linkages. ${ }^{84}$ The reaction of 9-decen-1-ol with $5 \mathrm{~mol} \% \mathbf{4}$ at $70{ }^{\circ} \mathrm{C}$ results in the complete isomerization to an internal olefin, likely 8-decen-1ol, after $2 \mathrm{~h}$ (Scheme 9). Prolonged reaction time (24 h) results in no further changes. In contrast, the $\mathrm{Ru}(\mathrm{II})$ catalyst $\mathbf{4}$, the Grotjahn system, $\left[\mathrm{CpRu}\left\{\kappa^{2}-P, N-\mathrm{P}\left({ }^{i} \mathrm{Pr}\right)_{2}\left(\mathrm{C}_{8} \mathrm{H}_{13} \mathrm{~N}_{2}\right)\right\}(\mathrm{NCMe})\right]-$ $\left[\mathrm{PF}_{6}\right](5 \mathrm{~mol} \%)$, was found to catalyze the conversion of 9-decen-1-ol $\left(70{ }^{\circ} \mathrm{C}\right)$ to decanal in $84 \%$ yield after 4 h. ${ }^{84}$

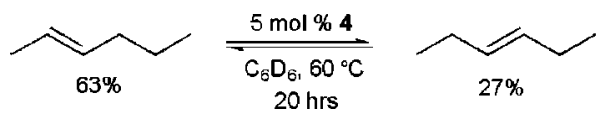

A possible mechanism for the hydrogenation (and isomerization of olefins) is shown in Scheme 10. Assuming that complex $\mathbf{4}$ is 4 -coordinate $\mathrm{Ru}(\mathrm{II})$ with a 14 -valence electron count, olefin association is likely the initial step. If $\mathrm{N}_{2}$ is coordinated to $\mathbf{4}$, it is likely very labile (at room temperature, see above). Olefin insertion would give a 5-coordinate 16 electron complex that could be followed by insertion of the olefin into the $\mathrm{Ru}-\mathrm{H}$ bond. After insertion, $\beta$-hydride elimination/reinsertion/ $\beta$-hydride elimination sequences followed by olefin dissociation provides a pathway for olefin isomerization. At this time, we do not have data that would allow for us to discern between $\mathrm{H}_{2}$ oxidative addition and $\sigma$-bond metathesis.

The reduction of aldehydes and ketones using $\mathrm{H}_{2}$ in place of $\mathrm{NaBH}_{4}$ or $\mathrm{LiAlH}_{4}$ (stoichiometric reducing agents) is a widely employed reaction for both commodity and fine chemical synthesis due to the atom economical nature of the reaction, and the ability to produce enantiomerically pure alcohols from prochiral ketones. ${ }^{85} \mathrm{Ru}(\mathrm{II})$ complexes have been shown to possess exceptional reactivity for the addition of $\mathrm{H}_{2}$ across $\mathrm{C}=\mathrm{O}$

(84) Grotjahn, D. B.; Larsen, C. R.; Gustafson, J. L.; Nair, R.; Sharma, A. J. Am. Chem. Soc. 2007, 129, 9592-9593.

(85) Noyori, R. Angew. Chem., Int. Ed. 2002, 41, 2008-2022.
Scheme 8. Isomerization and Subsequent Hydrogenation of 1-Hexene Mediated by 4

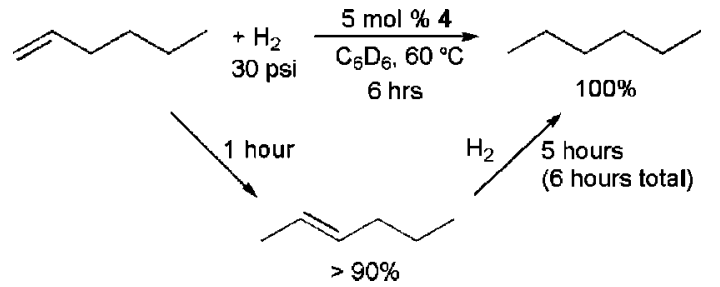

Scheme 9. Isomerization of 9-Decen-1-ol Catalyzed by Complex 4 Compared to the $\left[\mathrm{CpRu}\left\{\kappa^{2}-P, N-\mathrm{P}\left({ }^{i} \mathrm{Pr}\right)_{2^{-}}\right.\right.$ $\left.\left.\left(\mathrm{C}_{8} \mathrm{H}_{13} \mathrm{~N}_{2}\right)\right\}(\mathrm{NCMe})\right]\left[\mathrm{PF}_{6}\right]$ Catalyzed Isomerization

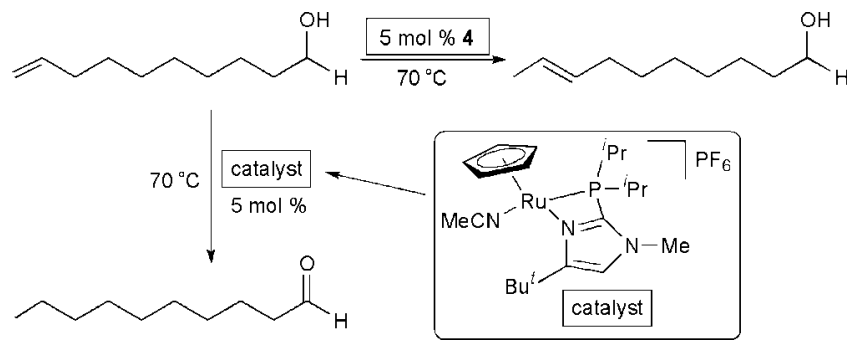

bonds. ${ }^{85-87}$ Extension of hydrogenation to carbonyl groups by 1 and $\mathbf{4}$ was explored (Table 3). Complex $\mathbf{4}$ is less active for the hydrogenation of carbonyl groups than for olefins, and complex 1 essentially shows little reactivity for carbonyl hydrogenation (entry 1 , Table 3 ). Whittlesey et al. have reported that complex 1 catalyzes the hydrogenation of the $\mathrm{C}=\mathrm{O}$ group of para-substituted acetophenones. Similar to our observations with benzaldehyde, they report less than quantitative conversions under forcing conditions $\left(75^{\circ} \mathrm{C}, 150 \mathrm{psi} \mathrm{H}_{2}, 10 \mathrm{~h}\right) .{ }^{61}$

The hydrogenation of benzaldehyde by $\mathbf{4}$ to benzyl alcohol occurs at a slightly slower rate (entry 2, Table 3) than the hydrogenation of styrene (entry 5, Table 2). The hydrogenation of acetone by $\mathbf{4}$ was found to be slowest of all substrates studied (entry 3 , Table 3 ). To explore the selectivity of hydrogenation of $\mathrm{C}=\mathrm{C}$ versus $\mathrm{C}=\mathrm{O}$ substrates, we attempted the hydrogenation

(86) Sandoval, C. A.; Ohkuma, T.; Muiz, K.; Noyori, R. J. Am. Chem. Soc. 2003, 125, 13490-13503.

(87) Noyori, R. Asymmetric Catalysis in Organic Synthesis; John Wiley and Sons: New York, 1994. 
Scheme 10. Possible Pathway for Olefin Hydrogenation Mediated by Complex 4

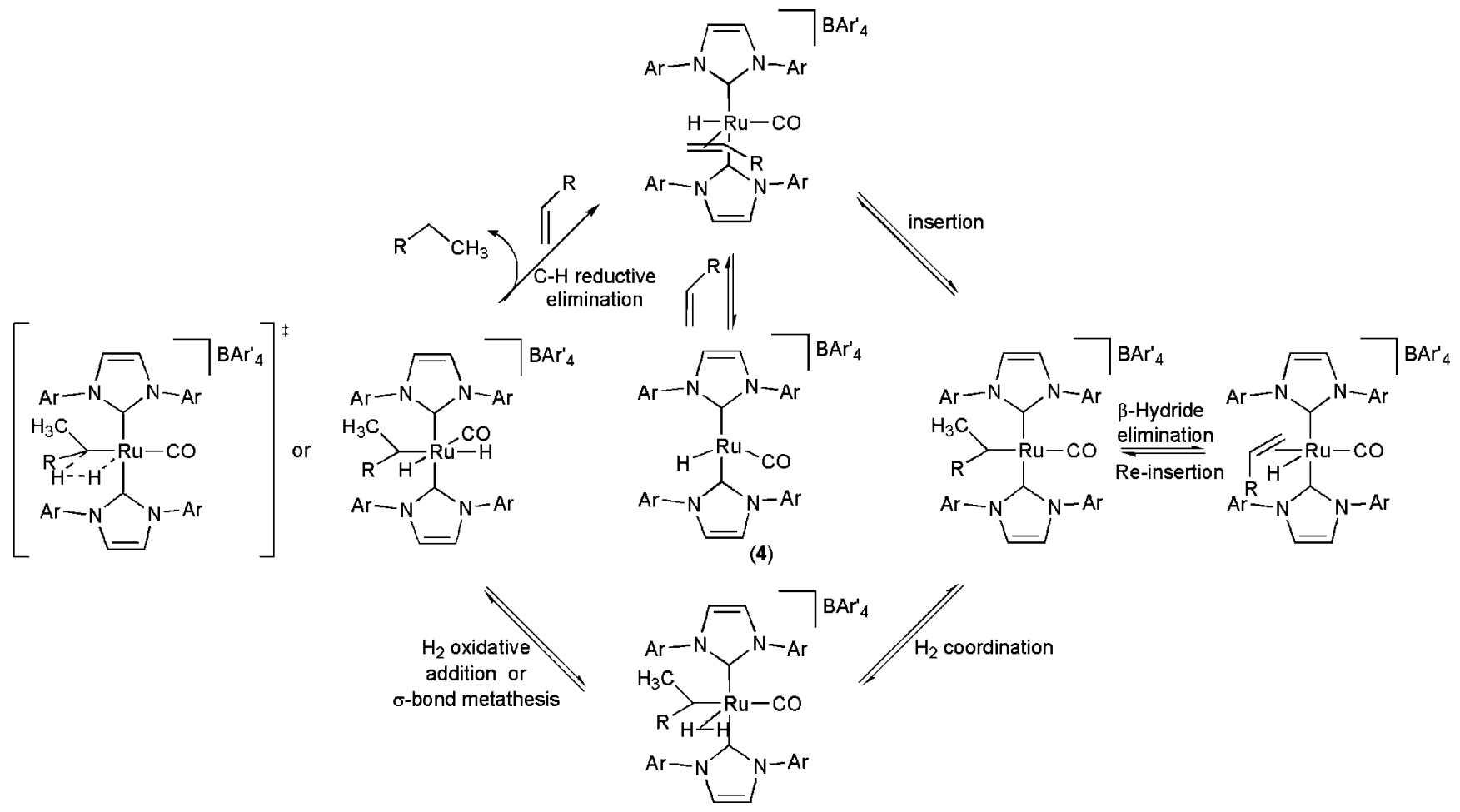

Scheme 11. Stepwise Hydrogenation of 3-Vinyl-Benzaldehyde Catalyzed by 4

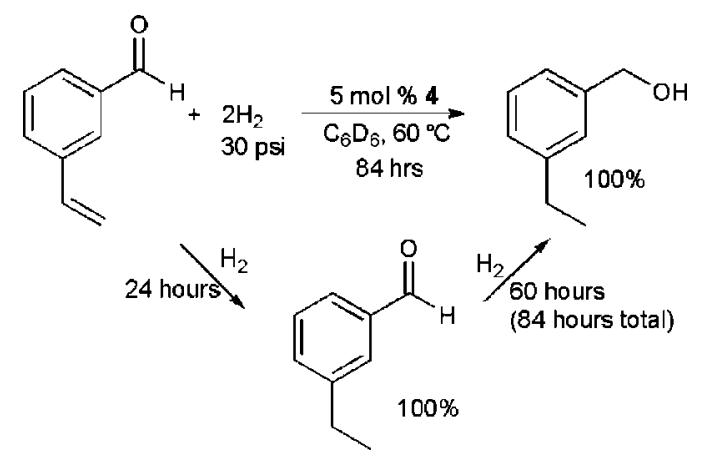

of 3-vinyl-benzaldehyde. Complete hydrogenation of the vinyl group to produce 3-ethyl-benzaldehyde is observed after $24 \mathrm{~h}$ by ${ }^{1} \mathrm{H}$ NMR spectroscopy (Scheme 11). At this time, there is no evidence (by ${ }^{1} \mathrm{H}$ NMR spectroscopy) for reduction of the carbonyl group. The intermediate aldehyde is characterized by ${ }^{1} \mathrm{H}$ NMR spectroscopy with a new aldehyde $\mathrm{C}-\mathrm{H}$ resonance $(9.72 \mathrm{ppm})$ compared to the vinyl-aldehyde $(9.64 \mathrm{ppm})$, resonances consistent with an ethyl group $\left(2.29 \mathrm{ppm}, \mathrm{q},{ }^{3} J_{\mathrm{HH}}\right.$ $=8 \mathrm{~Hz} ; 0.95 \mathrm{ppm}, \mathrm{t},{ }^{3} \mathrm{~J}_{\mathrm{HH}}=8 \mathrm{~Hz}$ ) and complete disappearance of the resonances due to the vinyl group. Prolonged reaction time (84 total hours) results in the complete hydrogenation of the carbonyl to produce 3-ethyl-benzylalcohol (entry 4, Table 3). Though complex 4 can hydrogenate both $\mathrm{C}=\mathrm{C}$ and $\mathrm{C}=\mathrm{O}$ substrates, these results suggest that it is kinetically selective for the $\mathrm{C}=\mathrm{C}$ functionality. Attempted extension of catalytic hydrogenation to carboxamides ( $N$-methylacetamide) or esters (methyl acetate) resulted in no reaction or decomposition of $\mathbf{4}$, respectively.

\section{Summary and Conclusions}

The sterically encumbering and strongly donating IMes ligands of $\mathbf{1}$ were utilized to synthesize, isolate and characterize a reactive 4-coordinate $\mathrm{Ru}(\mathrm{II})$ complex, [(IMes $\left.)_{2} \mathrm{Ru}(\mathrm{H})(\mathrm{CO})\right]-$ $\left[\mathrm{BAr}_{4}^{\prime}\right]$ (4). Facile ligand coordination (e.g., ${ }^{t} \mathrm{BuNC}$ ), reversible intramolecular $\mathrm{C}-\mathrm{H}$ activation and reversible $\mathrm{N}_{2}$ coordination have been observed for $\mathbf{4}$. In addition, complex $\mathbf{4}$ was found to be active for olefin, ketone, and aldehyde hydrogenation with kinetic selectivity for $\mathrm{C}=\mathrm{C}$ over $\mathrm{C}=\mathrm{O}$ hydrogenation. DFT calculations are consistent with the temperature dependent and reversible coordination of $\mathrm{N}_{2}$ to 4 .

Previous examples of four-coordinate $\mathrm{Ru}(\mathrm{II})$ complexes include paramagnetic square planar systems that are stabilized by a $\pi$-donor ligand and diamagnetic systems in which two $\mathrm{C}-\mathrm{H}$ agostic interactions complete an octahedral coordination sphere. However, the combined experimental and computational results that have been presented herein suggest that a diamagnetic 14-electron species is accessible in the absence of $\mathrm{C}-\mathrm{H}$ agostic interactions. As anticipated, initial studies have revealed an array of reactivity of the four-coordinate complex $\mathbf{4}$ including catalytic hydrogenation, intramolecular $\mathrm{C}-\mathrm{H}$ activation, coordination of dinitrogen and facile coordination of traditional Lewis bases.

\section{Experimental Section}

General Methods. Unless otherwise noted, all reactions and procedures were performed under anaerobic conditions in a nitrogen filled glovebox or using standard Schlenk techniques. Glovebox purity was maintained by periodic nitrogen purges and monitored by an oxygen analyzer $\left\{\mathrm{O}_{2}(\mathrm{~g})<15 \mathrm{ppm}\right.$ for all reactions $\}$. Hexanes were purified by passage through two columns of activated alumina. Acetonitrile and methanol were purified by distillation from calcium hydride. Pentane was purified by distillation from sodium. Benzene, tetrahydrofuran, and toluene were purified by distillation from sodium/benzophenone. $\mathrm{CD}_{3} \mathrm{CN}, \mathrm{C}_{6} \mathrm{D}_{6}, \mathrm{CDCl}_{3}, \mathrm{CD}_{3} \mathrm{OD}, \mathrm{CD}_{2} \mathrm{Cl}_{2}$, and $\mathrm{C}_{6} \mathrm{D}_{5} \mathrm{CD}_{3}$ were degassed via three freeze-pump-thaw cycles and stored over $4 \AA$ sieves. Photolysis experiments were performed using a $450 \mathrm{~W}$ power supply, $450 \mathrm{~W}$ lamp, and a quartz cooling jacket with flowing water. ${ }^{1} \mathrm{H}$ and ${ }^{13} \mathrm{C}$ NMR spectra were obtained on either a Varian Mercury $300 \mathrm{MHz}$ or Varian Mercury $400 \mathrm{MHz}$ 
spectrometer (operating frequencies for ${ }^{13} \mathrm{C}$ NMR are 75 and 100 $\mathrm{MHz}$, respectively) and referenced against tetramethylsilane using residual proton signals $\left({ }^{1} \mathrm{H}\right.$ NMR) or the ${ }^{13} \mathrm{C}$ resonances of the deuterated solvent $\left({ }^{13} \mathrm{C}\right.$ NMR). ${ }^{19} \mathrm{~F}$ NMR spectra were obtained on a Varian $300 \mathrm{MHz}$ spectrometer (operating frequency $282 \mathrm{MHz}$ ) and referenced against an external standard of hexafluorobenzene $(\delta=-164.9) .{ }^{31} \mathrm{P}$ NMR spectra were obtained on a Varian 400 $\mathrm{MHz}$ spectrometer (operating frequency $161 \mathrm{MHz}$ ) and referenced against an external standard of $\mathrm{H}_{3} \mathrm{PO}_{4}(\delta=0) .{ }^{2} \mathrm{H}$ NMR spectra were obtained on a Bruker $500 \mathrm{MHz}$ spectrometer (operating frequency $78 \mathrm{MHz}$ ) in $\mathrm{C}_{6} \mathrm{H}_{6}$ and referenced against residual $\mathrm{C}_{6} \mathrm{D}_{6}$ $(\delta=7.16)$. Unless otherwise noted NMR spectra were acquired at room temperature. IR spectra were obtained on a Mattson Genesis II spectrometer as either thin films on a $\mathrm{KBr}$ plate or in a solution flow cell. Elemental analyses were performed by Atlantic Microlabs, Inc. $\left[\mathrm{Ru}(\mathrm{CO})_{2} \mathrm{Cl}_{2}\right]_{n}$, IMes, and $\mathrm{NaBAr}_{4}{ }_{4}$ were prepared according to reported procedures. ${ }^{8-90}$ Cyclohexene was degassed via three freeze-pump-thaw cycles and stored over $4 \AA$ sieves. Styrene was vacuum distilled from $\mathrm{CaH}_{2}$. Carbon monoxide (99.5\%) and $\mathrm{H}_{2}(99.9 \%)$ were obtained from MWSC High-Purity Gases and used as received. $\mathrm{D}_{2}(99.8 \% \mathrm{D})$ was obtained from Cambridge Isotope Laboratories and used as received. All other reagents were purchased from commercial sources and used without further purification.

(IMes) $)_{2} \mathbf{R u}(\mathbf{C l})(\mathbf{H})(\mathbf{C O})$ (1). A yellow heterogeneous solution of $\left[\mathrm{Ru}(\mathrm{CO})_{2} \mathrm{Cl}_{2}\right]_{\mathrm{n}}(0.162 \mathrm{~g}, 0.711 \mathrm{mmol})$, IMes $(0.443 \mathrm{~g}, 1.46 \mathrm{mmol})$ and toluene $(20 \mathrm{~mL})$ in a sealed pressure tube was heated in an oil bath to $100{ }^{\circ} \mathrm{C}$ for $24 \mathrm{~h}$. After the heating period, the orange solution was filtered, and the volatiles were removed from the filtrate in vacuo to produce an orange residue. The residue was dissolved in methanol $(20 \mathrm{~mL})$ and heated to reflux for $48 \mathrm{~h}$. During the heating period, an orange precipitate formed. The volatiles were reduced to approximately $5 \mathrm{~mL}$. After stirring overnight in methanol, the orange solid was collected by vacuum filtration, washed with hexanes, and dried in vacuo $\left(0.148 \mathrm{~g}, 27 \%\right.$ yield). IR (KBr): $v_{\mathrm{CO}}$ $=1886 \mathrm{~cm}^{-1} \cdot{ }^{1} \mathrm{H}$ NMR (room temperature $\mathrm{C}_{6} \mathrm{D}_{6}, \delta$ ): $6.83,6.79$ (8H total, 1:1 ratio, each a br s, IMes aryl), 6.17 (4H total, s, IMes $H \mathrm{C}=\mathrm{CH}), 2.34,2.19,2.08$ (36H total, 1:1:1 ratio, each a br s, IMes $\left.-\mathrm{CH}_{3}\right),-25.30(\mathrm{~s}, \mathrm{Ru}-H) .{ }^{13} \mathrm{C} \mathrm{NMR}$ (room temperature $\mathrm{C}_{6} \mathrm{D}_{6}, \delta$ ): $202.2\left(\mathrm{~d},{ }^{2} J_{\mathrm{CH}}=10 \mathrm{~Hz}, \mathrm{Ru}-\mathrm{CO},\right), 195.3\left\{\mathrm{~d},{ }^{2} J_{\mathrm{CH}}=10 \mathrm{~Hz}, \mathrm{Ru}-\right.$ $C$ (IMes) $\}$, (The $C O$ and $C$ (IMes) resonances were found to be coupled to the Ru-H; however, when a ${ }^{13} \mathrm{C}\left\{{ }^{1} \mathrm{H}\right\}$ was obtained with only the $\mathrm{Ru}-H$ resonance decoupled the $C \mathrm{O}$ and $C$ (IMes) resonances collapsed to singlets.) $137.7,137.3,136.7,136.4,129.4$ (each a s, IMes-aryl, likely one overlap), $121.9(\mathrm{NCH}=C \mathrm{HN}), 21.7\left(\mathrm{~s}, p-\mathrm{CH}_{3}\right)$, $19.5\left(\mathrm{~s}, o-\mathrm{CH}_{3}\right), 19.4\left(\mathrm{~s}, o-\mathrm{CH}_{3}\right)$. MS (EI) Calculated (Found): $\mathrm{m} / \mathrm{z}$ $738.6(739, \sigma=0.4 \mathrm{ppm})\left\{(\mathrm{IMes})_{2} \mathrm{Ru}(\mathrm{H})(\mathrm{CO})\right\}^{+}$.

$(\mathrm{IMes})_{2} \mathbf{R u}(\mathrm{Cl})(\mathrm{H})(\mathbf{C O})_{2}$ (2). Carbon monoxide was gently bubbled through a yellow solution of $1(0.078 \mathrm{~g}, 0.100 \mathrm{mmol})$ in benzene $(20 \mathrm{~mL})$ in a $100 \mathrm{~mL}$ round-bottom Schlenk flask. The solution immediately turned colorless. After stirring for $1 \mathrm{~h}$ at room temperature, the $\mathrm{CO}$ purge was stopped, and the volatiles were reduced to $\sim 1 \mathrm{~mL}$ in vacuo. Hexanes were added to precipitate a white solid, which was collected by vacuum filtration, washed with hexanes, and dried in vacuo (0.066 g, 82\% yield). Crystals suitable for an X-ray diffraction study were grown by layering a benzene solution of 2 with pentane at room temperature under a $\mathrm{N}_{2}$ atmosphere. IR (KBr): $v_{\mathrm{Ru}-\mathrm{H}}=1941 \mathrm{~cm}^{-1}, v_{\mathrm{CO}}=2035 \mathrm{~cm}^{-1}, 1905$ $\mathrm{cm}^{-1} .{ }^{1} \mathrm{H}$ NMR $\left(\mathrm{C}_{6} \mathrm{D}_{6}, \delta\right): 6.74,6.73$ (8H total, $1: 1$ ratio, each a br s, IMes aryl), 6.07 (4H total, s, IMes $H C=C H), 2.25,2.19(36 \mathrm{H}$ total, 1:2 ratio, each a s, IMes $\left.-\mathrm{CH}_{3}\right),-4.22(1 \mathrm{H}, \mathrm{s}, \mathrm{Ru}-H){ }^{13} \mathrm{C}$ NMR $\left(\mathrm{C}_{6} \mathrm{D}_{6}, \delta\right): 204.1$ (s, Ru-CO), 185.5 \{s, Ru-C(IMes)\}, 139.5,

(88) Grocott, S. C.; Wild, S. B. Inorg. Chem. 1982, 21, 3535-3540.

(89) Arduengo III, A. J.; Dias, H. V. R.; Harlow, R. L.; Kline, M. J. Am. Chem. Soc. 1992, 114, 5530-5534. 3591 .

(90) Yakelis, N. A.; Bergman, R. G. Organometallics 2005, 24, 3579-
137.7, 137.0, 136.7, 129.8, 129.7 (each a s, IMes-aryl), 123.4 $(\mathrm{NCH}=C \mathrm{HN}), 21.6\left(\mathrm{~s}, p-\mathrm{CH}_{3}\right), 19.2\left(\mathrm{~s}, o-\mathrm{CH}_{3}\right), 19.1\left(\mathrm{~s}, o-\mathrm{CH}_{3}\right)$.

$(\mathrm{IMes})_{2} \mathbf{R u}(\mathbf{C l})_{2}(\mathbf{C O})_{2}(3)$. $\mathrm{HCl}$ (4 M solution in 1,4-dioxane, $0.050 \mathrm{~mL}, 0.20 \mathrm{mmol})$ was added to a yellow solution of $2(0.055$ $\mathrm{g}, 0.068 \mathrm{mmol})$ in benzene $(20 \mathrm{~mL})$ in a $100 \mathrm{~mL}$ round-bottom flask. The solution was stirred for $1 \mathrm{~h}$ at which time the volatiles were reduced to $\sim 1 \mathrm{~mL}$ in vacuo. Hexanes were added to precipitate a white solid, which was collected by vacuum filtration, washed with hexanes, and dried in vacuo $(0.047 \mathrm{~g}, 82 \%$ yield). IR $(\mathrm{KBr})$ : $v_{\mathrm{CO}}=2025$ and $1955 \mathrm{~cm}^{-1}$. ${ }^{1} \mathrm{H}$ NMR $\left(\mathrm{C}_{6} \mathrm{D}_{6}, \delta\right): 6.72(8 \mathrm{H}$ total, br s, IMes aryl), 5.95 (4H total, s, IMes $H \mathrm{C}=\mathrm{CH}), 2.27,2.14(36 \mathrm{H}$ total, 2:1 ratio, each a s, IMes $\left.-\mathrm{CH}_{3}\right) \cdot{ }^{13} \mathrm{C} \mathrm{NMR}\left(\mathrm{CDCl}_{3}, \delta\right): 194.7$ (s, Ru-CO), 174.5 \{s, Ru-C(IMes) $\}, 138.6,138.5,136.6$ (each a s, IMes-Aryl), $125.0(\mathrm{NCH}=C \mathrm{HN}), 21.4\left(\mathrm{~s}, p-\mathrm{CH}_{3}\right), 18.8\left(\mathrm{~s}, o-\mathrm{CH}_{3}\right)$. MS (EI) Calculated (Found): $m / z, 801.05$ (801, $\sigma=0.4$ ppm) $\left\{(\mathrm{IMes})_{2} \mathrm{Ru}(\mathrm{CO})_{2}(\mathrm{Cl})\right\}^{+}$.

[(IMes) $\left.)_{2} \mathbf{R u}(\mathbf{H})(\mathbf{C O})\right]\left[\mathbf{B A r}_{4}^{\prime}\right]$ (4). $\mathrm{NaBAr}_{4}{ }_{4}(0.085 \mathrm{~g}, 0.096 \mathrm{mmol})$ was added to a yellow solution of $1(0.094 \mathrm{~g}, 0.120 \mathrm{mmol})$ in benzene $(20 \mathrm{~mL})$, and the mixture was stirred at room temperature for $24 \mathrm{~h}$. The resulting orange-yellow solution was filtered through a plug of Celite. The filtrate was reduced to $\sim 1 \mathrm{~mL}$ in vacuo. Hexanes were added to precipitate an orange-red solid. After storing at $-20{ }^{\circ} \mathrm{C}$ overnight to maximize precipitation, the brick-red solid was collected by vacuum filtration, washed with hexanes, and dried in vacuo $\left(0.105 \mathrm{~g}, 54 \%\right.$ yield). IR $\left(\mathrm{C}_{6} \mathrm{H}_{6}\right): v_{\mathrm{CO}}=1933 \mathrm{~cm}^{-1} \cdot{ }^{1} \mathrm{H}$ NMR $\left(\mathrm{C}_{6} \mathrm{D}_{6}, \delta\right): 8.39$ ( $8 \mathrm{H}$ total, br s, $\left.o-\mathrm{Ar}^{\prime}\right), 7.69$ (4H total, br s, p-Ar'), 6.69 (8H total, br s, IMes aryl), 6.00 (4H total, br s, IMes $H \mathrm{C}=\mathrm{C} H), 2.21,1.58,1.50(36 \mathrm{H}$ total, each a s, $1: 1: 1$ ratio IMes $\left.-\mathrm{CH}_{3}\right),-26.43(1 \mathrm{H}$ total, br s, Ru- $H){ }^{13} \mathrm{C}$ NMR $\left(\mathrm{C}_{6} \mathrm{D}_{6}, \delta\right): 202.9$ (br s, Ru-CO), 188.4 \{br s, Ru-C(IMes)\}, 163.1 (1:1:1:1 ratio, q, $\left.{ }^{1} J_{\mathrm{BC}}=50 \mathrm{~Hz}, \mathrm{~B}-C\right), 139.7,135.8,135.6,135.2,135.0,130.1,130.0$, $127.4,123.8,123.3,120.2$ (each a sharp s, IMes-aryl and $\mathrm{BAr}_{4^{-}}{ }^{-}$ aryl), 131.0, 130.1, 129.6 (each a br s, IMes-aryl and $\mathrm{BAr}^{\prime}{ }_{4}$-aryl), $125.6\left(\mathrm{q},{ }^{1} J_{\mathrm{FC}}=271 \mathrm{~Hz}, \mathrm{BAr}^{\prime}{ }_{4}-\mathrm{CF}_{3}\right), 118.4(\mathrm{NCH}=\mathrm{CHN}), 21.2$ $\left(\mathrm{s}, o-C \mathrm{H}_{3}\right), 17,7\left(\mathrm{~s}, p-\mathrm{CH}_{3}\right) .{ }^{19} \mathrm{~F} \mathrm{NMR}\left(\mathrm{C}_{6} \mathrm{D}_{6}, \delta\right):-60.8$ (s).

$\left[(\mathbf{I M e s})_{2} \mathbf{R u}(\mathbf{H})\left(\mathbf{C N}^{t} \mathbf{B u}\right)_{2}(\mathbf{C O})\right]\left[\mathrm{BAr}^{\prime}{ }_{4}\right](5) . \mathrm{CN}^{t} \mathrm{Bu}(0.012 \mathrm{~mL}$, $0.11 \mathrm{mmol})$ was added to a yellow solution of $4(0.051 \mathrm{~g}, 0.032$ $\mathrm{mmol})$ in benzene $(20 \mathrm{~mL})$ in a $100 \mathrm{~mL}$ round-bottom flask. The solution immediately turned colorless. After stirring for $1 \mathrm{~h}$, the volatiles were reduced to $\sim 1 \mathrm{~mL}$ in vacuo. Hexanes were added to precipitate a white solid, which was collected by vacuum filtration, washed with hexanes, and dried in vacuo (0.046 g, 82\% yield). Crystals suitable for an X-ray diffraction study were grown by layering a benzene solution of $\mathbf{5}$ with pentane at room temperature under a $\mathrm{N}_{2}$ atmosphere. IR (KBr): $v_{\mathrm{CN}}=2150 \mathrm{~cm}^{-1}, 2120 \mathrm{~cm}^{-1}$, $v_{\mathrm{CO}}=1975 \mathrm{~cm}^{-1}$ (also has a low energy shoulder, likely $\mathrm{Ru}-\mathrm{H}$ stretch). ${ }^{1} \mathrm{H}$ NMR $\left(\mathrm{C}_{6} \mathrm{D}_{6}, \delta\right): 8.42$ (8H total, s, o-Ar'), $7.72(4 \mathrm{H}$ total, s, $p$-Ar'), 6.68, 6.67 (8H total, 1:1 ratio, each a br s, IMes aryl), $5.87(4 \mathrm{H}$ total, s, IMes $H \mathrm{C}=\mathrm{CH}), 2.13,1.76(36 \mathrm{H}$ total, $1: 2$ ratio, each a s, IMes $\left.-\mathrm{CH}_{3}\right), 0.98,0.77\{18 \mathrm{H}$ total, $1: 1$ ratio, each a s, $\left.-\mathrm{C}\left(\mathrm{CH}_{3}\right)_{3}\right\},-7.99(1 \mathrm{H}$ total, s, Ru- $H) .{ }^{13} \mathrm{C}$ NMR $\left(\mathrm{C}_{6} \mathrm{D}_{6}, \delta\right): 200.8$ (s, Ru-CO), $183.0\{\mathrm{~s}, \mathrm{Ru}-C(\mathrm{IMes})\}, 162.0\left(1: 1: 1: 1\right.$ ratio, $\mathrm{q},{ }^{1} J_{\mathrm{BC}}=$ $50 \mathrm{~Hz}, \mathrm{~B}-\mathrm{C}), 139.3,138.4,136.0,135.8,135.0,129.6,129.5,126.6$, 124.2, 123.0, 119.4, 117.6 (each a s, IMes-aryl, $\mathrm{BAr}^{\prime}{ }_{4}$-aryl, Ru$\left.C \mathrm{~N}^{t} \mathrm{Bu}, \mathrm{NCH}=C \mathrm{HN}\right), 129.0\left(\mathrm{q},{ }^{2} J_{\mathrm{FC}}=28 \mathrm{~Hz}\right.$, meta-BAr' $\left.{ }_{4}\right), 124.8$ $\left(\mathrm{q},{ }^{1} J_{\mathrm{FC}}=271 \mathrm{~Hz}, \mathrm{BAr}^{\prime}{ }_{4}-\mathrm{CF}_{3}\right), 57.5,56.4$ each a s, $\left.-\mathrm{C}\left(\mathrm{CH}_{3}\right)_{3}\right\}$ 30.2, 29.7, 21.2, 19.0, 18.8 \{each a s, $-\mathrm{C}\left(\mathrm{CH}_{3}\right)_{3} o-\mathrm{CH}_{3}, p-\mathrm{CH}_{3}$ \}. ${ }^{19} \mathrm{~F} \quad \mathrm{NMR} \quad\left(\mathrm{C}_{6} \mathrm{D}_{6}, \quad \delta\right): \quad-60.8 \quad(\mathrm{~s})$. Anal. Calcd For $\mathrm{C}_{85} \mathrm{H}_{79} \mathrm{~B}_{1} \mathrm{~F}_{24} \mathrm{~N}_{6} \mathrm{O}_{1} \mathrm{Ru}$ : C, 57.74; H, 4.47; N, 4.75. Found: C, 57.26; $\mathrm{H}, 4.45 ; \mathrm{N}, 4.76$.

Reaction of $\left[\mathrm{Ru}(\mathrm{CO})_{2} \mathrm{Cl}_{2}\right]_{n}$ With IMes in Toluene-d $\mathrm{d}_{\mathbf{8}}$ and $\mathrm{CD}_{3}$ OD. A yellow heterogeneous solution of $\left[\mathrm{Ru}(\mathrm{CO})_{2} \mathrm{Cl}_{2}\right]_{\mathrm{n}}(0.037$ $\mathrm{g}, 0.16 \mathrm{mmol})$, IMes $(0.110 \mathrm{~g}, 0.36 \mathrm{mmol})$ and toluene $(5 \mathrm{~mL})$ in a sealed pressure tube was heated in an oil bath to $100{ }^{\circ} \mathrm{C}$ for $24 \mathrm{~h}$. After the heating period, an aliquot was analyzed by ${ }^{1} \mathrm{H}$ NMR spectroscopy, which showed a mixture of (IMes)Ru products (none of which corresponded to 1 ) and a single resonance upfield of 0 
$\mathrm{ppm}$ at $-4.5 \mathrm{ppm}$. The mixture was filtered, and the orange filtrate was equally divided between two $38 \mathrm{~mL}$ pressure tubes. $\mathrm{CH}_{3} \mathrm{OH}$ and $\mathrm{CD}_{3} \mathrm{OD}(5 \mathrm{~mL})$ were added separately to the reaction mixtures. The tubes were sealed and heated in an oil bath to $80{ }^{\circ} \mathrm{C}$ for $24 \mathrm{~h}$. After the heating period, aliquots were removed from each, and the volatiles were removed in vacuo. The residues from each reaction were dissolved in $\mathrm{C}_{6} \mathrm{D}_{6} .{ }^{1} \mathrm{H}$ NMR spectroscopy of both samples $\left(\mathrm{CH}_{3} \mathrm{OH}\right.$ and $\mathrm{CD}_{3} \mathrm{OD}$ reactions $)$ revealed complex 1 without incorporation of deuterium.

Variable Temperature ${ }^{1} \mathbf{H}$ NMR Spectroscopy of (IMes) ${ }_{2}$ $\mathbf{R u}(\mathbf{C l})(\mathbf{H})(\mathbf{C O})$ (1). (a) An orange solution of complex 1 (0.006 $\mathrm{g}, 0.008 \mathrm{mmol})$ in toluene- $d_{8}(0.6 \mathrm{~mL})$ was transferred to a screwcap NMR tube. ${ }^{1} \mathrm{H}$ NMR spectra were obtained at $10{ }^{\circ} \mathrm{C}$ intervals from 25 to $95{ }^{\circ} \mathrm{C}$, which resulted in only minor changes from the room temperature ${ }^{1} \mathrm{H}$ NMR spectrum. No observation of the methyl resonances coalescing into a 2:1 ratio was made, which would be indicative of rapid rotation of both the $\mathrm{N}-\mathrm{C}_{\text {mesityl }}$ and $\mathrm{Ru}-\mathrm{C}_{\mathrm{NHC}}$ bonds on the NMR time scale. (b) The solution was then cooled in the NMR probe. ${ }^{1} \mathrm{H}$ NMR spectra were obtained at $20^{\circ} \mathrm{C}$ intervals ranging from 20 to $-60{ }^{\circ} \mathrm{C}$. At $-20^{\circ} \mathrm{C}$, two resonances due to the methyl resonances began to decoalesce. At $-40{ }^{\circ} \mathrm{C}$, the resonances due to the aryl hydrogens began to decoalesce. At $-60{ }^{\circ} \mathrm{C}$, a near idealized $\mathrm{C}_{\mathrm{s}}$ molecular symmetry for $\mathbf{1}$ was observed where the aryl hydrogens were 4 singlets, the backbone hydrogens of the imidazole rings resonate as 2 singlets, and the methyl resonances were observed as 5 singlets (possibly 6 resonances due to overlap with the solvent). (c) An orange solution of complex 1 (0.006 g, $0.008 \mathrm{mmol})$ in methylene chloride- $d_{2}(0.6 \mathrm{~mL})$ was transferred to an NMR tube. ${ }^{1} \mathrm{H}$ NMR spectra were obtained at $5{ }^{\circ} \mathrm{C}$ intervals ranging from 0 to $-70{ }^{\circ} \mathrm{C}$. At $-10{ }^{\circ} \mathrm{C}$, a set of IMes methyl resonance is at the coalescence temperature. Further cooling allowed this resonance to decoalesce into two singlets. These resonances were followed until no further change was observed in chemical shift or peak width at half-height $\left(-65^{\circ} \mathrm{C}\right)$. These data were used to calculate a rate constant for $\mathrm{Ru}-\mathrm{C}_{\mathrm{IMes}}$ bond rotation using line broadening and the coalescence temperature.

Reactivity of (IMes) $)_{2} \operatorname{RuCl}(\mathrm{H})(\mathrm{CO})$ (1) with Acetonitrile and Trimethylphosphine. (a) As a control experiment, an orange solution of complex 1 (0.006 g, $0.008 \mathrm{mmol})$ in $\mathrm{C}_{6} \mathrm{D}_{6}(0.6 \mathrm{~mL})$ was transferred to a screw-cap NMR tube. The solution was heated to $90{ }^{\circ} \mathrm{C}$ for $12 \mathrm{~h}$, which resulted in no reaction by ${ }^{1} \mathrm{H}$ NMR spectroscopy. (b) An orange solution of complex 1 (0.006 g, 0.008 $\mathrm{mmol})$ in $\mathrm{C}_{6} \mathrm{D}_{6}(0.6 \mathrm{~mL})$ was transferred to a screw-cap NMR tube. Acetonitrile $(3 \mu \mathrm{L}, 0.057 \mathrm{mmol})$ was added. The solution was heated to $90{ }^{\circ} \mathrm{C}$ for $12 \mathrm{~h}$ with no reaction by ${ }^{1} \mathrm{H}$ NMR spectroscopy. (c) An orange solution of complex $1(0.010 \mathrm{~g}, 0.01 \mathrm{mmol})$ in $\mathrm{C}_{6} \mathrm{D}_{6}$ $(0.6 \mathrm{~mL})$ was transferred to a screw-cap NMR tube. Trimethylphosphine ( $7 \mu \mathrm{L}, 0.079 \mathrm{mmol})$ was added. The solution was heated to $90{ }^{\circ} \mathrm{C}$ for $12 \mathrm{~h}$ with no reaction by ${ }^{1} \mathrm{H}$ NMR spectroscopy.

NMR Scale Preparation of $(\mathrm{IMes})_{2} \mathrm{Ru}(\mathrm{Cl})(\mathrm{D})(\mathrm{CO})_{\mathbf{2}}\left(\mathbf{2}-\mathrm{d}_{\mathbf{1}}\right)$. An orange solution of complex $1(0.008 \mathrm{~g}, 0.009 \mathrm{mmol})$ in $\mathrm{C}_{6} \mathrm{D}_{6}(0.6$ $\mathrm{mL}$ ) was transferred to a J-Young NMR tube. The tube was evacuated by two freeze-pump-thaw cycles, pressurized with $\mathrm{D}_{2}$ (30 psi) and heated to $60^{\circ} \mathrm{C}$. After $6 \mathrm{~h}$, complete conversion to the

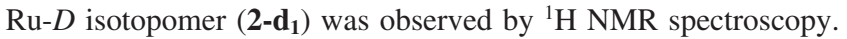
Incorporation of deuterium into the methyl groups of the IMes ligands was not observed. IR analysis (thin film on $\mathrm{KBr}$ ) showed disappearance of the absorption at $1941 \mathrm{~cm}^{-1}$.

Reaction of $\left[(\mathrm{IMes})_{2} \mathrm{Ru}(\mathrm{H})(\mathrm{CO})\right]\left[\mathrm{BAr}_{4}{ }_{4}\right](4)$ with $\left[\mathrm{Bu}_{4} \mathrm{~N}\right]-$ [Cl]. An orange solution of complex $4(0.006 \mathrm{~g}, 0.004 \mathrm{mmol})$ in $\mathrm{C}_{6} \mathrm{D}_{6}(0.6 \mathrm{~mL})$ was added to $\left[\mathrm{Bu}_{4} \mathrm{~N}\right][\mathrm{Cl}](0.003 \mathrm{~g}, 0.011 \mathrm{mmol})$, stirred for $5 \mathrm{~min}$ and transferred to an NMR tube. Quantitative formation of complex 1 was observed by ${ }^{1} \mathrm{H}$ NMR spectroscopy.

Attempts to produce $(\mathrm{IMes})_{2} \mathrm{Ru}(\mathrm{Cl})_{2}(\mathrm{CO})$ from (IMes) $)_{2}$ $\operatorname{Ru}(\mathbf{C l})(\mathbf{H})(\mathbf{C O})$ (1). (a) Reaction of (IMes) ${ }_{2} \mathrm{Ru}(\mathrm{Cl})(\mathrm{H})(\mathrm{CO})(\mathbf{1})$ with $\mathrm{HCl}$. $\mathrm{HCl}$ (4 M solution in 1,4-dioxane, $0.050 \mathrm{~mL}, 0.20 \mathrm{mmol}$ ) was added to a yellow solution of $1(0.062 \mathrm{~g}, 0.080 \mathrm{mmol})$ in benzene $(20 \mathrm{~mL})$ in a $100 \mathrm{~mL}$ round-bottom flask. The solution was stirred for $3 \mathrm{~h}$, after which the volatiles were reduced to $\sim 1$ $\mathrm{mL}$ in vacuo. Hexanes were added to precipitate a cream-yellow solid, which was collected by vacuum filtration, washed with hexanes, and dried in vacuo $(0.057 \mathrm{~g})$. IR $(\mathrm{KBr})$ : $v_{\mathrm{CO}}=1939 \mathrm{~cm}^{-1}$. The ${ }^{1} \mathrm{H}$ NMR spectrum $\left(\mathrm{CDCl}_{3}\right)$ revealed two complexes with no resonances upfield of $0 \mathrm{ppm}$; however, we were unable to separate the complexes despite several attempts at chromatographic separation. (b) Reaction of $(\mathrm{IMes})_{2} \mathrm{Ru}(\mathrm{Cl})(\mathrm{H})(\mathrm{CO})(\mathbf{1})$ with $\mathrm{CCl}_{4}$. A yellow solution of $1(0.010 \mathrm{~g}, 0.013 \mathrm{mmol})$ in $\mathrm{CCl}_{4}(20 \mathrm{~mL})$ in a $100 \mathrm{~mL}$ round-bottom flask was heated to reflux. After $3 \mathrm{~h}$, analysis of the reaction mixture by IR (thin film on $\mathrm{KBr}$ ) showed no reaction. (c) Reaction of $(\mathrm{IMes})_{2} \mathrm{Ru}(\mathrm{Cl})(\mathrm{H})(\mathrm{CO})(\mathbf{1})$ with $\mathrm{N}$-chlorosuccinimide. $\mathrm{N}$-Chlorosuccinimide $(0.003 \mathrm{~g}, 0.023 \mathrm{mmol})$ was added to a yellow solution of $1(0.016 \mathrm{~g}, 0.021 \mathrm{mmol})$ in toluene $(5 \mathrm{~mL})$ in a 100 $\mathrm{mL}$ round-bottom flask. The solution was heated to reflux for $3 \mathrm{~h}$. Analysis of the reaction mixture by IR (thin film on $\mathrm{KBr}$ ) and ${ }^{1} \mathrm{H}$ NMR spectroscopy showed the formation of multiple (IMes) Ru systems. (d) Reaction of (IMes) $)_{2} \mathrm{Ru}(\mathrm{Cl})_{2}(\mathrm{CO})_{2}$ (3) with $\mathrm{Me}_{3} \mathrm{NO}$. $\mathrm{Me}_{3} \mathrm{NO}(0.025 \mathrm{~g}, 0.333 \mathrm{mmol})$ was added to a yellow solution of $3(0.012 \mathrm{~g}, 0.015 \mathrm{mmol})$ in toluene $(10 \mathrm{~mL})$ in a $100 \mathrm{~mL}$ roundbottom flask. The solution was heated to reflux for $8 \mathrm{~h}$. Analysis of the reaction mixture by IR (thin film on $\mathrm{KBr}$ ) showed no reaction.

Variable Temperature ${ }^{1} \mathrm{H}$ NMR Spectroscopy of [(IMes) $)_{2}$ $\mathbf{R u}(\mathbf{H})(\mathbf{C O})]\left[\mathbf{B A r}^{\prime}{ }_{4}\right]$ (4). (a) An orange solution of complex 4 (0.012 $\mathrm{g}, 0.007 \mathrm{mmol})$ in toluene- $d_{8}(0.6 \mathrm{~mL})$ was transferred to a screwcap NMR tube. ${ }^{1} \mathrm{H}$ NMR spectra were obtained at $10{ }^{\circ} \mathrm{C}$ intervals ranging from 25 to $-80{ }^{\circ} \mathrm{C}$. At $0{ }^{\circ} \mathrm{C}$, two complexes $(2: 1$ ratio) were observed. At temperatures below $0{ }^{\circ} \mathrm{C}$, no further changes are observed until the temperature reaches $-80{ }^{\circ} \mathrm{C}$ where all resonances broadened into the baseline. Warming back to room temperature resulted in the original spectrum. b) ${ }^{1} \mathrm{H}$ NMR spectra were then obtained at $20^{\circ} \mathrm{C}$ intervals ranging from 20 to $80{ }^{\circ} \mathrm{C}$. As the temperature was increased only the single room temperature complex was present, and the resonances sharpened slightly including the $\mathrm{Ru}-\mathrm{H}$ resonance.

Reversible formation of $\left[(\mathrm{IMes})_{2} \mathrm{Ru}(\mathrm{H})(\mathrm{CO})\left(\mathrm{N}_{2}\right)\right]\left[\mathrm{BAr}_{4}{ }_{4}\right]$ (4- $\mathbf{N}_{2}$ ) Under $\mathbf{N}_{2}$ Pressure. An orange solution of complex 4 (0.007 $\mathrm{g}, 0.004 \mathrm{mmol})$ in $\mathrm{C}_{6} \mathrm{D}_{5} \mathrm{CD}_{3}(0.6 \mathrm{~mL})$ was transferred to a J-Young NMR tube. The tube was evacuated by two freeze-pump-thaw cycles and backfilled with $\mathrm{N}_{2}(80 \mathrm{psi})$ at room temperature. The room temperature ${ }^{1} \mathrm{H}$ NMR spectrum showed resonances consistent with complex $\mathbf{3}$ and complex $\mathbf{4}-\mathbf{N}_{\mathbf{2}}$ (as observed by low temperature ${ }^{1} \mathrm{H}$ NMR spectroscopy) in an approximate $3: 1$ ratio favoring complex 4 . The tube was evacuated by five freeze-pump-thaw cycles and back-filled with argon (40 psi). The room temperature ${ }^{1} \mathrm{H}$ NMR spectrum showed complex 4 with no evidence of complex 4-N.

Variable Temperature ${ }^{1} \mathrm{H}$ NMR Spectroscopy of [(IMes) $)_{2}$ $\operatorname{Ru}(\mathrm{H})(\mathrm{CO})]\left[\mathrm{BAr}_{4}^{\prime}\right]$ (4) Under Argon. An orange solution of complex $4(0.013 \mathrm{~g}, 0.008 \mathrm{mmol})$ in $\mathrm{C}_{6} \mathrm{D}_{5} \mathrm{CD}_{3}(0.6 \mathrm{~mL})$ was transferred to a J-Young NMR tube. The tube was evacuated by four freeze-pump-thaw cycles and backfilled with argon (1 atm) at room temperature. The room temperature ${ }^{1} \mathrm{H}$ NMR spectrum showed resonances consistent with complex 4 including the $\mathrm{Ru}-\mathrm{H}$ and one unassigned resonance at $3.5 \mathrm{ppm}$. The NMR probe was cooled from 20 to $-40{ }^{\circ} \mathrm{C}$, and spectra were obtained at $20{ }^{\circ} \mathrm{C}$ intervals. At low temperature only one complex was present in solution as compared to two complexes when the solution of $\mathbf{4}$ is under a dinitrogen atmosphere.

NMR Scale Preparation of $(\mathrm{IMes})_{2} \mathbf{R u}(\mathrm{CI})(\mathrm{D})(\mathrm{CO})\left(\mathbf{1}-\mathbf{d}_{\mathbf{1}}\right)$. An orange solution of complex $1(0.007 \mathrm{~g}, 0.009 \mathrm{mmol})$ in $\mathrm{C}_{6} \mathrm{D}_{6}(0.6$ $\mathrm{mL}$ ) was transferred to a J-Young NMR tube. The tube was evacuated by two freeze-pump-thaw cycles, pressurized with $\mathrm{D}_{2}$ (30 psi) and heated to $60^{\circ} \mathrm{C}$. After $6 \mathrm{~h}$, complete conversion to the $\mathrm{Ru}-D$ isotopomer (1-d $\mathbf{d}_{\mathbf{1}}$ ) and free $\mathrm{H}_{2}$ and $\mathrm{HD}$ were observed by ${ }^{1} \mathrm{H}$ NMR spectroscopy. Incorporation of deuterium into the methyl 
groups of the IMes ligands was not observed. The volatiles were removed in vacuo, and the sample was dried overnight. The residue was taken up in $\mathrm{C}_{6} \mathrm{H}_{6}(0.6 \mathrm{~mL})$ and transferred to an NMR tube. ${ }^{2} \mathrm{H}$ NMR spectroscopy showed a singlet at $-25 \mathrm{ppm}$ (referenced to residual $\mathrm{C}_{6} \mathrm{D}_{6}$ ). The ${ }^{2} \mathrm{H}$ NMR spectrum was acquired overnight using a $10 \mathrm{~s}$ pulse delay.

NMR Scale Preparation of $\left[(\mathrm{IMes})_{2} \mathrm{Ru}(\mathrm{D})(\mathrm{CO})\right]\left[\mathrm{BAr}_{4}^{\prime}\right]$ (4-d $\mathbf{d}_{1}$. An orange solution of complex $4(0.010 \mathrm{~g}, 0.0062 \mathrm{mmol})$ in $\mathrm{C}_{6} \mathrm{D}_{6}(0.6 \mathrm{~mL})$ was transferred to a J-Young NMR tube. The tube was evacuated by two freeze-pump-thaw cycles and pressurized with $\mathrm{D}_{2}(30 \mathrm{psi})$ at room temperature. After $3 \mathrm{~h}$, complete conversion to the Ru- $D$ isotopomer (4-d $\mathbf{d}_{1}$ ) was observed by ${ }^{1} \mathrm{H}$ NMR spectroscopy. In addition, incorporation of deuterium into the methyl groups of the IMes ligand(s) was observed (approximately 20\% D incorporation after $3 \mathrm{~h}$ ). The volatiles were removed in vacuo, and the sample was dried overnight. The residue was taken up in $\mathrm{C}_{6} \mathrm{H}_{6}$ $(0.6 \mathrm{~mL})$ and transferred to an NMR tube. ${ }^{2} \mathrm{H}$ NMR spectroscopy showed only a singlet at $1.7 \mathrm{ppm}$ for $\mathrm{D}$ incorporation into the IMes Me groups (referenced to residual $\mathrm{C}_{6} \mathrm{D}_{6}$ ) with no observable resonance in the region of -20 to $-30 \mathrm{ppm}$, which is consistent with the very broad $\mathrm{Ru}-H$ resonance for $\mathbf{4}$ observed by ${ }^{1} \mathrm{H}$ NMR spectroscopy. The ${ }^{2} \mathrm{H}$ NMR spectrum was acquired overnight using a $10 \mathrm{~s}$ pulse delay time.

Variable Temperature ${ }^{1} \mathrm{H}$ NMR Spectroscopy of [(IMes) $)_{2}$ $\mathbf{R u}(\mathrm{H})(\mathrm{CO})]\left[\mathrm{BAr}_{4}^{\prime}\right]$ (4) Under $\mathrm{D}_{\mathbf{2}}$ Pressure. An orange solution of complex 4 (0.014 g, $0.0087 \mathrm{mmol})$ in $\mathrm{C}_{6} \mathrm{D}_{5} \mathrm{CD}_{3}(0.6 \mathrm{~mL})$ was transferred to a J-Young NMR tube. The tube was evacuated by two freeze-pump-thaw cycles and pressurized with $\mathrm{D}_{2}$ (30 psi) at room temperature. At room temperature, ${ }^{1} \mathrm{H}$ NMR spectroscopy showed complex 3 and no resonance for the $\mathrm{Ru}-\mathrm{H}$. The probe was cooled from 20 to $-60{ }^{\circ} \mathrm{C}$, and spectra were obtained at 10 ${ }^{\circ} \mathrm{C}$ intervals. As the probe was cooled there was no observable change in the ${ }^{1} \mathrm{H}$ NMR spectrum. As the probe was warmed (20 to $80{ }^{\circ} \mathrm{C}$ ) there was no observable change in the ${ }^{1} \mathrm{H}$ NMR spectrum of 4.

Variable Temperature ${ }^{1} \mathrm{H}$ NMR Spectroscopy of [(IMes) $)_{2}$ $\mathbf{R u}(\mathrm{D})(\mathrm{CO})]\left[\mathrm{BAr}^{\prime}{ }_{4}\right]$ (4-d $\mathbf{d}_{\mathbf{1}}$ ) Under $\mathbf{H}_{\mathbf{2}}$ Pressure. An orange solution of complex $4(0.017 \mathrm{~g}, 0.011 \mathrm{mmol})$ in $\mathrm{C}_{6} \mathrm{D}_{5} \mathrm{CD}_{3}(0.6 \mathrm{~mL})$ was transferred to a J-Young NMR tube. The tube was evacuated by two freeze-pump-thaw cycles and pressurized with $\mathrm{D}_{2}$ (30 psi) at room temperature. After $20 \mathrm{~min},{ }^{1} \mathrm{H}$ NMR spectroscopy showed complete disappearance of the $\mathrm{Ru}-\mathrm{H}$ resonance of 4 . The tube was evacuated by two freeze-pump-thaw cycles and pressurized with $\mathrm{H}_{2}$ (30 psi) at room temperature. At room temperature ${ }^{1} \mathrm{H}$ NMR spectroscopy showed complex $\mathbf{4}$, no resonance for the $\mathrm{Ru}-\mathrm{H}$, and a broad singlet at $0.62 \mathrm{ppm}$ assigned as a time average between free dihydrogen and $\mathrm{Ru}$-coordinated hydrogen species due to rapid exchange. The probe was cooled from 20 to $-60{ }^{\circ} \mathrm{C}$ with ${ }^{1} \mathrm{H}$ NMR spectra obtained at $10{ }^{\circ} \mathrm{C}$ intervals. As the probe was cooled the broad resonance at $0.62 \mathrm{ppm}$ broadened into the baseline, which is consistent with the assignment of the resonance at $0.62 \mathrm{ppm}$ as the average of a rapid exchange between free dihydrogen and $\mathrm{Ru}-$ coordinated hydrogen; however, at $-60{ }^{\circ} \mathrm{C}$ the slow exchange regime was not reached. Warming the sample solution (20 to 80 ${ }^{\circ} \mathrm{C}$ ) resulted in sharpening of the resonance at $0.62 \mathrm{ppm}$ (broad at room temperature). These data are consistent with a time-averaged resonance for free dihydrogen and coordinated hydrogen ligands at $0.62 \mathrm{ppm}$ and explain the inability to observe free HD from the reaction of $D_{2}$ with complex 4 .

Variable Temperature ${ }^{1} \mathrm{H}$ NMR Spectroscopy of [(IMes) $)_{2}$ $\mathbf{R u}(\mathbf{H})(\mathrm{CO})]\left[\mathrm{BAr}_{4}{ }_{4}\right]$ (4) Under $\mathrm{H}_{2}$ Pressure. An orange solution of complex 4 (0.010 g, $0.0061 \mathrm{mmol})$ in $\mathrm{C}_{6} \mathrm{D}_{5} \mathrm{CD}_{3}(0.6 \mathrm{~mL})$ was transferred to a J-Young NMR tube. The tube was evacuated by two freeze-pump-thaw cycles and pressurized with $\mathrm{H}_{2}$ (30 psi) at room temperature. At room temperature, ${ }^{1} \mathrm{H}$ NMR spectroscopy showed complex 4 and a broad singlet at $0.62 \mathrm{ppm}$. Variable temperature NMR spectroscopy was identical to that described immediately above.

Rate of Incorporation of Deuterium into (IMes) $)_{2} \mathrm{Ru}-$ $(\mathrm{Cl})(\mathrm{H})(\mathrm{CO})(\mathbf{1})$ and $\left[(\mathrm{IMes})_{2} \mathbf{R u}(\mathbf{H})(\mathrm{CO})\right]\left[\mathrm{BAr}^{\prime}{ }_{4}\right]$ (4). (a) A 0.013 $\mathrm{M}$ stock solution of $\mathbf{1}(0.031 \mathrm{~g}, 0.040 \mathrm{mmol})$ in $\mathrm{C}_{6} \mathrm{D}_{6}(3 \mathrm{~mL})$ was prepared. Aliquots $(0.5 \mathrm{~mL})$ of the stock solution were transferred to three separate J-Young NMR tubes along with hexamethyldisiloxane $(2 \mu \mathrm{L}, 0.0094 \mathrm{mmol})$ as an internal standard. The NMR tubes were degassed by two freeze-pump-thaw cycles and backfilled with $\mathrm{D}_{2}$ (30 psi). The reactions were monitored by ${ }^{1} \mathrm{H}$ NMR spectroscopy. For all data acquisition, the spectral window was 8 $\mathrm{ppm}$ to $-28 \mathrm{ppm}$ with a $10 \mathrm{~s}$ pulse delay. The disappearance of the hydride resonance was measured as a function of time. Each sample a plot of $\ln$ [hydride resonance integration] versus time gave a straight line, and a $k_{\text {obs }}$ was found by taking the average of the three plots (see Supporting Information). (b) An orange solution of complex $4(0.014 \mathrm{~g}, 0.0087 \mathrm{mmol})$ in $\mathrm{C}_{6} \mathrm{D}_{5} \mathrm{CD}_{3}(0.6 \mathrm{~mL})$ was transferred to a J-Young NMR tube. The tube was evacuated by two freeze-pump-thaw cycles and pressurized with $\mathrm{D}_{2}$ (30 psi) at room temperature. After $5 \mathrm{~min}$, the $\mathrm{Ru}-\mathrm{H}$ resonance had completely disappeared by ${ }^{1} \mathrm{H}$ NMR spectroscopy. Thus, $t_{1 / 2} \leq 1$ $\min$.

Rate Dependence on $D_{2}$ for $H / D$ Exchange at the Hydride Position of $(\mathbf{I M e s})_{2} \mathbf{R u}(\mathbf{C l})(\mathbf{H})(\mathbf{C O})(\mathbf{1})$. A $0.013 \mathrm{M}$ stock solution of $1(0.121 \mathrm{~g}, 0.156 \mathrm{mmol})$ in $\mathrm{C}_{6} \mathrm{D}_{6}(12 \mathrm{~mL})$ was prepared. Aliquots $(0.5 \mathrm{~mL})$ of the stock solution were transferred to three separate J-Young NMR tubes along with hexamethyldisiloxane $(2 \mu \mathrm{L}$, $0.0094 \mathrm{mmol}$ ) as an internal standard. The NMR tubes were degassed by two freeze-pump-thaw cycles and back-filled with $\mathrm{D}_{2}$. Each set of three reactions was done at $15 \mathrm{psi}, 45$ and 60 psi $\mathrm{D}_{2}$. The reactions were monitored by ${ }^{1} \mathrm{H}$ NMR spectroscopy. For all data acquisition the spectral window was $8 \mathrm{ppm}$ to $-28 \mathrm{ppm}$, and a $10 \mathrm{~s}$ pulse delay time was used. The disappearance of the hydride resonance was measured as a function of time. For each sample, a plot of $\ln$ [hydride resonance integration] versus time gave a straight line, and a $k_{\mathrm{obs}}$ was found by taking the average of the three plots (see Supporting Information).

Sample Hydrogenation Reaction (Cyclohexene). $\mathrm{NaBAr}_{4}$ ( $0.006 \mathrm{~g}, 0.007 \mathrm{mmol})$ was added to a yellow solution of $\mathbf{1}(0.005$ $\mathrm{g}, 0.006 \mathrm{mmol})$ in $\mathrm{C}_{6} \mathrm{D}_{6}(0.6 \mathrm{~mL})$ in a screw-cap vial. After stirring for $5 \mathrm{~min}$, the solution was transferred to a J-Young NMR tube along with hexamethyldisiloxane $(2 \mu \mathrm{L}, 0.0094 \mathrm{mmol})$ as an internal standard. The olefin (cyclohexene; $0.013 \mathrm{~mL}, 0.128 \mathrm{mmol}$ ) was added to the NMR tube. The NMR tube was degassed by two freeze-pump-thaw cycles and back-filled with $\mathrm{H}_{2}$ (30 psi) and heated to $60{ }^{\circ} \mathrm{C}$. The reactions were monitored periodically by ${ }^{1} \mathrm{H}$ NMR spectroscopy until either the reaction had reached completion (complete consumption of olefin) or the reaction had stopped.

Hydrogenation of 1-Hexene at Room Temperature and 60 psi $\mathbf{H}_{2}$. $\mathrm{NaBAr}_{4}{ }_{4}(0.011 \mathrm{~g}, 0.012 \mathrm{mmol})$ was added to a yellow solution of $1(0.007 \mathrm{~g}, 0.009 \mathrm{mmol})$ in $\mathrm{C}_{6} \mathrm{D}_{6}(0.6 \mathrm{~mL})$ in a screwcap vial. After stirring for $5 \mathrm{~min}$, the solution was transferred to a J-Young NMR tube along with hexamethyldisiloxane $(2 \mu \mathrm{L}, 0.0094$ $\mathrm{mmol}$ ) as an internal standard. The olefin (1-hexene; $0.025 \mathrm{~mL}$, $0.200 \mathrm{mmol}$ ) was added to the NMR tube. The NMR tube was degassed by two freeze-pump-thaw cycles and back-filled with $\mathrm{H}_{2}$ (30 psi) and heated to $60{ }^{\circ} \mathrm{C}$. The reactions were monitored periodically by ${ }^{1} \mathrm{H}$ NMR spectroscopy until the reaction had stopped.

Isomerization of Trans-2-hexene. $\mathrm{NaBAr}_{4}^{\prime}(0.010 \mathrm{~g}, 0.010$ $\mathrm{mmol})$ was added to a yellow solution of $\mathbf{1}(0.010 \mathrm{~g}, 0.011 \mathrm{mmol})$ in $\mathrm{C}_{6} \mathrm{D}_{6}(0.6 \mathrm{~mL})$ in a screw-cap vial. After stirring for $5 \mathrm{~min}$, the solution was transferred to a screw-cap NMR tube along with hexamethyldisiloxane $(2 \mu \mathrm{L}, 0.0094 \mathrm{mmol})$ as an internal standard. Trans-2-hexene $(0.026 \mathrm{~mL}, 0.207 \mathrm{mmol})$ was added to the NMR tube, and the solution was heated to $60{ }^{\circ} \mathrm{C}$. The reaction was monitored periodically by ${ }^{1} \mathrm{H}$ NMR spectroscopy until equilibrium 
between trans-2-hexene and trans-3-hexene was reached (no other organic products were observed by ${ }^{1} \mathrm{H}$ NMR spectroscopy).

Isomerization of 9-decen-1-ol. $\mathrm{NaBAr}_{4}{ }_{4}(0.008 \mathrm{~g}, 0.009 \mathrm{mmol})$ was added to a yellow solution of $\mathbf{1}(0.006 \mathrm{~g}, 0.008 \mathrm{mmol})$ in $\mathrm{C}_{6} \mathrm{D}_{6}$ $(0.6 \mathrm{~mL})$ in a screw-cap vial. After stirring for $5 \mathrm{~min}$, the solution transferred to a screw-cap NMR tube along with hexamethyldisiloxane $(2 \mu \mathrm{L}, 0.0094 \mathrm{mmol})$ as an internal standard. 9-Decen-1-ol $(0.030 \mathrm{~mL}, 0.168 \mathrm{mmol})$ was added to the NMR tube, and the solution was heated to $60{ }^{\circ} \mathrm{C}$. The reaction was monitored periodically by ${ }^{1} \mathrm{H}$ NMR spectroscopy. After $2 \mathrm{~h},{ }^{1} \mathrm{H}$ NMR showed complete conversion to an isomer containing an internal $\mathrm{C}=\mathrm{C}$ bond, which is likely 8 -decen-1-ol. Prolonged heating ( $24 \mathrm{~h})$ resulted in only minor additional changes.

Hydrogenation of Styrene With $\mathbf{D}_{2}$. NaBAr ${ }_{4}(0.013 \mathrm{~g}, 0.014$ mmol) was added to a yellow solution of $1(0.011 \mathrm{~g}, 0.014 \mathrm{mmol})$ in $\mathrm{C}_{6} \mathrm{D}_{6}(0.6 \mathrm{~mL})$ in a screw-cap vial. After stirring for $5 \mathrm{~min}$ the solution transferred to a J-Young NMR tubes along with hexamethyldisiloxane ( $2 \mu \mathrm{L}, 0.0094 \mathrm{mmol})$ as an internal standard. Styrene (0.030 $\mathrm{mL}, 0.272 \mathrm{mmol}$ ) was added to the NMR tube. The NMR tube was degassed by two freeze-pump-thaw cycles and backfilled with $\mathrm{D}_{2}(30 \mathrm{psi})$ and heated to $60{ }^{\circ} \mathrm{C}$. The reactions were monitored periodically by ${ }^{1} \mathrm{H}$ NMR spectroscopy until the reaction had reached completion (complete consumption of olefin) to produce $\mathrm{PhCHDCH}_{2} \mathrm{D}$.

Computational Methods. All calculations were carried out using the Gaussian03 package, ${ }^{91}$ with the B3LYP functional (Becke's three-parameter hybrid functional ${ }^{92}$ using the LYP correlation functional containing both local and nonlocal terms of Lee, Yang, and Parr) ${ }^{93}$ and VWN (Slater local exchange functional ${ }^{94}$ plus the local correlation functional of Vosko, Wilk, and Nusair). ${ }^{95}$ The

(91) Frisch, M. J.; et al. Gaussian 03, revision D.01; Gaussian, Inc., Wallingford, CT, 2004.

(92) Becke, A. D. J. Chem. Phys. 1993, 98, 5648-5652.

(93) Lee, C.; Yang, W.; Parr, R. G. Phys. Rev. 1988, B37, 785-789.

(94) Kohn, W.; Sham, L. Phys. Rev. 1965, 140, 1133-1138.

(95) Vosko, S. H.; Wilk, L.; Nusair, M. Can. J. Chem. 1980, 58, 12001211.
Stevens (SBK) valence basis sets triplet-zeta and effective core potentials were employed for ruthenium atom. Standard 6-31G basis set were used for the carbon and hydrogen atoms of the four 2,4,6-trimethylphenyl substituents in IMes ligands. ${ }^{96}$ Standard $6-311 G^{* *}$ basis sets were used for all other atoms for the calculated systems. The largest system is composed of 725 contracted Gaussian basis functions contracted from primitive Gaussians. All systems were fully optimized unrestricted Kohn-Sham formalism without symmetry constraint. Analytic calculations of the energy Hessian were performed to confirm species as minima and to obtain enthalpies and free energies (using unscaled vibrational frequencies) in the gas phase at $1 \mathrm{~atm}$ and $298.15 \mathrm{~K} / 213.15 \mathrm{~K}$.

Acknowledgment. T.B.G. acknowledges The Office of Basic Energy Sciences, U.S. Department of Energy (DEFG02-03ER15490) for financial support. T.R.C. acknowledges The Office of Basic Energy Sciences, U.S. Department of Energy (DE-FG02-03ER15387) for financial support. Z.K. thanks the China Scholarship Council (No. 2007102840) for their support of his research at the University of North Texas. We thank Professor Hanna Gracz (NCSU) for assistance with ${ }^{2} \mathrm{H}$ NMR experiments, Ms. Joanna Webb for assistance with experiments, Mr. Matthew M. Lyndon (NCSU), and Dr. George Dubay (Duke University) for assistance with mass spectrometry experiments and Professor Kenneth G. Caulton (Indiana University) for valuable discussions.

Supporting Information Available: Complete data for X-ray

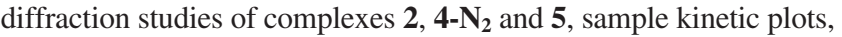
and sample ${ }^{1} \mathrm{H}$ NMR spectra. This material is available free of charge via the Internet at http://pubs.acs.org.

\section{OM801111C}

(96) Stevens, W. J.; Krauss, M.; Basch, H.; Jasien, P. G. Can. J. Chem. 1992, 70, 612-630. 